\title{
EXPERIMENTAL STUDY OF IN-SITU UPGRADING FOR HEAVY \\ OIL USING HYDROGEN DONORS AND CATALYST \\ UNDER STEAM INJECTION CONDITION
}

\author{
A Thesis \\ by \\ ZHIYONG ZHANG \\ Submitted to the Office of Graduate Studies of \\ Texas A\&M University \\ in partial fulfillment of the requirements for the degree of \\ MASTER OF SCIENCE
}

May 2011

Major Subject: Petroleum Engineering 
Experimental Study of In-Situ Upgrading for Heavy Oil Using Hydrogen Donors and Catalyst under Steam Injection Condition Copyright 2011 Zhiyong Zhang 


\title{
EXPERIMENTAL STUDY OF IN-SITU UPGRADING FOR HEAVY \\ OIL USING HYDROGEN DONORS AND CATALYST \\ UNDER STEAM INJECTION CONDITION
}

\author{
A Thesis \\ by \\ ZHIYONG ZHANG

\begin{abstract}
Submitted to the Office of Graduate Studies of Texas A\&M University

in partial fulfillment of the requirements for the degree of

MASTER OF SCIENCE
\end{abstract}

Approved by:

Co-Chairs of Committee, Maria Barrufet

Robert Lane

Committee Member, Benchun Duan

Head of Department, Stephen A. Holditch

May 2011

Major Subject: Petroleum Engineering 


\begin{abstract}
Experimental Study of In-Situ Upgrading for Heavy Oil Using Hydrogen Donors and Catalyst under Steam Injection Condition. (May 2011)

Zhiyong Zhang, B.S., Tsinghua University;

M.S., Peking University

Co-Chairs of Advisory Committee: Dr. Maria Barrufet

Dr. Robert Lane
\end{abstract}

This research is a study of the in-situ upgrading of Jobo crude oil using steam, tetralin or decalin, and catalyst $\left(\mathrm{Fe}(\mathrm{acac})_{3}\right)$ at temperatures of $250{ }^{\circ} \mathrm{C}, 275^{\circ} \mathrm{C}$ and $300^{\circ} \mathrm{C}$ for 24 hours, 48 hours and 72 hours using an autoclave. Viscosity, API gravity and compositional changes were investigated. We found that tetralin and decalin alone were good solvents for heavy oil recovery. Tetralin or decalin at concentrations of $9 \%$ (weight basis) could reduce the Jobo crude oil viscosity measured at $50{ }^{\circ} \mathrm{C}$ by $44 \pm 2 \%$ and $39 \pm 3 \%$. Steam alone had some upgrading effects. It could reduce the oil viscosity by $10 \%$ after 48 hours of contact at $300^{\circ} \mathrm{C}$. Tetralin, decalin or catalyst showed some upgrading effects when used together with steam and caused $5.4 \pm 4 \%, 4 \pm 1 \%$ and $19 \pm 3 \%$ viscosity reduction compared with corresponding pre-upgrading mixture after 48 hours of reaction at $300^{\circ} \mathrm{C}$. The combination of hydrogen donor tetralin or decalin and catalyst reduced the viscosity of the mixture the most, by $56 \pm 1 \%$ and $72 \pm 1 \%$ compared with pre-upgrading mixture. It meant that hydrogen donors and catalyst had strong synergetic effects on heavy oil upgrading. We also found that $300{ }^{\circ} \mathrm{C}$ was an effective temperature 
for heavy oil upgrading with obvious viscosity reduction in the presence of steam, hydrogen donors and catalyst. Reaction can be considered to have reached almost equilibrium condition after 48 hours. The GC-MS analysis of the gas component showed that light hydrocarbon gases and $\mathrm{CO}_{2}$ were generated after reaction. The viscosity reduction from decalin use is larger than that of tetralin because decalin has more hydrogen atoms per molecule than tetralin. A mechanism of transferring $\mathrm{H}$ (hydrogen atom) from $\mathrm{H}_{2} \mathrm{O}$ and hydrogen donors to heavy oil, which can lead to structure and composition changes in heavy oil, is explained. The study has demonstrated that in-situ heavy oil upgrading has great potential applications in heavy and extra heavy oil recovery. 
DEDICATION

To my family 


\section{ACKNOWLEDGEMENTS}

I would like to express my sincere gratitude to my current advisors, Dr. Maria Barrufet, Dr. Robert Lane and emeritus advisor, Dr. Daulat Mamora. Their guidance and help enabled me to complete the research project. I would also like to thank Dr. Benchun Duan for his kindly serving as a committee member and reviewing my thesis.

I would also like to thank graduate student, Masoud Alfi for helping me analyze the components of gas and liquid samples.

I feel grateful to all my family members for their love and support. The birth of my daughter Emily brings me so much joy and hope. I thank my parents for raising me and taking care of my little daughter. Special thanks go to my wife Wenxu for her constant love, support and patience during the difficult times.

Thanks also to my friends and colleagues and the department faculty and staff for making my time at Texas A\&M University such a great experience.

Finally, great appreciation goes to the Crisman Institute for providing the financial support of this research. 


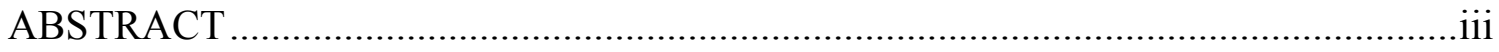

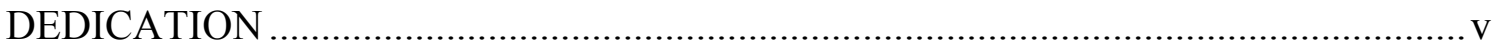

ACKNOWLEDGEMENTS ………………............................................................ vi

TABLE OF CONTENTS ...................................................................................... vii

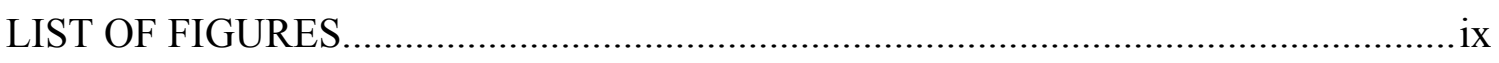

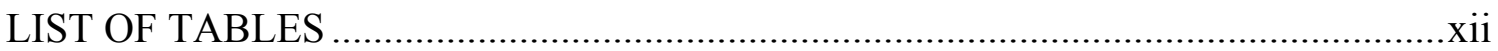

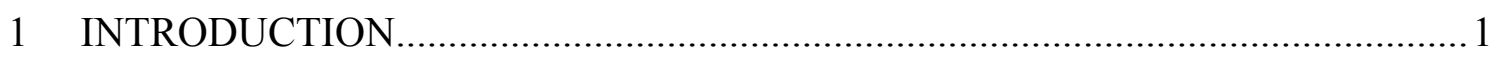

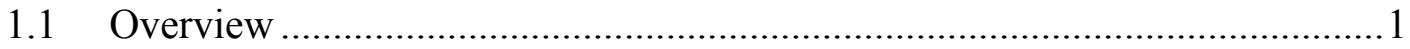

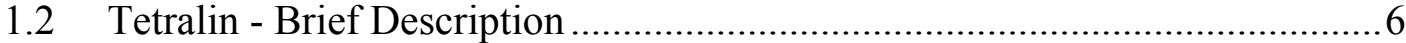

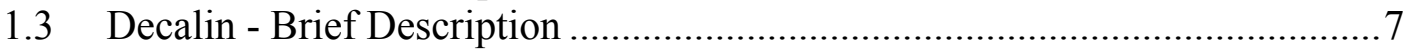

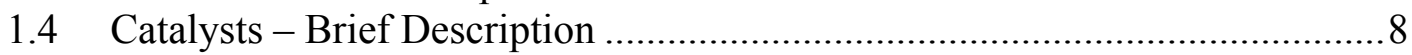

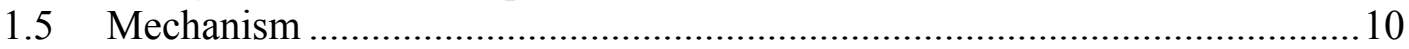

1.6 Research Objectives ................................................................................ 14

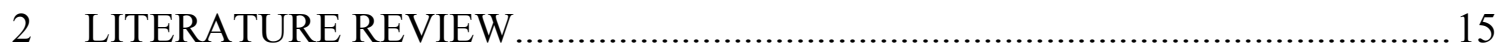

3 EXPERIMENTAL APPARATUS AND PROCEDURES …………........................28

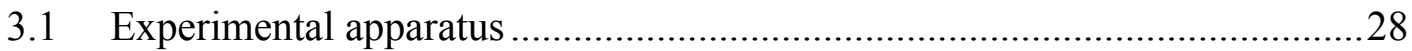

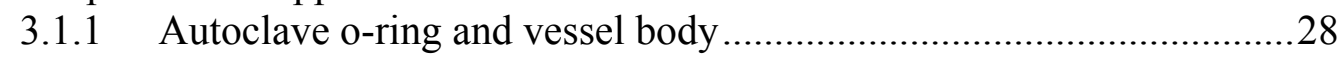

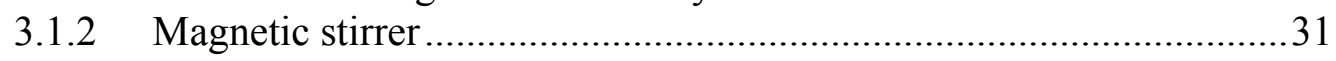

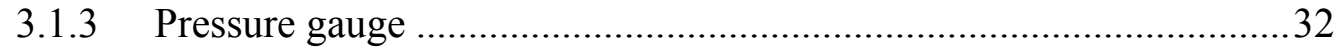

3.1.4 Standard mini mica band heaters ......................................................... 32

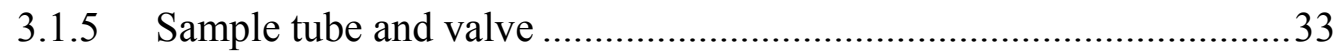

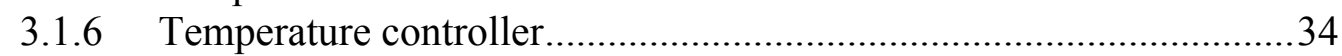

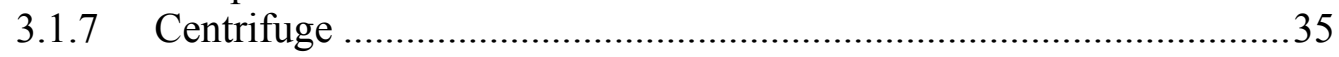

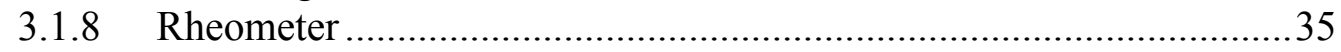

3.1.9 Density/specific gravity meter …………………….............................39

3.1.10 Gas chromatography - mass spectrometry (GC-MS) analyzer ............40

3.2 Experimental Procedures............................................................................ 41 


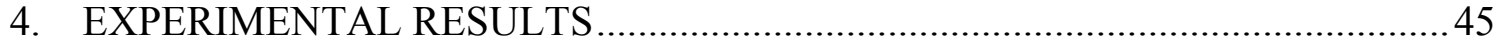

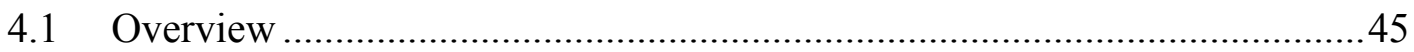

4.2 Upgrading of Crude Oil with Water..............................................................45

4.3 Upgrading of Crude Oil with Water and Catalyst...........................................46

4.4 Crude Oil, Decalin or Tetralin Mixture before Upgrading …………..............48

4.5 Upgrading of Crude Oil with Water and Tetralin ..........................................50

4.6 Upgrading of Crude Oil with Water and Decalin ...........................................51

4.7 Upgrading of Crude Oil with Water, Tetralin and Catalyst ............................51

4.8 Upgrading of Crude Oil with Water, Decalin and Catalyst ............................55

4.9 Effects of Temperature on Heavy Oil Upgrading ..........................................57

4.10 Effects of Time on Heavy Oil Upgrading ........................................................62

4.11 Gas and Liquid Component Analysis after Upgrading Using Tetralin and

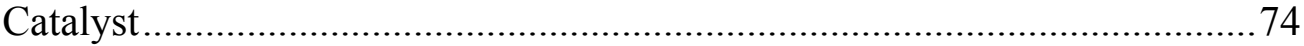

4.12 Gas and Liquid Component Analysis after Upgrading Using Decalin and

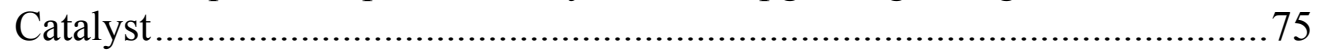

4.13 Comparison and Discussion of Results .......................................................

5. SUMMARY, CONCLUSIONS AND RECOMMENDATIONS ............................... 81

5.1 Summary …

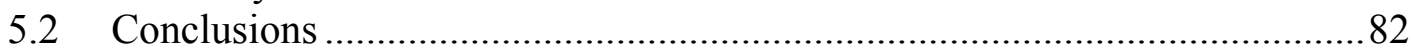

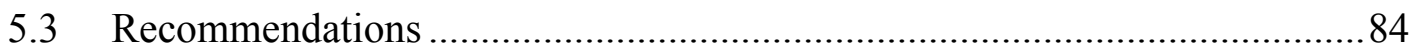

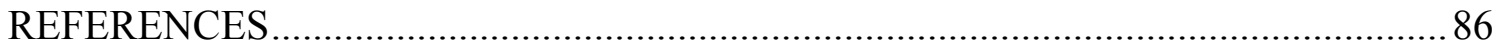

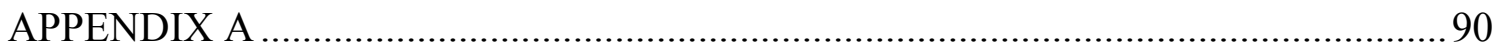

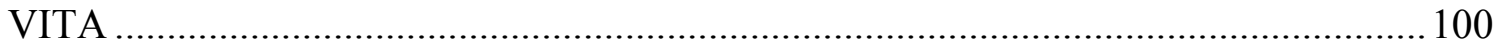




\section{LIST OF FIGURES}

Page

Figure 1.1 The structure of tetralin........................................................................ 6

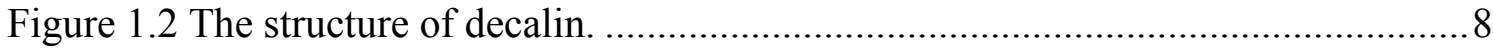

Figure 1.3 The structure of ferric acetylacetonate $(\mathrm{Fe}(\mathrm{acac}) 3)$..................................

Figure 1.4 Cleavage temperature and rates scheme for $\mathrm{C}-\mathrm{S}, \mathrm{C}-\mathrm{N}, \mathrm{C}-\mathrm{O}$ and $\mathrm{C}-\mathrm{C}$ bonds (Zhao et al., 2006).

Figure 1.5 Hydrogen is transferred from the tetralin to the asphaltene.......................... 12

Figure 1.6 Two-step model for transfer of hydrogen from tetralin to heavy oil.............13

Figure 3.1 Experiment set up includes an autoclave, a temperature controller, a magnetic stirrer controller, an external heating band temperature monitor,

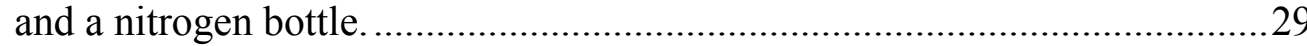

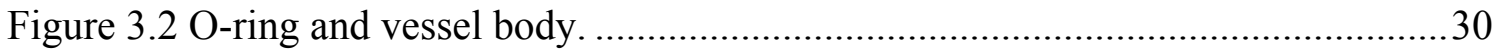

Figure 3.3 Reaction vessel is assembled to the cover fixed in the supporting shelf........31

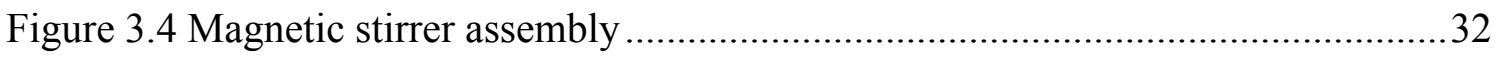

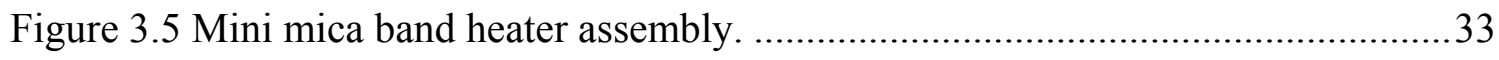

Figure 3.6 A 1/16 DIN autotune PID/on-off controllers with modular output options. ..35

Figure 3.7 Photograph of the HN-SII general purpose centrifuge ................................ 36

Figure 3.8 Photograph of the programmable rheometer. .......................................... 37

Figure 3.9 Photograph of the spindle (to the right) and container (to the left) where it

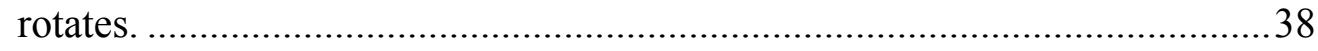

Figure 3.10 Photograph of the water bath for rheometer. ........................................ 39

Figure 3.11 Photograph of the density meter. ....................................................... 40

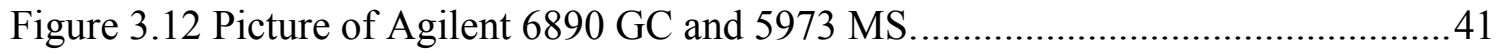


Figure 4.1 Viscosity changes as function of temperature before and after crude oil react with water, and w/ or w/o catalyst.

Figure 4.2 Viscosity reductions ((viscosity before upgrading - viscosity after upgrading) / viscosity before upgrading) in percentages as function of temperature after crude oil react with water, and w/ or w/o catalyst.

Figure 4.3 Viscosity as a function of temperature for crude oil, decalin or tetralin mixture before upgrading.

Figure 4.4 Viscosity reduction ((viscosity before upgrading - viscosity after upgrading) / viscosity before upgrading) in percentages as a function of temperature for crude oil, decalin or tetralin mixture before upgrading.

Figure 4.5 The function of viscosity versus temperature for dewatered mixture before and after upgrading using crude oil, water and decalin.....

Figure 4.6 The function of viscosity reductions ((viscosity before upgrading viscosity after upgrading) / viscosity before upgrading) in percentages versus temperature for dewatered mixture after upgrading using crude oil, water and decalin.

Figure 4.7 Comparison of viscosity versus temperature for dewatered mixture before and after upgrading using crude oil, water, tetralin and catalyst.

Figure 4.8 Comparison of viscosity reductions ((viscosity before upgrading - viscosity after upgrading) / viscosity before upgrading) in percentages versus temperature for dewatered mixture after upgrading using crude oil, water, tetralin and catalyst.

Figure 4.9 Comparison of viscosity versus temperature for dewatered mixture before and after upgrading using crude oil, water, decalin and catalyst.

Figure 4.10 Comparison of viscosity reductions ((viscosity before upgrading viscosity after upgrading) / viscosity before upgrading) in percentages versus temperature for dewatered mixture after upgrading using crude oil, water, decalin and catalyst.

Figure 4.11 Viscosity as a function of temperature before and after upgrading at different temperature using tetralin and catalyst. 
Figure 4.12 Viscosity as a function of temperature before and after upgrading at different temperature using decalin and catalyst..

Figure 4.13 Viscosity reductions ((viscosity before upgrading - viscosity after upgrading) / viscosity before upgrading) in percentages as a function of temperature after upgrading at different temperature using tetralin and catalyst.

Figure 4.14 Viscosity reductions ((viscosity before upgrading - viscosity after upgrading) / viscosity before upgrading) in percentages as a function of temperature after upgrading at different temperature using decalin and catalyst.

Figure 4.15 Viscosity as a function of temperature before and after upgrading for different lengths of time using tetralin and catalyst.

Figure 4.16 Viscosity reductions ((viscosity before upgrading - viscosity after upgrading) / viscosity before upgrading) in percentages as a function of temperature after upgrading for different lengths of time using tetralin and catalyst.

Figure 4.17 Viscosity measured at $50{ }^{\circ} \mathrm{C}$ versus reaction time after upgrading using steam, tetralin or decalin and catalyst at $300{ }^{\circ} \mathrm{C}$

Figure 4.18 Viscosity reductions ((viscosity before upgrading - viscosity after upgrading) / viscosity before upgrading) in percentages measured at $50{ }^{\circ} \mathrm{C}$ versus reaction time after upgrading using steam, tetralin or decalin and catalyst at $300^{\circ} \mathrm{C}$

Figure 4.19 Viscosity as a function of temperature before and after upgrading for different lengths of time using decalin and catalyst.

Figure 4.20 Viscosity reductions ((viscosity before upgrading - viscosity after upgrading) / viscosity before upgrading) in percentages as a function of temperature after upgrading for different lengths of time using decalin and catalyst.. 


\section{LIST OF TABLES}

Page

Table 1.1 The basic properties of tetralin................................................................. 7

Table 1.2 The basic properties of Decalin............................................................... 8

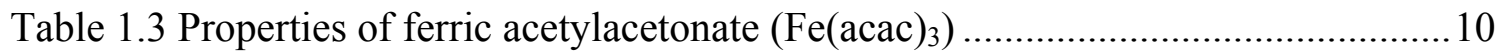

Table 1.4 C-S, C-N, C-O and C-C Bond Energy .................................................... 11

Table 2.1 Summary of literature review on in-situ upgrading of heavy oil ...................26

Table 4.1 Viscosity and API gravity changes after upgrading using crude oil, steam

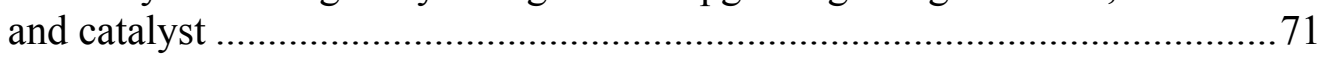

Table 4.2 Viscosity and API gravity changes after upgrading using crude oil, steam,

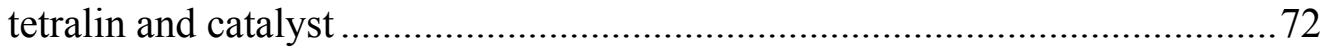

Table 4.3 Viscosity and API gravity changes after upgrading using crude oil, steam,

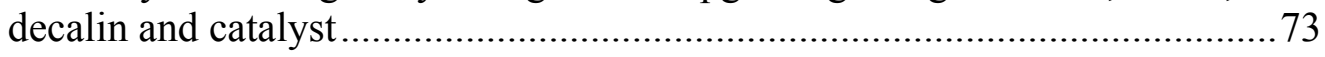

Table 4.4 Gas components after reaction at $300^{\circ} \mathrm{C}$ for 48 hours with water, tetralin

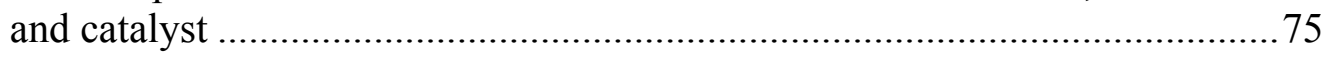

Table 4.5 Major liquid components after upgraded at $300{ }^{\circ} \mathrm{C}$ for 48 hours with

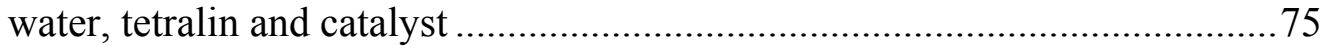

Table 4.6 Gas components after reaction at $300^{\circ}$ for 48 hours with water, decalin

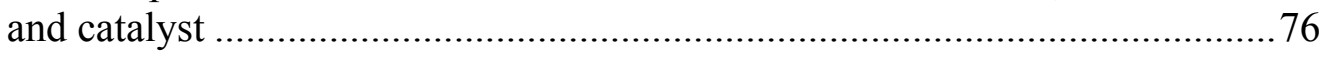

Table 4.7 Major liquid components after being upgraded at $300^{\circ}$ for 48 hours with water, decalin and catalyst ............................................................... 77

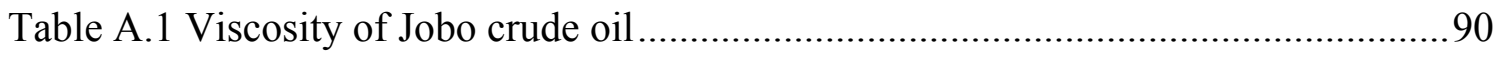

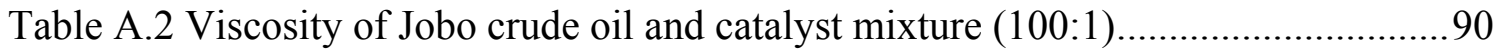

Table A.3 Viscosity dewatered crude oil after upgrading with steam for 48 hours at $300{ }^{\circ} \mathrm{C}$ 
Table A.4 Viscosity of dewatered mixture after upgrading of crude with steam and catalyst (100:100:1) for 48 hours at $300{ }^{\circ} \mathrm{C}$

Table A.5 Viscosity of crude oil and tetralin mixture $(100: 10)$.................................92

Table A.6 Viscosity of crude oil tetralin and catalyst mixture $(100: 10: 1) \ldots \ldots \ldots \ldots \ldots \ldots . . . . .92$

Table A.7 Viscosity of dewatered mixture after upgrading of crude oil with steam, tetralin and catalyst $(100: 100: 10: 1)$ at $250{ }^{\circ} \mathrm{C}$ for 48 hours .........................92

Table A.8 Viscosity of dewatered mixture after upgrading of crude oil with steam, tetralin and catalyst $(100: 100: 10: 1)$ at $275^{\circ} \mathrm{C}$ for 48 hours .93

Table A.9 Viscosity of dewatered mixture after upgrading of crude oil with steam, tetralin and catalyst $(100: 100: 10: 1)$ at $300{ }^{\circ} \mathrm{C}$ for 48 hours

Table A.10 Viscosity of dewatered mixture after upgrading of crude oil with steam, tetralin $(100: 100: 10)$ at $300{ }^{\circ} \mathrm{C}$ for 48 hours

Table A.11 Viscosity of dewatered mixture after upgrading of crude oil with steam, tetralin and catalyst $(100: 100: 10: 1)$ at $300{ }^{\circ} \mathrm{C}$ for 24 hours

Table A.12 Viscosity of dewatered mixture after upgrading of crude oil with steam, tetralin and catalyst $(100: 100: 10: 1)$ at $300{ }^{\circ} \mathrm{C}$ for 72 hours

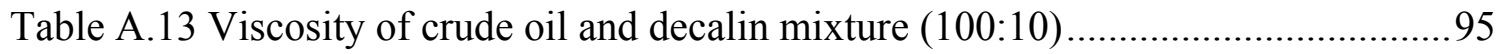

Table A.14 Viscosity of crude oil decalin and catalyst mixture (100:10:1)

Table A.15 Viscosity of dewatered mixture after upgrading of crude oil with steam, decalin and catalyst $(100: 100: 10: 1)$ at $250{ }^{\circ} \mathrm{C}$ for 48 hours .95

Table A.16 Viscosity of dewatered mixture after upgrading of crude oil with steam, decalin and catalyst $(100: 100: 10: 1)$ at $275^{\circ} \mathrm{C}$ for 48 hours ....

Table A.17 Viscosity of dewatered mixture after upgrading of crude oil with steam, decalin and catalyst (100:100:10:1) at $300{ }^{\circ} \mathrm{C}$ for 48 hours

Table A.18 Viscosity of dewatered mixture after upgrading of crude oil with steam, decalin (100:100:10) at $300{ }^{\circ} \mathrm{C}$ for 48 hours

Table A.19 Viscosity of dewatered mixture after upgrading of crude oil with steam, decalin and catalyst $(100: 100: 10: 1)$ at $300{ }^{\circ} \mathrm{C}$ for 24 hours 
Table A.20 Viscosity of dewatered mixture after upgrading of crude oil with steam, decalin and catalyst $(100: 100: 10: 1)$ at $300{ }^{\circ} \mathrm{C}$ for 72 hours ......................97

Table A.21 API gravity before and after upgrading using crude oil, steam and catalyst.98

Table A.22 API gravity before and after upgrading using crude oil, steam, tetralin

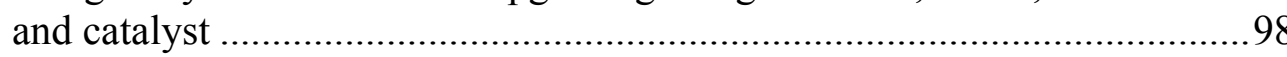

Table A.23 API gravity before and after upgrading using crude oil, steam, decalin and catalyst 


\section{INTRODUCTION}

\subsection{Overview}

As conventional crude oil reserves in the world is being depleted, heavy oil resources have great potential to meet the future demand for petroleum products. Conventional oil production is projected to be insufficient to meet the growing needs of the world in the coming few years, making unconventional oil more essential for future energy needs. Nowadays, heavy oil reserves make up a large portion of unconventional resources, which also include coalbed methane, tight gas, shale gas and hydrates. Heavy oil production has increased substantially in the last decade as a result of market demand and new technological advancements in drilling and recovery techniques. So a further significant increase in production is expected.

Heavy crude oil is defined as any liquid petroleum with an API gravity less than $20^{\circ}$ and extra heavy oil is defined with API gravity below $10.0^{\circ}$ API. Heavy oil, extra-heavy oil, and bitumen are unconventional oil resources that are characterized by high viscosities and high densities compared to conventional oil. They also have low hydrogen to carbon ratios, high carbon residues, and high asphaltene, heavy metal, sulfur and nitrogen content. For example, Orinoco extra heavy oil contains $4.5 \%$ sulfur as well as vanadium and nickel. (http://en.wikipedia.org/wiki/Heavy_crude_oil)

Heavy oil, extra-heavy oil, and bitumen resources are very large. The International Energy Agency (IEA) estimates that there are 6 trillion barrels in place in

The thesis follows the style of SPE Reservoir Evaluation \& Engineering. 
the world and most of these resources are currently untapped. The largest heavy oil accumulations worldwide are located in Canada and Venezuela. There are 2.5 trillion bbl in Western Canada, 1.5 trillion bbl in Venezuela, 1 trillion bbl in Russia, and 100 to 180 billion bbl in the United States. Western Canada and the United States are politically stable and can be secure sources of oil for the United States. (Besson, 2005)

Heavy oils can be profitably produced, but at a smaller profit margin compared with conventional oil, due to higher production costs caused by high viscosity, higher upgrading costs caused by additional processing, and the lower market price for heavier crude oils.

Canada, Venezuela, and the United States are the major leading producers of heavy oils. These countries use different production methods for heavy oil recovery. In Canada, approximately $50 \%$ of its heavy oil production is from open-pit mining of shallow oil sands. Steam injection and in-situ production of heavy oil with sand and water provide the remaining production. SAGD (Steam Assisted Gravity Drainage) production is rapidly growing. In Venezuela, due to high reservoir depth and permeability, cold production using horizontal and multilateral wells is used most commonly. While in the USA, steam flooding and cyclic steam stimulation predominate. (Clark, 2007)

Open-pit mining can only exploit resources near the surface and has a large environmental impact. However, there are several other commercial-ready in-situ production technologies. Several more technologies are in research or pilot phase that will be available in the near future, such as steam injection, in-situ combustion, or using 
a solvent to reduce heavy oil viscosity by itself or combined with steam. These methods have evolved in the past several decades to become commercially applicable. Steam injection is by far the most prevailing thermal method, and several variations of it have been developed and applied successfully worldwide in places such as Canada, Venezuela, United States and Indonesia. During steam injection, the latent and sensible heat is transferred to reservoir fluids and rock matrix, leading to increase in their temperature. This increase in temperature has several beneficial effects in production and recovery of heavy crude oil. It can reduce the oil viscosity, increase the oil volume and distill the lighter hydrocarbon fractions in the steam zone. These effects can increase the production and overall recovery, but do not improve the quality of the crude significantly.

Looking for an alternative, operators began to inject steam to reduce the heavy oil viscosity and increase recovery in the 1960s. In a CSS (Cyclic Steam Stimulation) process, steam is injected into a reservoir for several days to several weeks, depending upon the reservoir and the well conditions. The heat is then soaked into the formation and fluids around the well for an additional few weeks. The oil is then produced for a few months until the rate becomes uneconomic. Steam is injected again and the production procedure is repeated. To sweep oil zones that are too far away from well to be stimulated by CSS, steam flooding is usually performed following CSS, in which steam is injected into a few injection wells, while oil and water is produced from the other producing wells. It has been reported that steam flooding operations can produce 
over $70 \%$ of OOIP. Duri Field in Indonesia and several fields in the San Joaquin Valley in California are good examples. (Prats, 1986)

In a downstream refinery plant, crude oil is upgraded to improve oil quality for meeting application requirements and to increase price of the produced oil. Catalysts are used in upgrading processes such as hydro-treating, and hydro-cracking, and they have also been used for the removal of contaminants and pollutants, such as heavy metals and sulfur. These basic refinery processes are known as demetalization and desulfurization, after which final products are lighter and have more valuable components. Since the reservoir temperature is high during steam flooding, it is possible to apply similar upgrading process to downhole upgrading.

Therefore, several studies have been carried out to investigate the feasibility of heavy crude oil upgrading at subsurface during steam injection conditions using private or commercial catalysts with various hydrogen donors. In-situ combustion experiments, steam flooding experiments and reactor experiments have been performed using catalysts (Fan et al., 2001; Mateshov, 2010; Mohammad and Mamora, 2008). The hydrogen donors used in these studies include hydrogen gas, methane, tetralin, and decalin. Decalin is a relatively new hydrogen donor used in in-situ combustion. It has not been used in steam injection yet. In all of the previous studies, apparent improvements in oil properties were observed, including API gravity, hydrogen-carbon ratio, asphaltene, resin, heavy metal, sulfur content, and viscosity.

The use of in-situ upgrading processes has several advantages in comparison with above ground counterparts. First of all, in-situ upgrading enhances oil recovery, 
increases well production, and lowers lifting and transportation costs from reservoir to refinery. Enhanced oil recovery could be achieved by adding extra oil reserves and by sweeping more difficult fluids leading to an increase in production. Moreover, the in-situ upgrading would decrease the consumption of expensive light diluents for the heavy crude oil production, lifting and transportation; thus it can reduce production costs from the subsurface to the refining plants. Furthermore, in-situ upgrading processes improve oil quality by reducing oil viscosity and asphaltene, sulfur and heavy-metal content. This reduces refining severity and its environmental impact. Finally, underground upgrading technologies could take advantage of the high temperature energy. The implementation of in-situ upgrading significantly reduces energy consumption since the heat from the steam injection is used to produce and upgrade the oil. The presence of mineral formation in porous matrix may, in some cases, provide a natural catalyst to improve the crude oil properties. (Mohammad, 2008)

However, there are some challenges in the use of these underground technologies for upgrading heavy crude oil. First at all, in-situ processes are difficult to control and monitor, which prevent them from being applied widely. Furthermore, each reservoir and well may require special treatment. This increases the field operation complexity. Finally, it is difficult to disperse hydrogen donors and catalysts into the reservoir and mix them with crude oil.

This research is aimed at verifying the potential of in-situ upgrading of heavy oil during steam injection with the addition of a catalyst $\left(\mathrm{Fe}(\mathrm{acac})_{3}\right)$ and a hydrogen donor (tetralin or decalin) and finding the optimal operating temperature and reaction time. A 
series of experiments are performed to evaluate the potential and extent of oil upgrading in the presence of steam, catalyst and hydrogen donors, alone or combined, at different temperatures for different time periods. The potential and extent of upgrading will be confirmed from an additional analysis on the upgraded mixture.

\subsection{Tetralin - Brief Description}

Tetralin $\left(\mathrm{C}_{10} \mathrm{H}_{12}\right)$ is also known as 1,2,3,4-tetrahydronaphthalene. Its molecule structure is similar to naphthalene except that one ring is saturated. It is a bicyclic organic compound as illustrated in Fig. 1.1.

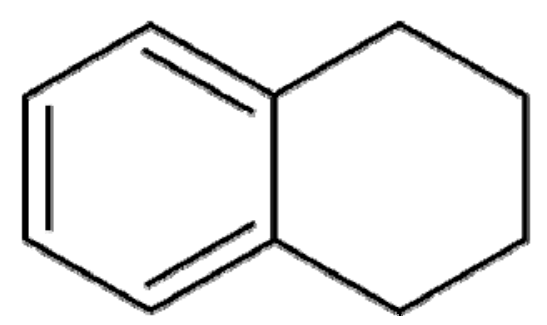

Fig. 1.1 The structure of tetralin.

Commercial grade tetralin is typically $97 \%$ pure by weight with the majority of the impurity comprising naphthalene and decahydronaphthalene. Tetralin has been obtained from pressed naphthalene isolated from coke tar by hydrogenating it over commercial catalyst $\mathrm{WS}_{2}+\mathrm{NiS}+\mathrm{Al}_{2} \mathrm{O}_{3}$ and $\mathrm{CoO}+\mathrm{MoO}_{3}+\mathrm{Al}_{2} \mathrm{O}_{3}$ under pressure of 50-300 atm. Tetralin is in very high demand as an industrial solvent for waxes, naphthalene, fat, resins and oils. (http://en.wikipedia.org/wiki/Tetralin) 
The basic properties of tetralin are shown in Table 1.1.

Table 1.1 The basic properties of tetralin

\begin{tabular}{|l|l|}
\hline Molecular formula & $\mathrm{C}_{10} \mathrm{H}_{12}$ \\
\hline Molar mass & $132.202 \mathrm{~g} / \mathrm{mol}$ \\
\hline Appearance & Clear, colorless liquid \\
\hline Density & $0.970 \mathrm{~g} / \mathrm{cm}^{3}$ \\
\hline Melting point & $-35.8^{\circ} \mathrm{C}\left(-32.4^{\circ} \mathrm{F}\right)$ \\
\hline Boiling point & $206-208^{\circ} \mathrm{C}\left(403-406^{\circ} \mathrm{F}\right)$ \\
\hline Solubility in water & Insoluble \\
\hline Flash point & $77^{\circ} \mathrm{C}\left(170.6^{\circ} \mathrm{F}\right)$ \\
\hline Autoignition temperature & $385^{\circ} \mathrm{C}\left(725^{\circ} \mathrm{F}\right)$ \\
\hline
\end{tabular}

\subsection{Decalin - Brief Description}

Decalin is also known as decahydronaphthalene, a bicyclic organic compound. It is a colorless liquid with an aromatic odor. As a saturated analog of naphthalene, it can be prepared by hydrogenation from naphthalene in a fused state in the presence of a catalyst. It is used as an industrial solvent for many resins or fuel additive. The structure of the decalin is shown in Fig. 1.2 and the major properties of decalin are tabbed in

Table 1.2. (http://en.wikipedia.org/wiki/Decalin) 


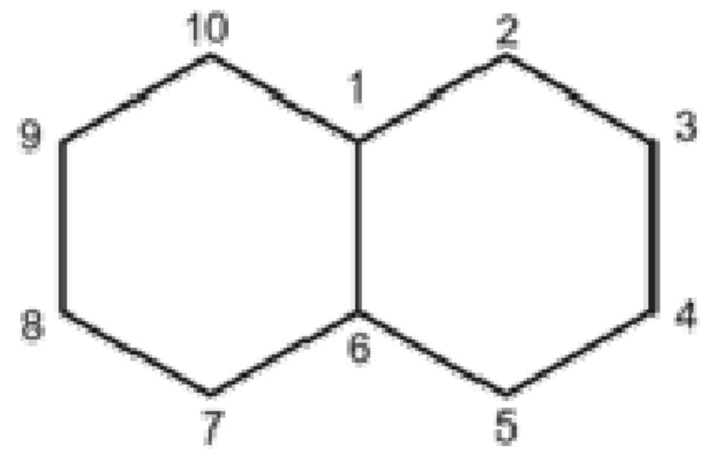

Fig. 1.2 The structure of decalin.

Table 1.2 The basic properties of Decalin

\begin{tabular}{|l|l|}
\hline Molecular formula & $\mathrm{C}_{10} \mathrm{H}_{18}$ \\
\hline Molar mass & $138.25 \mathrm{~g} / \mathrm{mol}$ \\
\hline Appearance & Clear, colorless liquid \\
\hline Density & $0.896 \mathrm{~g} / \mathrm{cm}^{3}$ \\
\hline Melting point & $-40^{\circ} \mathrm{C}\left(-40{ }^{\circ} \mathrm{F}\right)$ \\
\hline Boiling point & $187^{\circ} \mathrm{C}\left(369^{\circ} \mathrm{F}\right)$ \\
\hline Solubility in water & Insoluble \\
\hline Flash point & $57^{\circ} \mathrm{C}$ \\
\hline Autoignition temperature & $250^{\circ} \mathrm{C}$ \\
\hline
\end{tabular}

\subsection{Catalysts - Brief Description}

Previous research on catalytic effects of reservoir minerals, commercial and private catalysts showed that the upgrading processes can be accelerated (Fan et al., 2001; Fan et al., 2004; Mohammad and Mamora, 2008; Wen et al., 2007). It thus appeared reasonable to investigate potential catalysis of hydrogen donation in this study.

Ferric acetylacetonate $\left(\mathrm{Fe}(\mathrm{acac})_{3}\right)$, also known as ion acetylacetonate, is a homogeneous catalyst soluble in organic solvents, such as tetralin and decalin. Due to its 
molecular structure and properties, iron acetylacetonate is commonly used in various catalytic reagents for organic synthesis. The structure of the catalyst is illustrated in Fig. 1.3. Some properties of $\mathrm{Fe}(\mathrm{acac})_{3}$ are shown in Table 1.3. (Mohammad, 2008)

It can be used to increase the chemical reaction rates by increasing the chance of molecules to collide, either by adsorption or a process known as intermediate compounds. Adsorption happens when two molecules are held so close together on the surface of the catalyst, increasing the probability that the molecules will collide and therefore react with each other. In an intermediate compound process the reactive chemicals combine with the catalyst making a very unstable compound which breaks down and releases the original catalyst and the new compounds. The activation energy needed for the reaction is reduced by using both these methods.

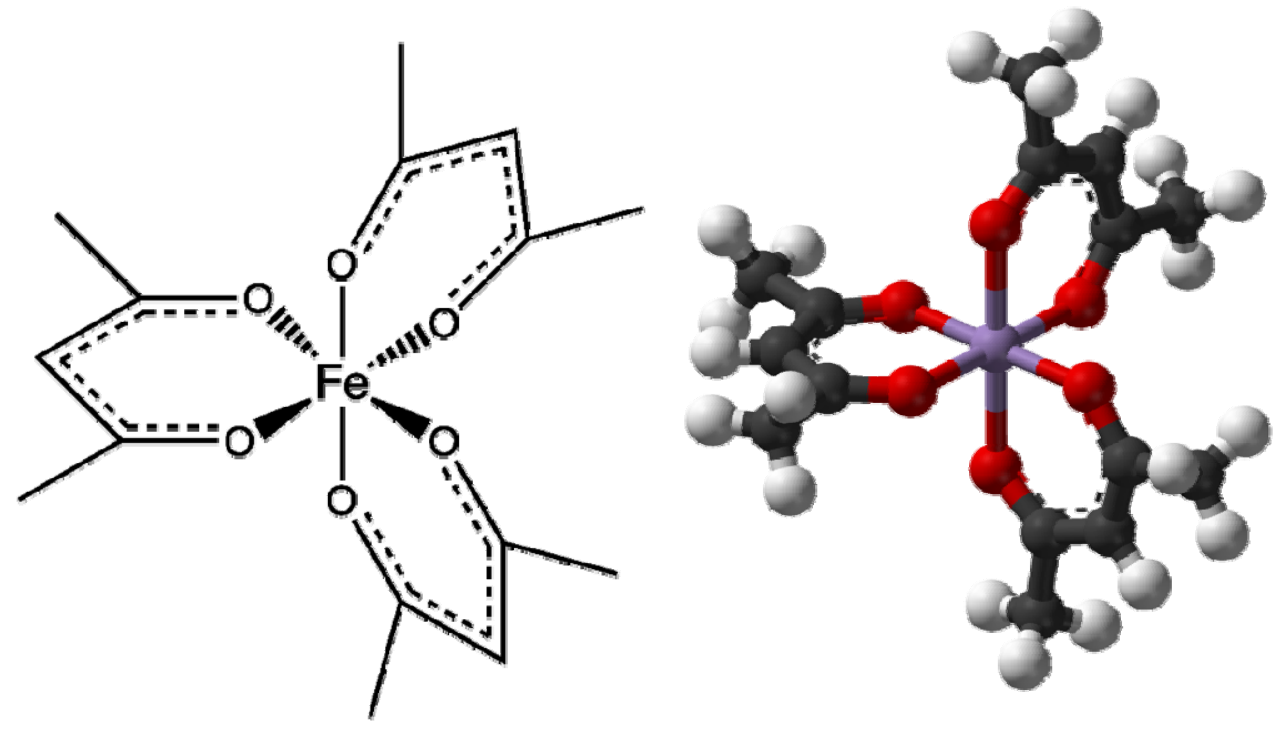

Fig. 1.3 The structure of ferric acetylacetonate ( $\mathrm{Fe}(\mathrm{acac}) 3)$. (http://en.wikipedia.org/wiki/Ferric_acetylacetonate) 
Table 1.3 Properties of ferric acetylacetonate $\left(\mathrm{Fe}(\mathrm{acac})_{3}\right)$

\begin{tabular}{|l|l|}
\hline Formula & $\mathrm{Fe}\left(\mathrm{CH}_{3} \mathrm{COCHCOCH}_{3}\right)_{3}$ \\
\hline Appearance & Orange-Red \\
\hline Molecular Weight & 353.18 \\
\hline Density & $5.24 \mathrm{~g} / \mathrm{cm} 3$ \\
\hline Melting Point & $184^{\circ} \mathrm{C}\left(363.2^{\circ} \mathrm{F}\right)$ \\
\hline Solubility & Soluble in organic solvents \\
\hline
\end{tabular}

\subsection{Mechanism}

Hyne et al. (1982) researched the details of the chemical reaction between steam, heavy oil and minerals, and described all of these reactions as "aquathermolysis". This process is commonly used for the heavy crude oil extraction and transportation. It is believed the heat energy that steam passes to the hydrocarbons breaks large molecules into smaller ones, leading to the reduction of viscosity and improvement in flow properties of heavy oils. Hydrocarbons can be broken down at temperatures above 300 ${ }^{\circ} \mathrm{C}$. Hyne et al. (1982) proposed the following chemical reaction for aquathermolysis:

$$
\mathrm{RCH}_{2} \mathrm{CH}_{2} \mathrm{SCH}_{3}+2 \mathrm{H}_{2} \mathrm{O}=\mathrm{RCH}_{3}+\mathrm{CO}_{2}+\mathrm{H}_{2}+\mathrm{H}_{2} \mathrm{~S}+\mathrm{CH}_{4}
$$

The principal mechanism behind this chemical reaction is that the C-S bond is broken down at high temperature. As a result, the viscosity of heavy crude oil is reduced. Even a small fraction of bond breakage can lead to huge improvement of flow properties of heavy crude oils. It is possible that the organosulfur compounds in heavy oil cleaved in a complex sequence of steps instead of a one-step reaction as depicted above.

The bond energies of C-S, C-N, C-O and C-C are different and they are tabbed on Table 1.4. We can see that C-S has the lowest bond energy among them, followed by C-N, C-O and C-C. The cracking temperature ranges are shown in Fig. 1.4 (Zhao et al., 
2006). The presence of C-S in heavy oil is important for in-situ upgrading as it is the easiest one to be broken down.

Table 1.4 C-S, C-N, C-O and C-C Bond Energy

\begin{tabular}{|c|c|}
\hline Bond & Energy (kJ/mol) \\
\hline C-S & 276 \\
\hline C-N & 284 \\
\hline C-O & 330 \\
\hline C-C & 334 \\
\hline
\end{tabular}

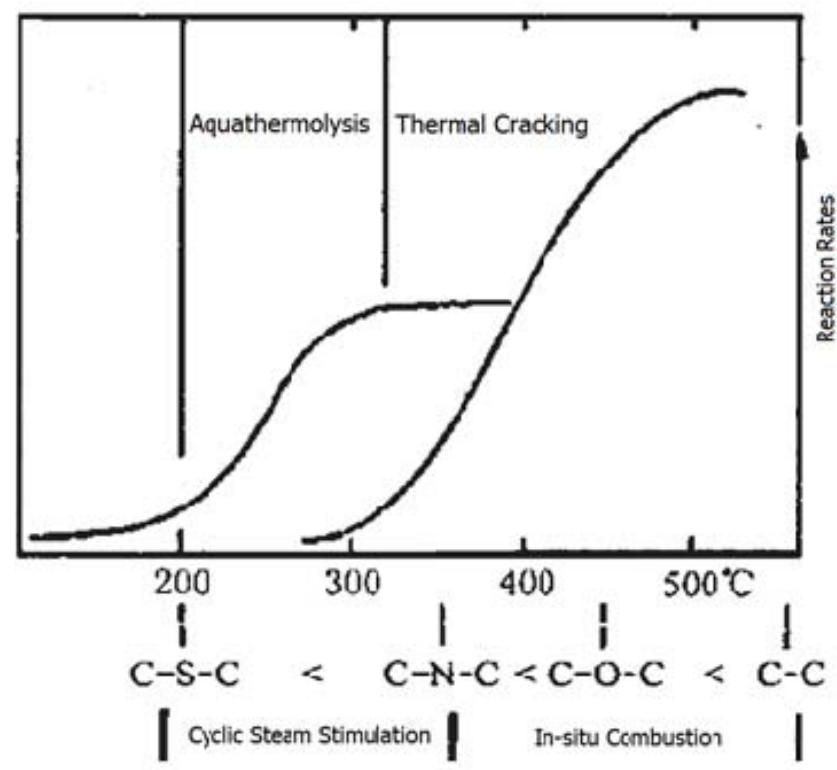

Fig. 1.4 Cleavage temperature and rates scheme for C-S, C-N, C-O and C-C bonds (Zhao et al., 2006).

The catalysts used for aquathermolysis can be divided into four categories: mineral, water-soluble catalysts, oil-soluble catalysts, and dispersed catalysts. The one we used in this research is an oil-soluble catalyst. 
Upon catalytic aquathermolysis, more heavy components of the heavy oil are pyrolyzed and the structures are changed to a larger degree, especially some heteroatom $(\mathrm{N}, \mathrm{O}$, and $\mathrm{S})$ containing structures. These changes could hardly be reversed and eventually lead to the reduction of the viscosity of heavy oil (Chen et al., 2008). All the reactions between heavy oil, steam and catalysts were described as "catalytic aquathermolysis". Catalysts mainly catalyzed the cleavage of the $\mathrm{C}-\mathrm{S}$ bonds and also caused changes in oxygen-containing groups such as the cleavage of $\mathrm{C}-\mathrm{O}$ bonds in phenolic, ethereal molecules, etc. from the heavy oil.

It is believed that at aquathermolysis conditions, hydrogen donors produce hydrogen which takes part in upgrading of heavy crude oils (Ovalles et al., 2003). A hydrogen transfer mechanism from the tetralin to the asphaltene at the low severity conditions $\left(315^{\circ} \mathrm{C}\right)$ is shown in Fig. 1.5.

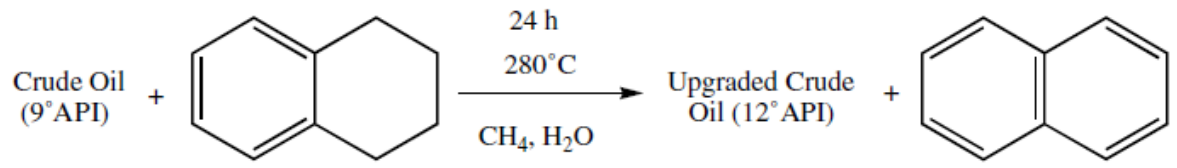

Fig. 1.5 Hydrogen is transferred from the tetralin to the asphaltene.

The reaction illustrated above can be summarized in terms of a two-step process in which tetralin transfers hydrogen to the crude oil and is converted into 1,2-dihydronaphthalene. Then the latter compound transfers two additional hydrogen atoms to form naphthalene and further upgrade the crude oil. The second reaction step is 
faster than the first one, leading to the steady state concentration of DHN during the upgrading process. The processes in illustrated in Fig. 1.6 (Ovalles et al., 2003).

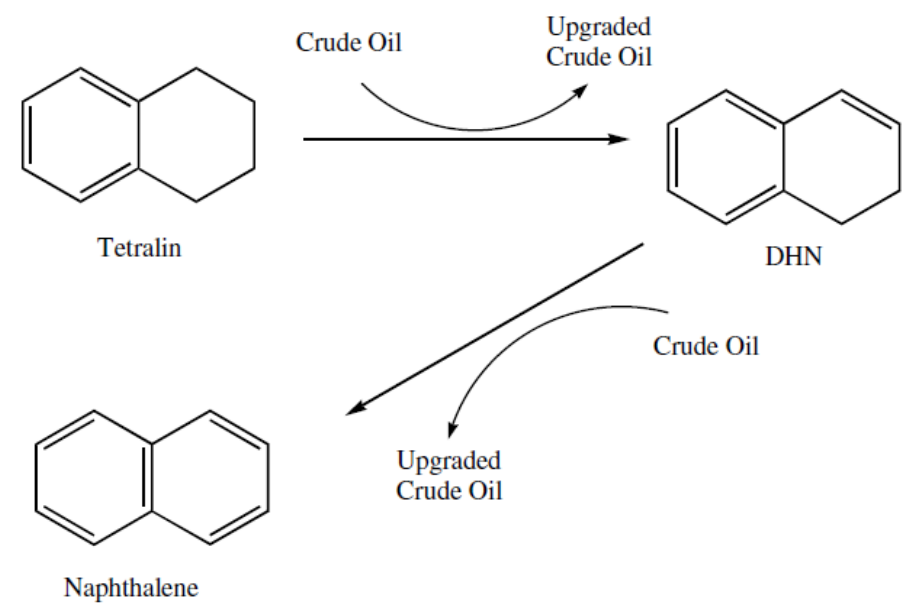

Fig. 1.6 Two-step model for transfer of hydrogen from tetralin to heavy oil.

There are some special aquathermolytic reactions for heavy oil components with different molecular structures. For instance, Belgrave et al.(1997) suggested that gases such as $\mathrm{CO}_{2}, \mathrm{H}_{2}$ and $\mathrm{CH}_{4}$ could be generated in slow thermal maturation reactions, which is similar to aquathermolytic reactions. It is very important to research slow thermal maturation of heavy oil in steamed region for a long period of time.

The mechanism for decalin is relatively unknown. But the principle is believed to be similar to Tetralin. 


\subsection{Research Objectives}

The main research objective is to evaluate the possibility of in-situ upgrading of heavy crude oil by steam injection with the aid of a catalyst and a hydrogen donor under different temperatures and different lengths of time. The extent and degree of oil upgrading will also be assessed to confirm the potential of replacing or partially replacing surface upgrading facilities. The extent of upgrading will be established through various analyses of the initial and produced crude oil. These would include measurements of oil gravity and oil viscosity. The optimal reaction temperature and reaction time will be investigated. 


\section{LITERATURE REVIEW}

Many experimental studies have been performed to improve the in-situ upgrading process. Adding different types of hydrogen donors and catalysts to upgrade heavy oil in situ have been investigated. In this section, reviews of some of these studies are presented.

Clark et al. (1990) studied the effects of aqueous metal ion species on homogenized oil sand samples with $240^{\circ} \mathrm{C}$ steam. An autoclave reactor was used to contain the mixture of oil sand, water and metal salts. After 14 days of reaction, viscosity and production gas were analyzed. They found that when aqueous metal species such as iron (II) or (III) sulfate were added, the viscosities of the recovered oils were reduced compared with values obtained in steam-only experiments. Iron salts were especially effective in reducing viscosity and these reductions were noted for a variety of oil sands. Analysis of some of the recovered oils for saturates, aromatics, resins and asphaltene showed that the metal species caused conversion of resin and asphaltene materials to aromatic and saturate classes and also reduced the size of asphaltene. They also found that the interaction of the metal species with organosulfur heavy oil components led to some molecular alteration.

Ovalles et al. (1995) studied the upgrading of Orinoco Belt extra-heavy crude oil by methane without catalysts using water as an additive. The mixture of Hamaca crude oil, water and methane was heated up to $380{ }^{\circ} \mathrm{C}$ in a batch reactor and pressure was maintained at 1,595 psi for 4 hours. The analysis of upgraded product showed that 
viscosity was reduced by two orders of magnitude (from 500,000 to $1,990 \mathrm{cp}$ ) at $30{ }^{\circ} \mathrm{C}$, the $>540{ }^{\circ} \mathrm{C}$ fraction was converted by $60 \%$ and sulfur was reduced by $11.3 \%$. When Nitrogen was used instead of methane, higher viscosity $(2,600 \mathrm{cp}), 54 \%$ conversion of the heavy fraction and $8.3 \%$ sulfur reduction was observed. It showed that the upgrading effects by using Nitrogen were not as significant as using methane. Nitrogen was used for maintaining the reaction pressure and did not take part in pyrolysis reaction. However, methane was involved in the upgrading reactions and most probably behaved as a source of hydrogen for the thermal processes. Reactions carried out with a dehydrated crude oil indicate that that the presence of water enhances methane's incorporation into the upgraded products. The concomitant production, methyl radicals, from the reaction of $\mathrm{OH}$ with methane, propagates upgrading chain process.

Three years later, Ovalles et al. (1998) investigated extra-heavy crude oil upgrading using methane as a source of hydrogen in the presence of a dispersed molybdenum catalyst derived from $\mathrm{MoO} 2(\mathrm{acac}) 2$ (acac $=$ acetylacetonate) in a batch reactor at $1,595 \mathrm{psi}$ and $410{ }^{\circ} \mathrm{C}$ for 1 hour. The reaction led to an increase of $7^{\circ} \mathrm{API}$ in the API gravity of the upgraded product, $16 \%$ reduction in sulfur content, and $55 \%$ conversion of the $>500{ }^{\circ} \mathrm{C}$ fraction with respect to the original crude. They proposed that $\mathrm{MoS}_{2}$ catalyst activated $\mathrm{CH}_{4}$ and generated $\mathrm{CH}_{\mathrm{x}}$ and $\mathrm{H}_{4-\mathrm{x}}$ species on the catalyst surface.

Ovalles, et al. (2001) simulated downhole extra heavy oil upgrading using tetralin as a hydrogen donor in the presence of methane under steam injection conditions. Hamaca oil sands, water, tetralin were mixed at weight ratio of 10:1:1. It is performed in a continuous bench scale plant pressurized with methane to $1600 \mathrm{psig}$ at 
$280{ }^{\circ} \mathrm{C}$ for 24 - 64 hours. The experiments showed a $3{ }^{\circ} \mathrm{API}$ increase in the oil gravity, a three-fold reduction in viscosity, and an $8 \%$ decrease in the asphaltene content with respect to the original crude. They concluded that the presence of the natural formation as catalysts and methane is necessary to enhance the upgrading process. Numerical Simulations are performed using a reaction model involving four pseudo-components (light, medium, heavy and asphaltene fractions). The kinetic parameters (pre-exponential factors and activation energies) were determined. The API gravities from simulation matched the experiment with an average relative error of $4 \%$.

Fan et al. (2001) studied the synergetic effects of mineral and steam on the composition changes of heavy oils. The results had shown that the mineral had a catalytic effect in the aquathermolysis of the heavy oils. When $10 \mathrm{wt} \%$ of mineral was added to the reaction system, the saturate and aromatic increased, the resin and asphaltene decreased. Oil molecular weight and asphaltene molecular weight was decreased by over $60 \%$. An increase in all the measured gases $\left(\mathrm{H}_{2}, \mathrm{CH}_{4}, \mathrm{C}_{2}, \mathrm{C}_{3}-\mathrm{C}_{7}, \mathrm{CO}_{2}\right.$ and $\mathrm{H}_{2} \mathrm{~S}$ ) was observed. Minerals and catalyst also had synergetic effects. When a proprietary catalyst was used, the viscosity was reduced further, from $23.4-25.6 \%$ to $84.2-86.3 \%$.

In another paper, Fan et al. (2002) conducted the aquathermolysis reaction in laboratory at $240{ }^{\circ} \mathrm{C}$ using the heavy oils obtained from Liaohe oil fields in China. The results showed that Liaohe heavy oils had been undergone visbreaking in the process of steam-drive and steam stimulation. After reaction with steam, the viscosity of the heavy oil was reduced by $28 \pm 42 \%$ and the amount of the saturated and aromatic hydrocarbons 
increased, while resin and asphaltene decreased. The increase of hydrocarbons less than $\mathrm{C}_{25}$ indicated that the large molecule was broken off into smaller ones, and thus viscosity of the oil was reduced and the quality of heavy oil was improved.

Later Liu and Fan (2002) conducted another research based on the previous one. They found that when there was no hydrogen donor additive in the reaction system, the viscosity of the reacted oil after reaction would regress rapidly in 5-20 days. That was due to the fact that the active chains, formed by the cleavage of $\mathrm{C}-\mathrm{S}$ and $\mathrm{C}-\mathrm{O}$ bonds during aquathermolysis, could integrate with each other and polymerize to form high molecules. However, if $0.8 \%$ weight percent of tetralin, one of the most popular hydrogen donor additives, was used, the viscosity did not regress again. Hydrogen donor additives could control the viscosity regression by terminating the active chains produced during the process of aquathermolysis of heavy oil.

Ovalles et al. (2003) studied downhole upgrading of extra-heavy crude oil using natural formation, tetralin hydrogen donors and methane under steam injection conditions with temperature $280-315{ }^{\circ} \mathrm{C}$ and residence time of at least $24 \mathrm{~h}$. The upgrading process led to $3^{\circ} \mathrm{API}$ increase in the API gravity (from $9^{\circ} \mathrm{API}$ to $12^{\circ} \mathrm{API}$ ), a two-fold reduction in the viscosity and an approximately $8 \%$ decrease in the asphaltene content with respect to the original crude. And if the temperature was increased to 315 ${ }^{\circ} \mathrm{C}$, the API gravity was increased to $15^{\circ} \mathrm{API}$. It was found that the presence of the natural formation (catalysts) and methane (natural gas) was essential to enhance the upgrading crude oil. The upgrading effect using natural formation was more significant compared with using inert solid ( $\mathrm{SiC})$. Isotopic labeling studies $\left(\mathrm{CD}_{4}\right.$ and $\left.{ }^{13} \mathrm{CH}_{4}\right)$ gave 
evidences that methane was involved in the upgrading reactions. GC and GC-MS results revealed the presence of small amounts of 1, 2-dihydronaphtalene (DHN) in the reaction medium. So a reaction pathway that involved hydrogen transfers from tetralin to the extra-heavy crude oil was proposed. It resulted the formation of 1,2-dihydronaphthalene. This compound was then transformed into naphthalene, upgraded crude oil further through hydrogen donation.

Zhong et al. (2003) conducted aquathermolytic experiments using crude oil, water, tetralin hydrogen donor and a Fe (II) catalyst at temperatures ranging from $160{ }^{\circ} \mathrm{C}$ to $260{ }^{\circ} \mathrm{C}$ for $24-240$ hours with pressures ranging between 1450 and 3625 psi. They concluded that the laboratory experiments resulted in decreases in the average molecular weight, asphaltene, sulfur and resin contents but increases in hydrogen-carbon ratio, aromatics and saturated hydrocarbons. Comparisons of aquathermolysis with and without a hydrogen donor in the absence of catalysts were studied. The results demonstrated that tetralin alone reduced the oil viscosity by $40 \%$. Comparisons of upgrading with and without a hydrogen donor in the presence of catalysts were also performed. They showed that the catalyst alone reduced the oil viscosity by $60 \%$, while the combination of catalyst and tetralin decreased the viscosity by $90 \%$, suggesting a synergetic effect on the heavy oil aquathermolysis. A 5-well field aquathermolysis test using a catalyst and a hydrogen donor was carried out at five Liaohe extra heavy oil wells. The oil recovery was improved and the treated oil was upgraded greatly. It was a successful field test which increased the production of each well by 828 tons and reduced the viscosity by $80 \%$. 
Jiang et al. (2005) applied aquathermolytic technology to Liaohe and Shengli heavy oils to investigate catalysis of some metal species and synergetic effects of catalysts and hydrogen donors. Significant reduction in viscosity and contents of asphaltene and resin were observed. They proposed the aquathermolytic mechanism that catalysts could lead to cleavage of some components of heavy oil; and then activated $\mathrm{H}$ from $\mathrm{H}_{2} \mathrm{O}$ and hydrogen donors could connect with fragments or radicals cleaved, leading to a permanent size reduction of some molecules in heavy oil. Therefore the combination of catalyst and hydrogen donor resulted in chemical changes in structures, compositions and reduction in viscosity of heavy oil. They also reported that field tests were performed and a significant increase in production was obtained (11,000 tons).

Nares et al. (2006) used several commercial and non-commercial catalysts for a comparative study, where heavy crude oil was mixed with each of the catalysts and was placed in a reactor. The results showed upgrading potential for all the catalysts, supported $\left(\mathrm{MoCoP} / \mathrm{Al}_{2} \mathrm{O}_{3}\right.$ \& $\left.\mathrm{MoWNiCo} / \mathrm{Al}_{2} \mathrm{O}_{3}\right)$ and unsupported $\left(\mathrm{Mo}(\mathrm{II})(\mathrm{acac})_{2}\right.$ \& $\left.\mathrm{Fe}(\mathrm{III})(\mathrm{acac})_{3}\right)$ at $350^{\circ} \mathrm{C}$ under pressure of $1566 \mathrm{psi}$ for 4 hours. The iron catalyst showed the highest increase of the API oil gravity. But it exhibited high coke formation. KU-H heavy crude oil's API gravity was increased from 12.5 to $21-26^{\circ} \mathrm{API}$, the kinematic viscosity decreased from $18,130 \mathrm{cSt}$ to $8-100 \mathrm{cSt}$ at $298 \mathrm{~K}\left(24.85^{\circ} \mathrm{C}\right)$, the asphaltene content reduced from $26 \mathrm{wt} \%$ to $7 \mathrm{wt} \%$, the removed sulfur ranged from $30 \%$ to $60 \%$, and the distillable fraction was increased from $20 \mathrm{wt} \%$ to $30 \mathrm{wt} \%$. Nares et al (2007) published two other papers on this topic. In one of them, Nares et al (2007) discussed the effects of some metallic oxides used to upgrade the heavy crude oil. They used alumina 
supported transition metals and liquid phase transition metals catalysts (derived from either acetylacetonate or alkylhexanoate compounds), which were homogeneously mixed with heavy crude oil. In the other one, Nares et al (2007) used ionic liquids elaborated with iron and molybdenum to upgrade the properties of a heavy crude oil. Both showed great upgrading effects.

Wen et al. (2007) studied aquathermolysis of Liaohe heavy crude oil during steam stimulation by using molybdenum oleate as oil-soluble catalyst for the reaction. The laboratory experiments showed that viscosity-reduction ratio of heavy oil was over $90 \%$ after reaction at $240^{\circ} \mathrm{C}$ for $24 \mathrm{hrs}$ with $0.5 \mathrm{wt} \%$ catalyst solution. A field test that applied aquathermolytic technology in puff-and-huff operation was carried out in Qi-40 and Qi-108 blocks of Liaohe oilfield. It showed that the viscosity was decreased by $78.2 \%$ (measured at $50{ }^{\circ} \mathrm{C}$ ) in the field test and that hydrogen in the heavy oil was increased significantly. The results also indicated that the oxygen, sulfur and nitrogen content decreased. As a result, the cycle decline rate of heavy oil production in huff-and-puff operation was clearly improved.

Ovalles and Rodriguez (2008) studied physical and numerical simulation of an extra-heavy crude oil downhole upgrading process using hydrogen donors under cyclic steam injection conditions again. More details on numerical simulation studies were elaborated than their paper in 2001 (Ovalles et al., 2001). Compositional-thermal numerical simulations were carried out using a commercial simulator (STARSTM from $\mathrm{CMG}$ ) and validated using bench scale data. The compositional model involved the use of four fractions (pseudo-components) that were separated from the original crude oil. In 
order to determine the kinetic model to be used in the numerical simulations, two different factors must be considered. They examined the reaction between Hamaca pseudo-components under steam injection conditions $\left(280-315^{\circ} \mathrm{C}\right)$ and investigated the hydrogen donor reaction order to model the tetralin conversion during the upgrading process. Numerical simulation under cyclic steam injection conditions showed that the cumulative API gravity of the oil in the tank for a 70-day production period was 11.8 ${ }^{\circ} \mathrm{API}$ (2.8 degrees increase from original $9{ }^{\circ} \mathrm{API}$ crude), which matched the API gravity $\left(12^{\circ} \mathrm{API}\right)$ for cumulative oil production from the physical experiment well. A reduction in the percentage of tetralin conversion (from 3\% to $0.8 \%$ ) was observed in the upgrading process in comparison with the bench scale experiments. This phenomenon was attributed to the gravitational segregation of the steam coupled with the low mixing efficiency of the hydrogen donor with the extra heavy crude oil at reservoir conditions.

Mohammad and Mamora (2008) conducted experiments to verify the feasibility of in-situ upgrading of heavy crude oil by using a hydrogen donor (tetralin) and an organometallic catalyst, $\mathrm{Fe}(\mathrm{acac})_{3}$. Three cases were considered in experiments: pure steam injection, steam injection with tetralin and steam injection with tetralin and catalyst. The catalyst was dissolved in tetralin at a concentration of $750 \mathrm{ppm}$. Two types of runs with steam additives were conducted: additives premixed with sand and additives injected as a slug. The Jobo oil used had an API gravity of $12.4^{\circ}$ API and viscosity of $7800 \mathrm{cp}$ at $30{ }^{\circ} \mathrm{C}$. Acceleration of oil production and increase in oil recovery were observed in all runs. Using tetralin alone as an additive at $5 \mathrm{wt} \%$ increased oil recovery 
by $15 \%$. However, the premixed tetralin and catalyst run showed $20 \%$ increase of oil recovery.

Chen et al. (2008) synthesized an amphiphilic metallic chelate-aromatic sulfonic iron. Its properties were characterized by Fourier transform infrared (FT-IR) spectroscopy. The laboratory experiments conducted at lower temperature $\left(140-200{ }^{\circ} \mathrm{C}\right)$ showed that this new catalyst was efficient, leading to a $90.66 \%$ viscosity reduction at $200{ }^{\circ} \mathrm{C}$ and $14.66 \%$ heavy contents conversion. Field tests were performed for wells G61012 and G6606 in the Henan oilfield. The production was increased by $120.6 \mathrm{t}$ (from $68.1 \mathrm{t}$ to $188.7 \mathrm{t}$ ) and $217 \mathrm{t}$ (from $283.4 \mathrm{t}$ to $500.4 \mathrm{t}$ ) in 14 days for these two wells after applying catalytic aquathermolysis technology. And the viscosity was reduced by $79.66 \%$ and $82.25 \%$, respectively.

Yi et al. (2009) studied catalytic aquathermolysis of resin and asphaltene separated from Liaohe heavy oil using water soluble catalysts $\left(\mathrm{NiSO}_{4}\right.$ and $\left.\mathrm{FeSO}_{4}\right)$ and oil soluble catalysts (nickel naphthenate and iron naphthenate). The property changes of resin and asphaltene were compared by different means. The results of conversion rate comparison was No-catalyst $<\mathrm{NiSO} 4<\mathrm{FeSO} 4<$ nickel naphthenate $<$ iron naphthenate. Oil soluble catalysts had better catalytic ability than water soluble ones. The amount of $\mathrm{H}_{2}$ and $\mathrm{CO}$ generated was increased significantly in the presence of catalysts. It was found that asphaltene and resin were partly aggregated after aquathermolysis. The molecular weight of asphaltene and resin increased after reaction without catalyst. However, catalysts can inhibit this trend. 
Wang et al. (2010) investigated the mechanism of catalytic aquathermolysis of heavy oil for two types of efficient catalytic ions: $\mathrm{Fe}^{3+}$ and $\mathrm{Mo}^{6+}$. The comparison analysis of these two catalysts showed that the aromatic sulfonic iron was more effective on resins, saturated hydrocarbons, and oxygen-containing groups, while aromatic sulfonic molybdenum led to more changes with regard to the asphaltene, aromatic hydrocarbon, and sulfur-containing groups. They also proposed seven types of reactions: pyrolysis, depolymerization, hydrogenation, isomerization, ring opening, oxygenation, alcoholization, and esterification, and reconstruction.

Wu et al. (2010) studied the aquathermolysis of Shengli extra-heavy oil during steam stimulation by using $0.2 \%$ anamphiphilic molybdenum chelate-aromatic sulfonic iron solution as catalyst for the reaction at $200{ }^{\circ} \mathrm{C}$ for 24 hours. The laboratory result showed there was $97.15 \%$ reduction in heavy oil viscosity. The percentage of saturate, aromatic and $\mathrm{H} / \mathrm{C}$ increased, and resin, asphalt and $\mathrm{S}, \mathrm{O}, \mathrm{N}$ decreased after the catalytic aquathermolysis. The heavy components were converted into light components, and the quality of the heavy oil was improved. They found the new mechanism of the catalyst that it not only broke C-S bonds, but also broke $\mathrm{C}-\mathrm{O}$ and $\mathrm{C}-\mathrm{N}$ bonds, and accelerated the reaction of aquathermolysis.

Mateshov (2010) used decalin $\left(\mathrm{C}_{10} \mathrm{H}_{18}\right)$ as a hydrogen donor for in-situ combustion of Gulf of Mexico heavy oil. Experiments using decalin showed better quality of produced oil, higher recovery factor, faster combustion front movement and higher temperatures of oxidation. API gravity of produced oil using decalin additive was $4^{\circ} \mathrm{API}$ higher than a base run without any additives and $5{ }^{\circ} \mathrm{API}$ more than original crude 
oil. Oil production increased by $7 \%$ of OOIP in comparison with base run and was $2 \%$ higher than the experiment with tetralin. The time required for the combustion front to reach bottom was accelerated. The experiments showed that decalin and organometallic catalysts perform successfully in in-situ combustion, and that decalin is a worthy replacement for tetralin.

Decalin is a hydrogen donor which has not been used in in-situ upgrading under steam injection condition. Tetralin has been used by Mohammad and Mamora (2008) in steam flooding experiment. However, the reaction time for their process is pretty short and may not be long enough to upgrade the heavy crude thoroughly. My main research objective is to investigate the upgrading abilities of decalin and tetralin with a catalyst, and their applicability to upgrade Jobo heavy oil from Venezuela.

The literature studies are also summarized in Table 2.1 for comparisons and reviews. 
Table 2.1 Summary of literature review on in-situ upgrading of heavy oil

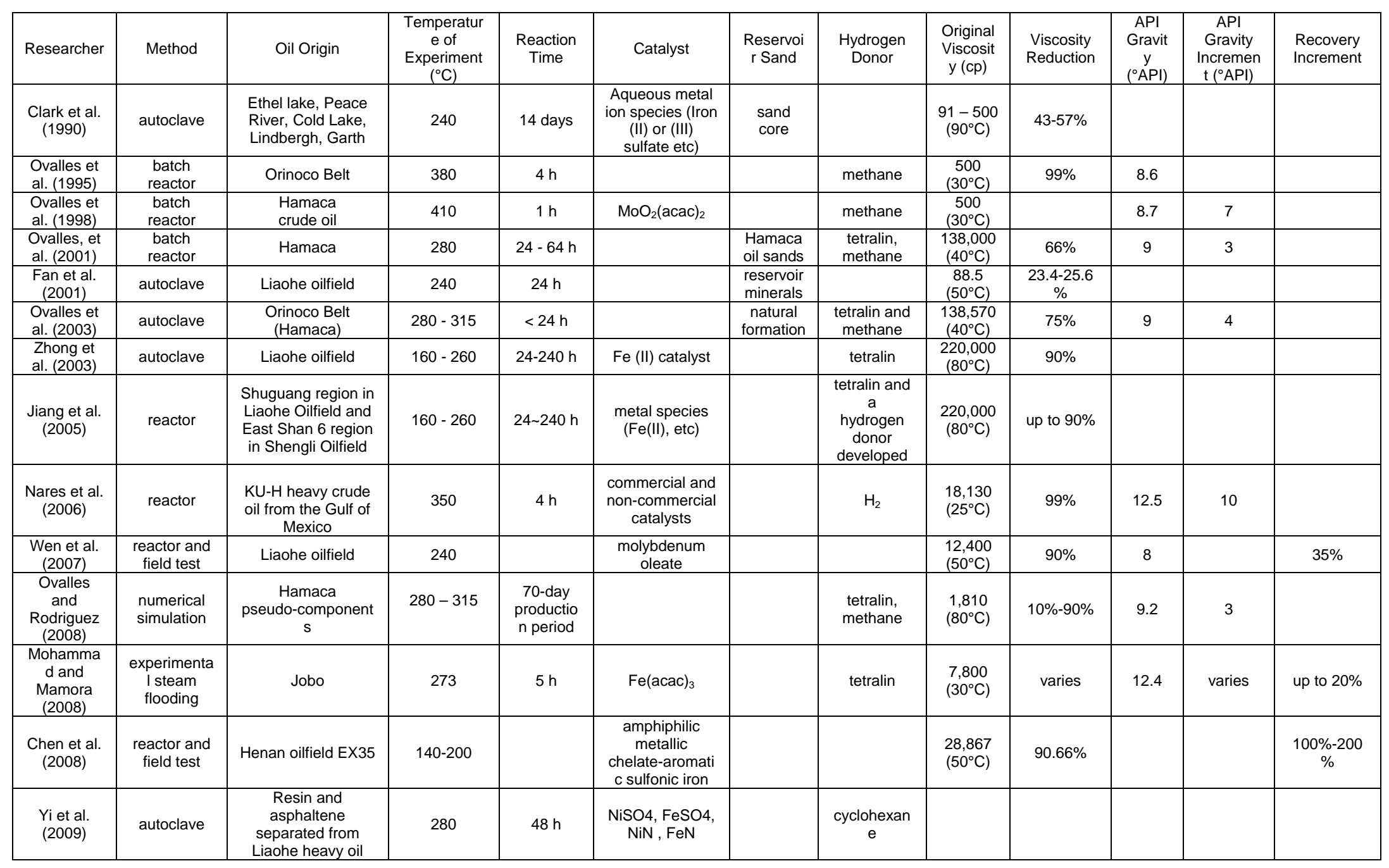


Table 2.1 Continued

\begin{tabular}{|c|c|c|c|c|c|c|c|c|c|c|c|c|}
\hline Researcher & Method & Oil Origin & $\begin{array}{c}\text { Temperature } \\
\text { of Experiment } \\
\left({ }^{\circ} \mathrm{C}\right)\end{array}$ & $\begin{array}{c}\text { Reaction } \\
\text { Time }\end{array}$ & Catalyst & $\begin{array}{l}\text { Reservoir } \\
\text { Sand }\end{array}$ & $\begin{array}{l}\text { Hydrogen } \\
\text { Donor }\end{array}$ & $\begin{array}{c}\text { Original } \\
\text { Viscosity } \\
(\mathrm{cp})\end{array}$ & $\begin{array}{l}\text { Viscosity } \\
\text { Reduction }\end{array}$ & $\begin{array}{c}\text { API } \\
\text { Gravity } \\
\left.\text { ( }{ }^{\circ} \mathrm{API}\right)\end{array}$ & $\begin{array}{c}\text { API Gravity } \\
\text { Increment } \\
\left({ }^{\circ} \mathrm{API}\right)\end{array}$ & $\begin{array}{l}\text { Recovery } \\
\text { Increment }\end{array}$ \\
\hline $\begin{array}{l}\text { Wang et al. } \\
\text { (2010) }\end{array}$ & autoclave & $\begin{array}{c}\text { DF32005 } \\
\text { extra-heavy } \\
\text { oil }\end{array}$ & 200 & $24 \mathrm{~h}$ & $\mathrm{Fe} 3+$ and Mo6+ & & & $\begin{array}{l}91,000 \\
\left(50^{\circ} \mathrm{C}\right)\end{array}$ & $\begin{array}{c}95.6 \% \text { and } \\
99.3 \%\end{array}$ & & & \\
\hline $\begin{array}{l}\text { Wu et al. } \\
\text { (2010) }\end{array}$ & & $\begin{array}{l}\text { Shengli } \\
\text { extra-heavy } \\
\text { oil }\end{array}$ & 200 & $24 \mathrm{~h}$ & $\begin{array}{c}\text { anamphiphilic } \\
\text { molybdenum } \\
\text { chelate-aromatic } \\
\text { sulfonic iron }\end{array}$ & & & $\begin{array}{c}524,500 \\
\left(50^{\circ} \mathrm{C}\right)\end{array}$ & $97.15 \%$ & & & \\
\hline $\begin{array}{c}\text { Mateshov } \\
(2010)\end{array}$ & $\begin{array}{c}\text { in-situ } \\
\text { combustion }\end{array}$ & $\begin{array}{c}\text { Gulf of } \\
\text { Mexico } \\
\text { heavy oil }\end{array}$ & $450-635$ & $12 \mathrm{~h}$ & $\mathrm{Fe}(\mathrm{acac})_{3}$ & sand & decalin & $\begin{array}{c}771 \\
\left(50^{\circ} \mathrm{C}\right)\end{array}$ & $71 \%$ & 10 & 5 & $\begin{array}{l}7 \% \text { of } \\
\text { OOIP }\end{array}$ \\
\hline
\end{tabular}




\section{EXPERIMENTAL APPARATUS AND PROCEDURES}

The experiment was performed in an autoclave made by Autoclave Engineers. It was a $100 \mathrm{ml}$ mini-reactor (Model \# M010SSH0010-E128A-50002-1E1101) including a vessel body, a magnetic stirrer, a pressure gauge, and a band heater. The temperature inside the vessel was monitored and controlled by a temperature controller made of an auto tune temperature controller and a relay. The system set up is shown on Fig. 3.1. The system was kept inside a fume hood to meet the safety specifications.

The equipment used for measurements were: a Brookfield DV-III programmable rheometer for measuring viscosity, an Anton Paar DMA 4100 density meter for measuring density, and a HP 6890 GC-MS machine for component analysis.

\subsection{Experimental apparatus}

\subsubsection{Autoclave o-ring and vessel body}

The autoclave uses an o-ring to seal the vessel body. The AE mini o-ring self-sealing closure on the vessel is designed specifically for low pressure and moderate temperature applications where o-ring seals are permissible. The o-ring self-sealing closure seals against pressure by the use of a radial o-ring seal. The radial seal works by creating a pocket between the cover and body and filling it with a soft and pliable material. Preload of the seal is created by making the pocket radially smaller than the seal cross section. Once the initial seal is created, pressure end load on the seal then forces the o-ring material tightly into the body and cover. If a CHEMRAZ or KALREZ 
o-ring is used, the sealing system can stand up to $2,900 \mathrm{psi}$ ( $200 \mathrm{bars})$ in pressure and the maximum operation temperature it can sustain is as high as $600{ }^{\circ} \mathrm{F}\left(315^{\circ} \mathrm{C}\right)$. The o-ring and vessel body is shown on Fig. 3.2. And Fig. 3.3 shows that the reaction vessel is assembled to the cover. (Autocalve Engineers' Autoclave Manuals)

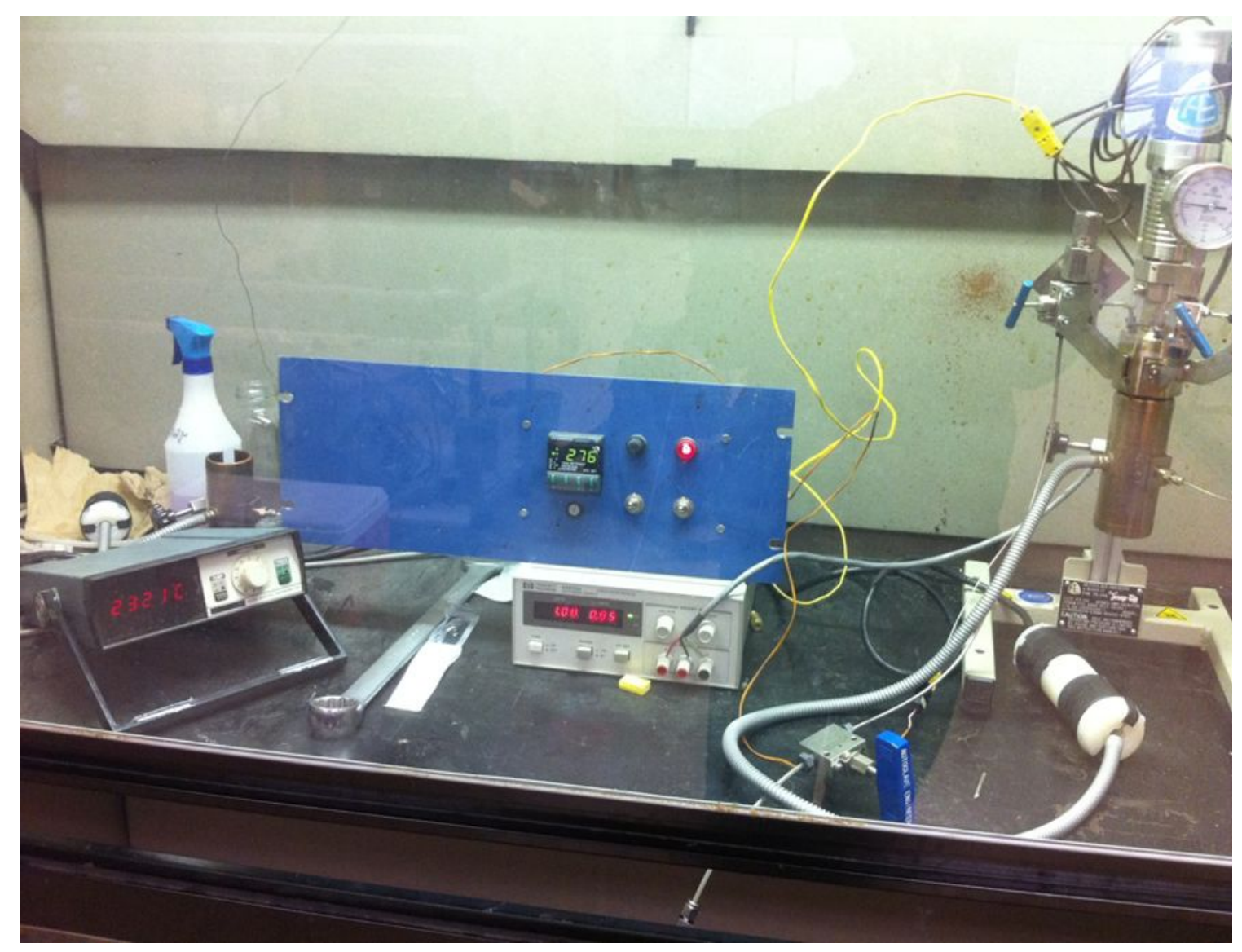

Fig. 3.1 Experiment set up includes an autoclave, a temperature controller, a magnetic stirrer controller, an external heating band temperature monitor, and a nitrogen bottle. 


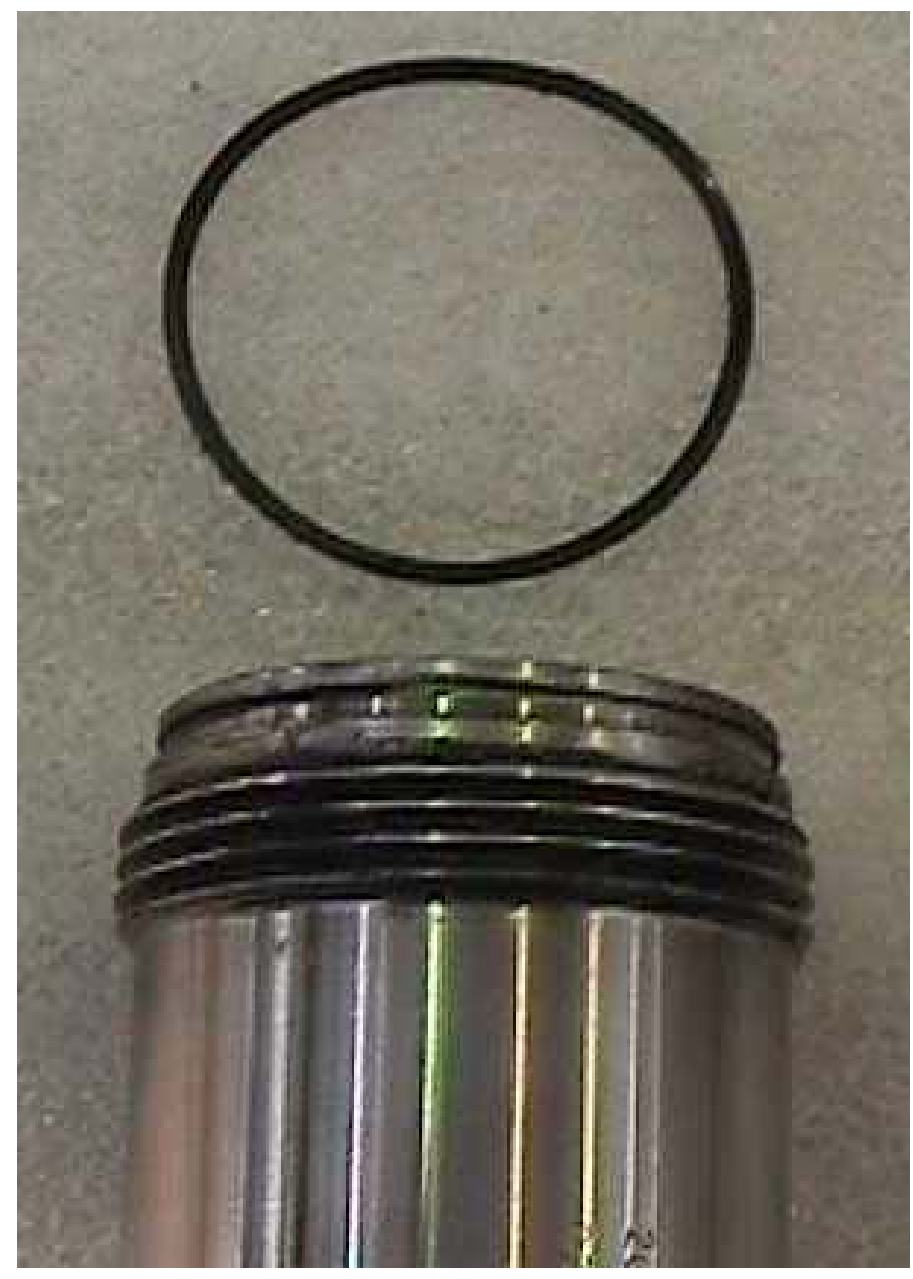

Fig. 3.2 O-ring and vessel body. 


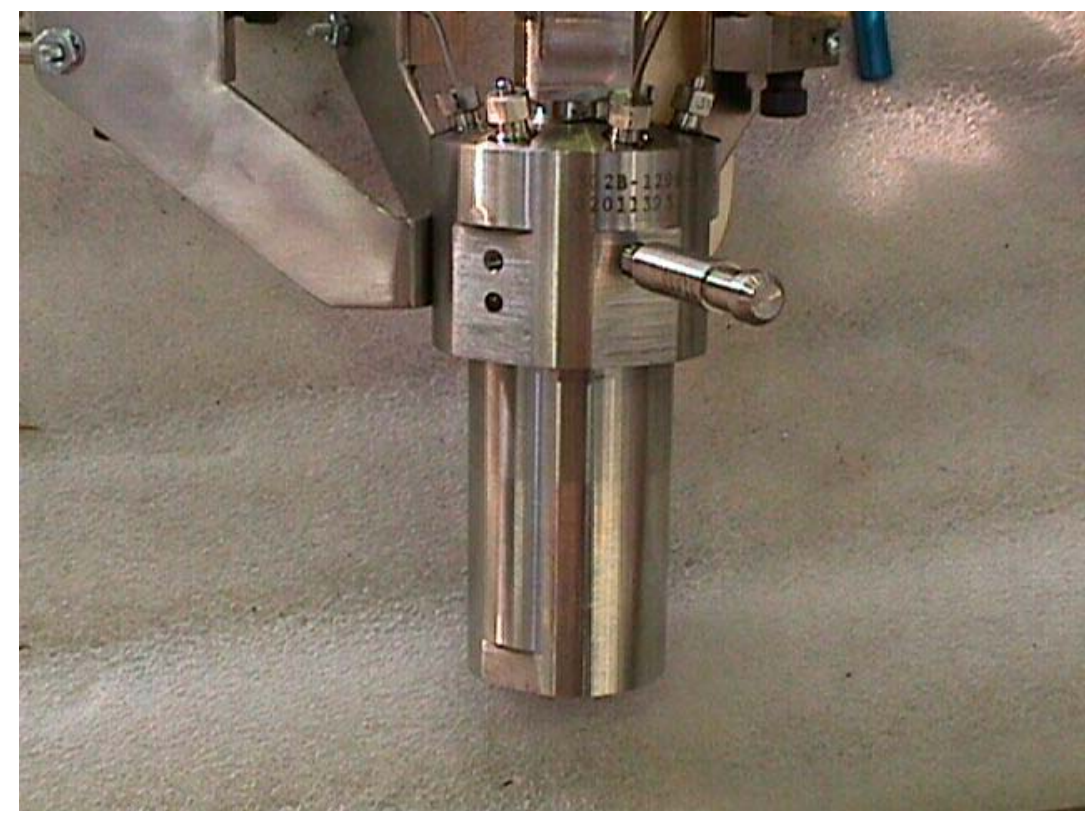

Fig. 3.3 Reaction vessel is assembled to the cover fixed in the supporting shelf.

\subsubsection{Magnetic stirrer}

The autoclave uses a MagneDrive stirrer. Its high speed rotary agitation is achieved by the rotation of external magnets which actuate internal magnets attached to the shaft. Its design eliminates leakage, lubricator contamination, and packing heat generation problems as seen on conventional stirrers. The external drive magnet assembly consists of an outer aluminum holder containing the stator magnets. This outer holder is placed over a pressure sealed housing containing the encapsulated rotor magnets, which are mounted on the mixing shaft. The magnetic circuit between the stator and rotor assemblies creates a strong magnetic coupling causing the inner rotor to rotate at the same speed as the outer holder. Its assembly is shown in Fig. 3.4. (Autocalve Engineers' Autoclave Manuals) 


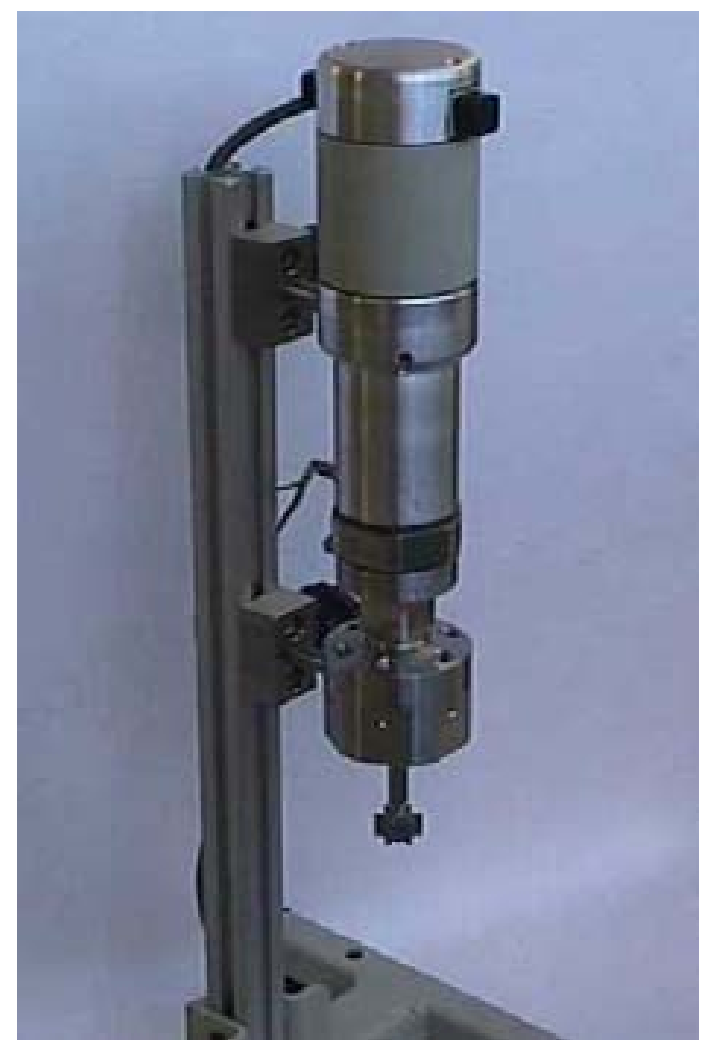

Fig. 3.4 Magnetic stirrer assembly.

\subsubsection{Pressure gauge}

The vessel pressure is constantly monitored by a pressure gauge from a non-isolated connection. It is manufactured by McDaniel Controls, Inc. and has a pressure range from 0 to 5000 psi with a 50 psi (1\% full scale) accuracy.

\subsubsection{Standard mini mica band heaters}

A mica insulated resistance type heater is used on this mini pressure vessel reactor. The cylindrical heater is constructed of stainless steel. The heater is equipped with a clamping knob for quick removal. A compression fitting accepting a pencil type 
thermocouple is provided. High temperature wire encased in a metal cable is used as external connection for power supply for the heating element. Internally, a high temperature heating element wire is insulated from contact with conducting material by mica insulation. A stainless steel shell encapsulates the furnace. The entire heater assembly can is shown on Fig. 3.5. (Autocalve Engineers' Autoclave Manuals)

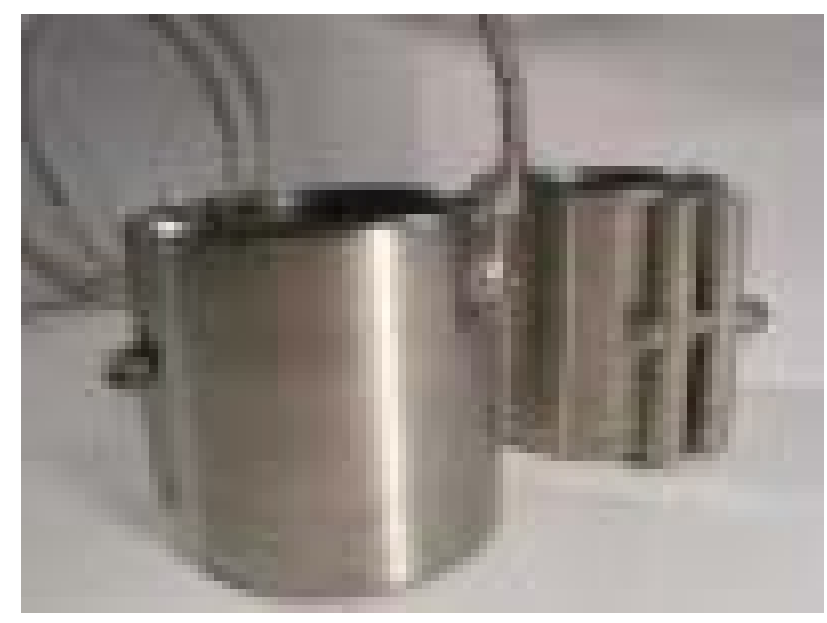

Fig. 3.5 Mini mica band heater assembly.

\subsubsection{Sample tube and valve}

The sample tube valve is mounted directly to the vessel cover to avoid disassembly of the valve connection in event the cover is removed. Samples can be taken at any time during a process run. When the valve is opened, pressure forces the fluid up the dip tube and through the valve. Open the valve slowly and use extreme care when taking samples. Use a beaker or sample cylinder to collect the sample. (Autocalve Engineers Autoclave Manuals) 


\subsubsection{Temperature controller}

The Omega CN9000A digital temperature controller features high accuracy and reliability. The sophisticated autotune algorithm will calculate the optimum PID values, and additionally recommends the best value for cycle time. It can accomplish optimal control during start-up and steady-state operation. The autotune parameters can be fine-tuned to an individual process by the operator at any time. (Omega C9000A Series User's Guide)

The microprocessor holds all data in non-volatile memory with the ability to retain data without power. The CN9000A has $31 / 2$ digit green LED readout, with 3 LED to indicate deviation from set point and auxiliary indicators for each output, as shown on Fig. 3.6. 


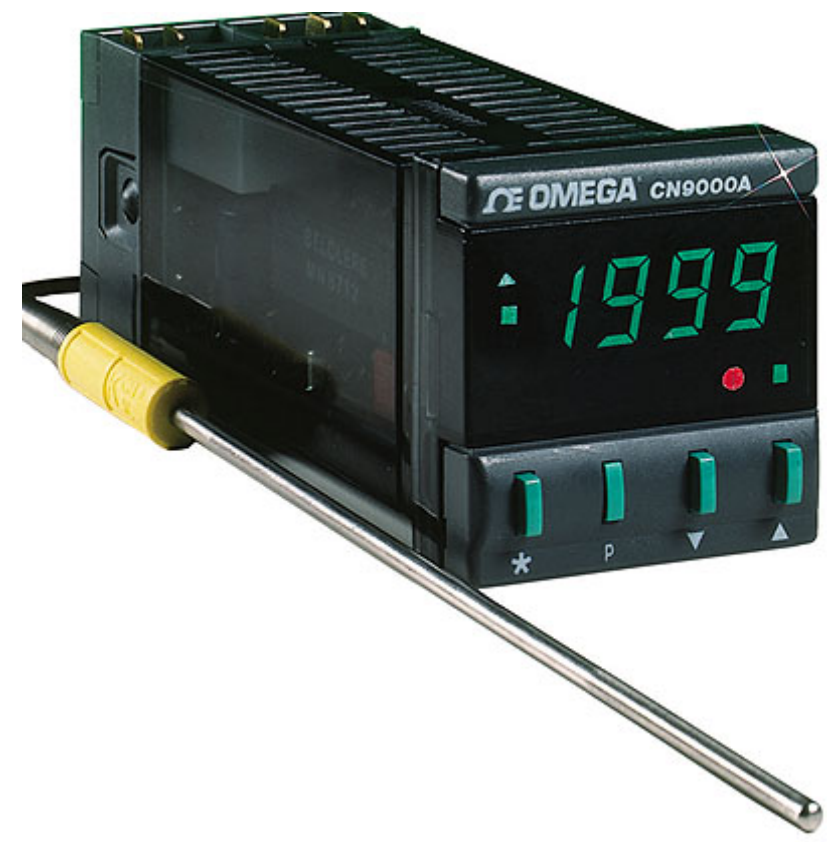

Fig. 3.6 A 1/16 DIN autotune PID/on-off controllers with modular output options.

\subsubsection{Centrifuge}

The HN-SII general purpose centrifuge (Fig. 3.7) combines the mechanical features and unique profile of the proven $\mathrm{HN}$ product line with modern solid state electronics. It has the capability of spinning a variety of applications, especially oil samples for ASTM test methods (e.g. D96). It can spin at a speed up to $4900 \mathrm{rpm}$ and hold four $100 \mathrm{ml}$ samples at the same time. (http://www.gmi-inc.com/Damon-IEC-HN-SII .html)

\subsubsection{Rheometer}

The Brookfield DV-III programmable rheometer (Fig. 3.8) measures fluid parameters of shear stress and viscosity at given shear stress. The principle of operation 
of the DV-III is to drive a spindle (which is immersed in the test fluid) through a calibrated spring. The viscous drag of the fluid against the spindle is measured by the spring deflection. Spring deflection is measured with a rotary transducer. The measuring range of a DV-III (in centipoises) is determined by the rotational speed of spindle, the size and shape of the spindle, the container the spindle is rotating in, and the full scale torque of the calibrated spring. The spindle number used for the measurements is 52 (Fig. 3.9). The rheometer is connected to a water bath which lets us to control the temperature at which measurements are made (Fig. 3.10). (Brookfield DV-III Ultra Operating Instructions)

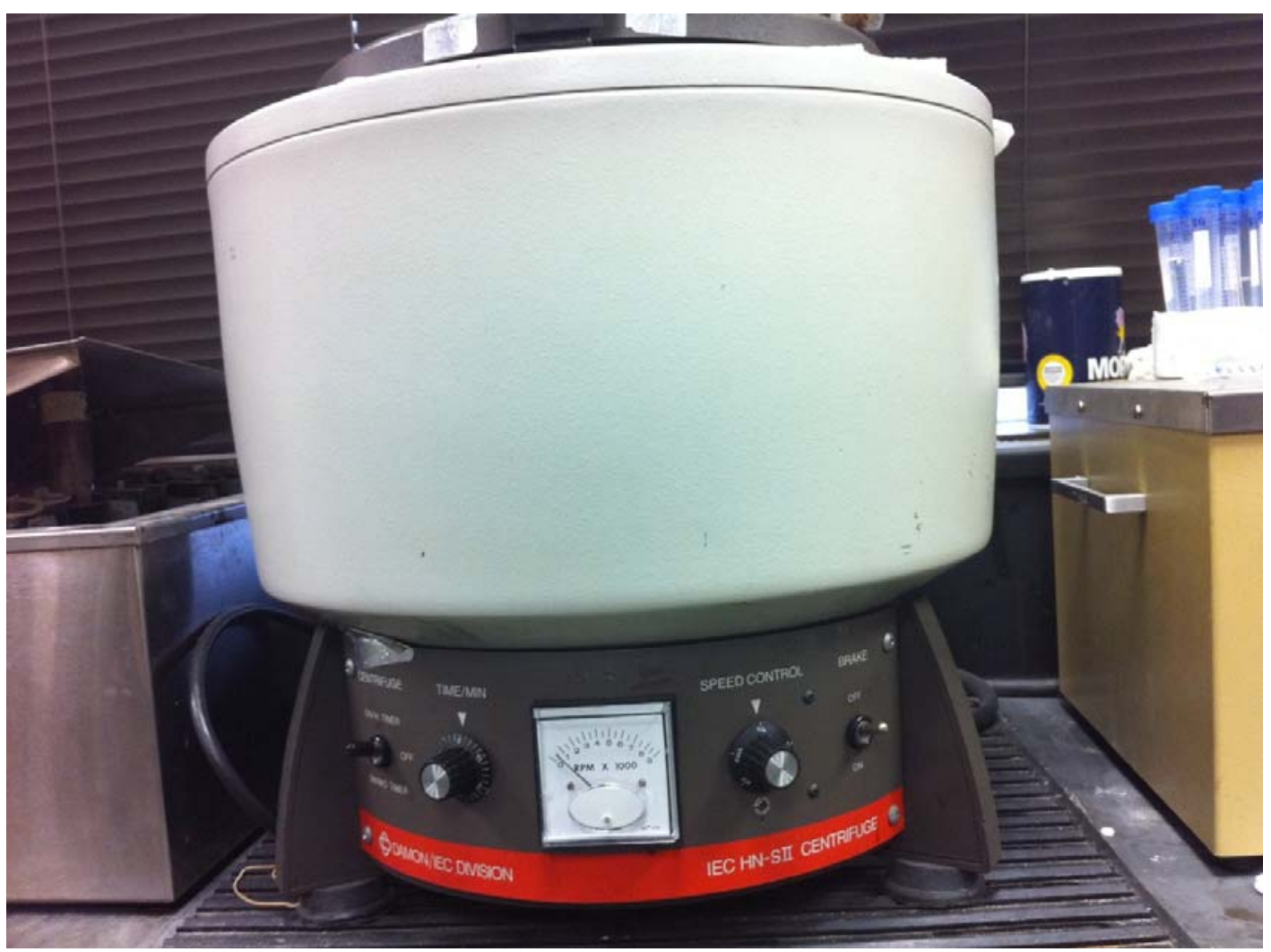

Fig. 3.7 Photograph of the HN-SII general purpose centrifuge 


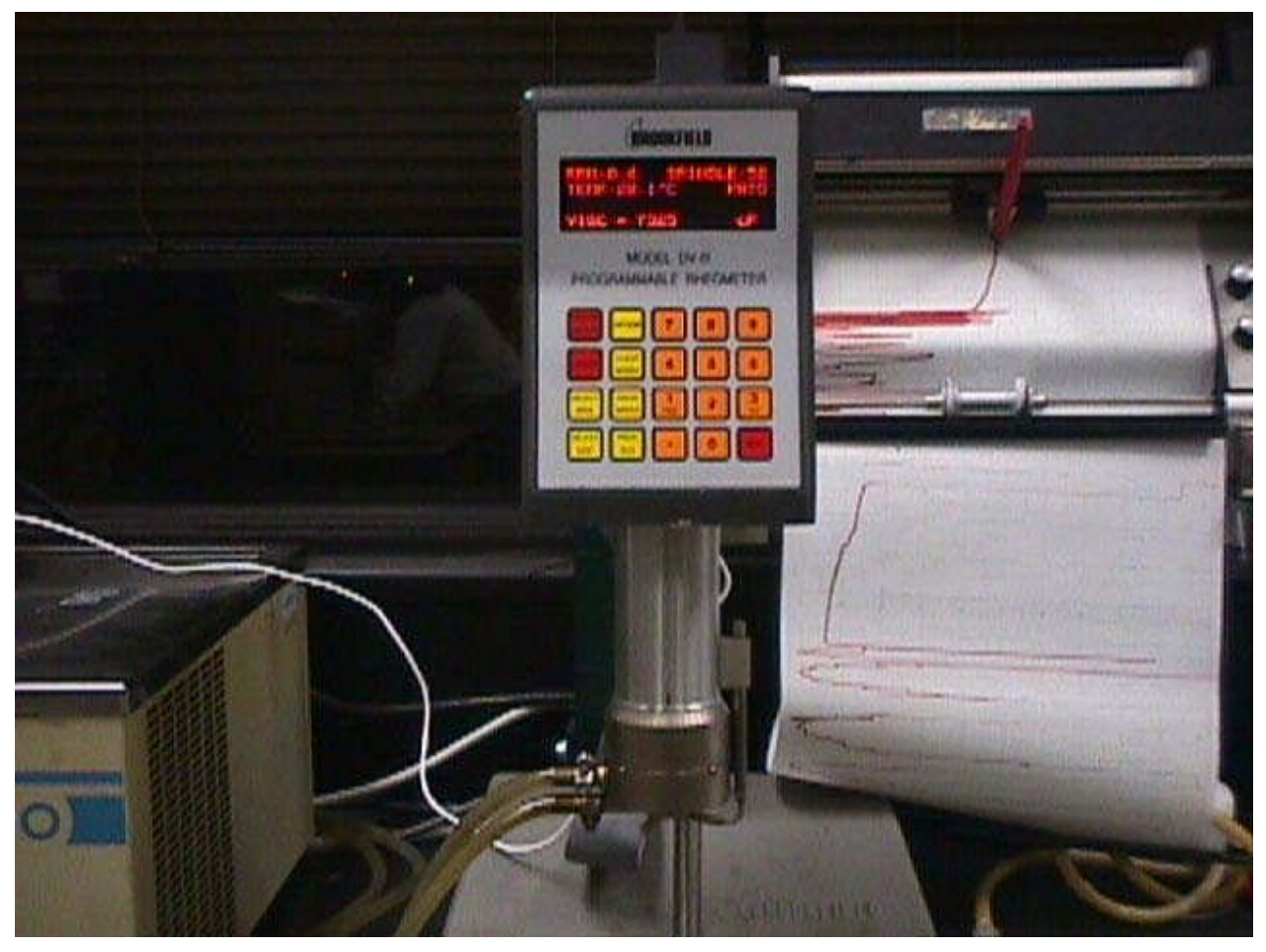

Fig. 3.8 Photograph of the programmable rheometer. 


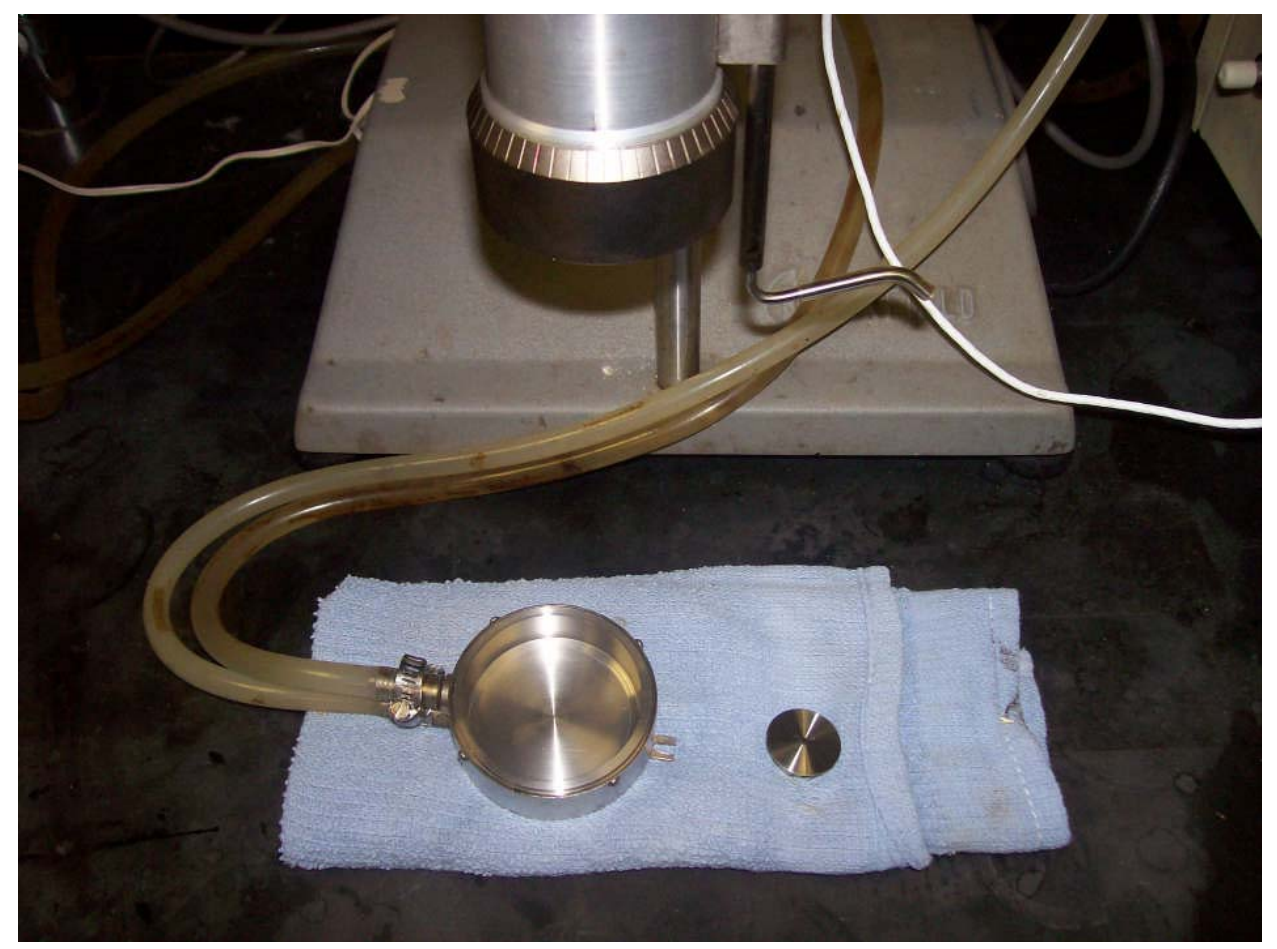

Fig. 3.9 Photograph of the spindle (to the right) and container (to the left) where it rotates. 


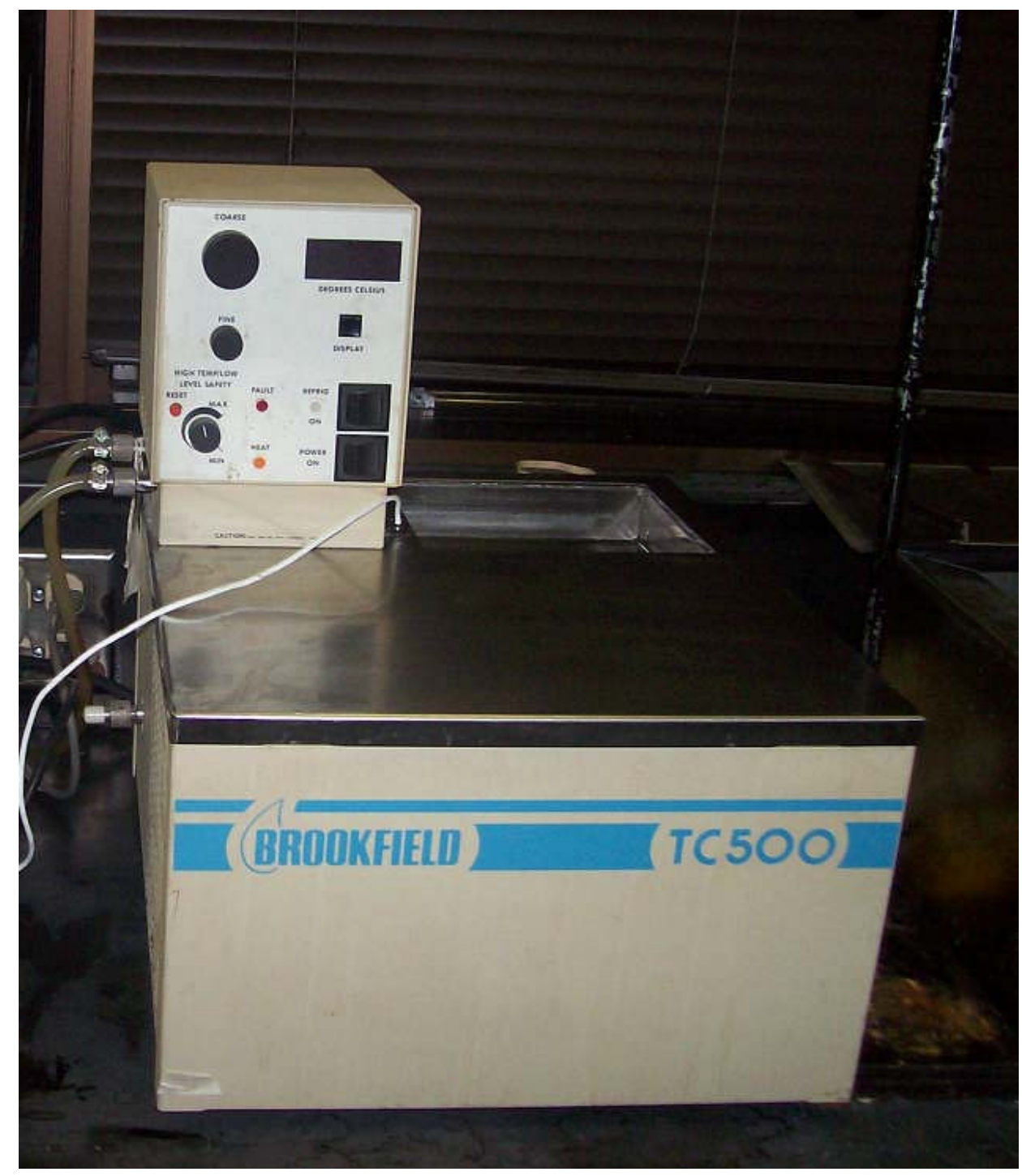

Fig. 3.10 Photograph of the water bath for rheometer.

\subsubsection{Density/specific gravity meter}

The 4-digit meter Anton Paar DMA 4100 density/specific gravity meter (Fig. 3.11) with fully-automatic compensation is ideal for measuring all types of petrochemical products. The compensation can eliminate the influences of the sample viscosity without altering the instrument settings. And there is a built-in electronic 
thermostat which ensures the correct measuring of temperature. The patented reference oscillator (AT 399051) eliminates long-term drift, so the waiting time between measurements for different temperatures is minimized. The measurements speed is fast. (Anton Paar's Instruction Manual for DMA 4100 Density Meter)

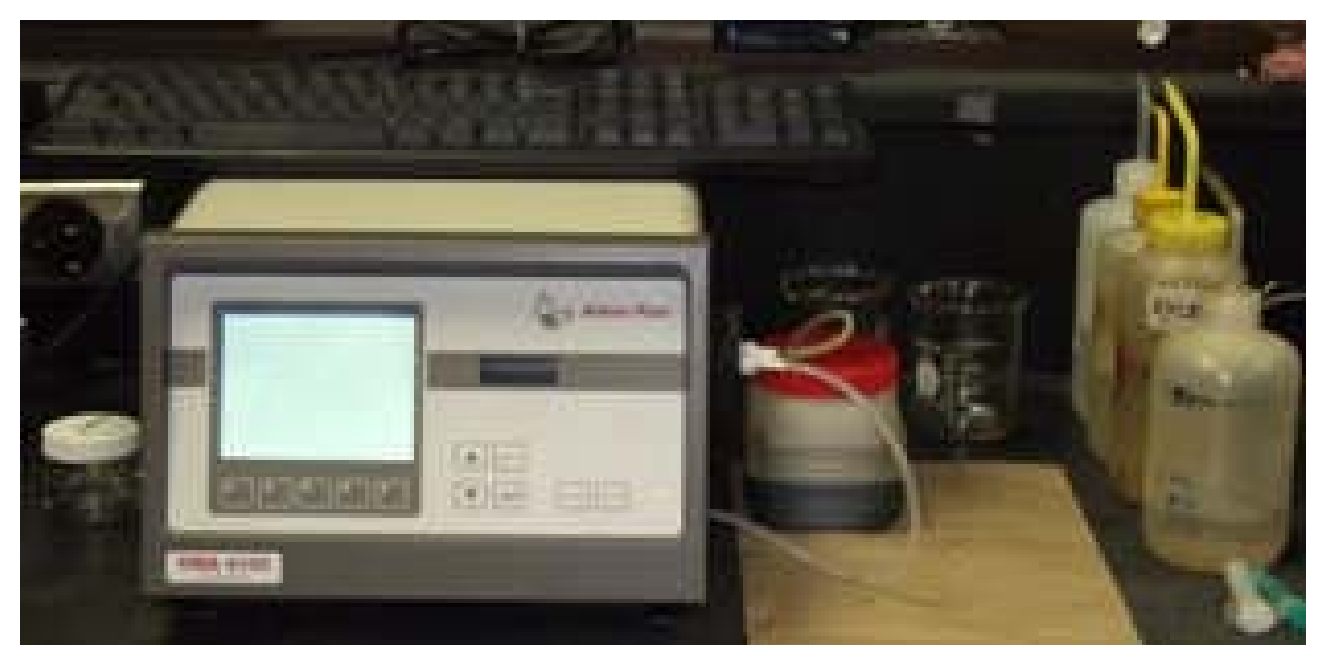

Fig. 3.11 Photograph of the density meter.

\subsubsection{Gas chromatography - mass spectrometry (GC-MS) analyzer}

Agilent $6890 \mathrm{GC}$ and 5973 MS (Fig. 3.12) is a powerful tool for identifying and quantifying volatile and semivolatile compounds in a variety of samples. The gas chromatograph functions to separate a mixture into its constituents. The mass spectrometer performs the analysis which provides the fingerprint. This fingerprint can be searched in a library of fingerprints to make an identification of unknowns. It is also possible to perform 2D GC giving more separating power to the technique. The tool is very sensitive. (http://www.consultingchemist.com/GCMS.pdf) 


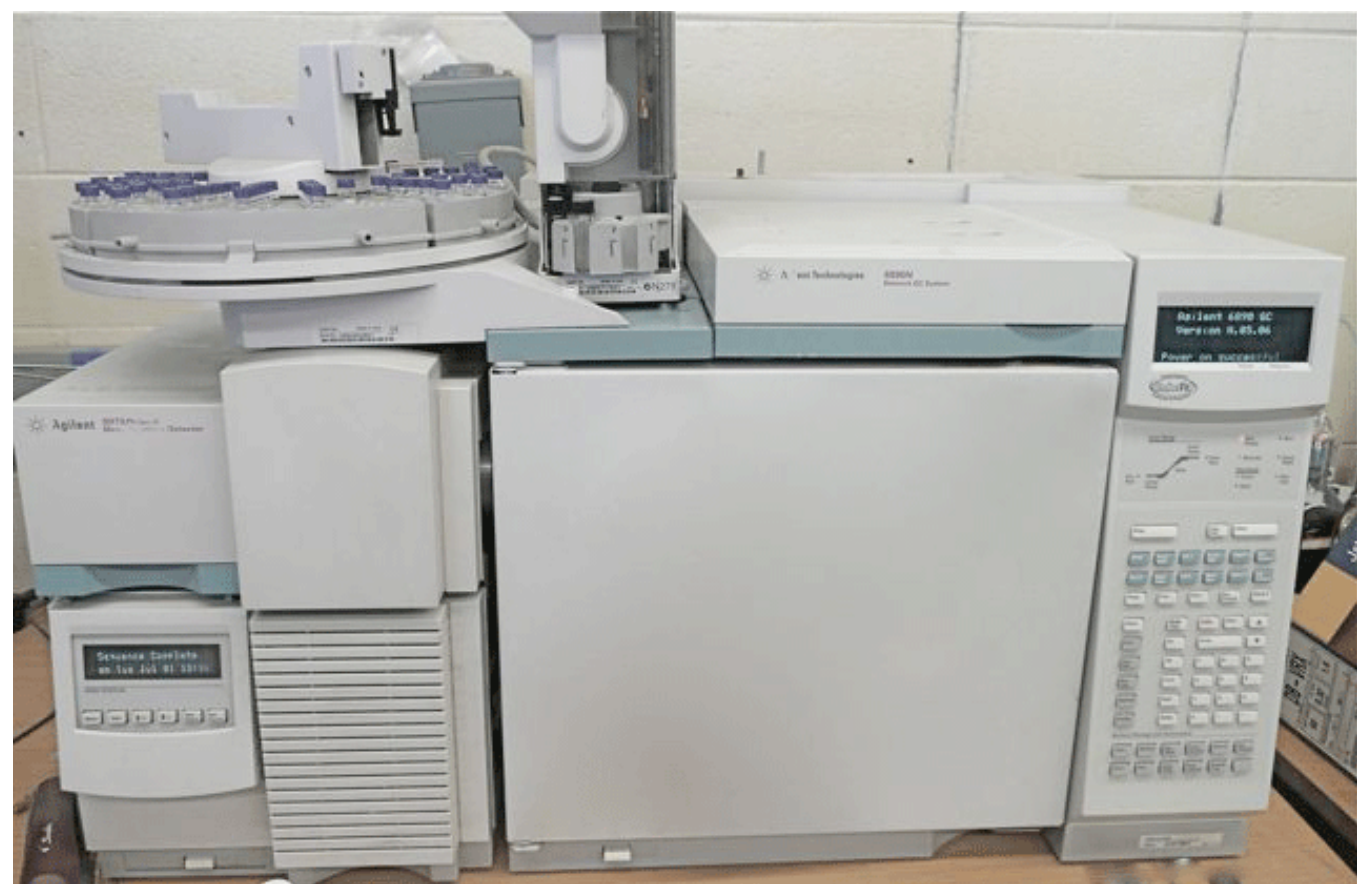

Fig. 3.12 Picture of Agilent 6890 GC and 5973 MS.

\subsection{Experimental Procedures}

A series of experiments is performed using the following procedures:

1) Clean the autoclave vessel completely with paint thinner and isopropyl alcohol.

2) Use a scale to measure certain weight amount of crude oil, tetralin or decalin contained in syringes and iron (III) acetylacetonate catalyst powder $\left(\mathrm{Fe}(\mathrm{acac})_{3}\right)$ using a small piece of paper.

3) Mix crude oil, tetralin or decalin hydrogen donor with iron (III) acetylacetonate catalyst powder $\left(\mathrm{Fe}(\mathrm{acac})_{3}\right)$ at a mass ratio of 100:10:1 into an autoclave vessel. 
4) Mount the autoclave vessel into the vessel cover using the following procedure:

4.1 Lubricate the body's external threads with lubrication suitable for our application temperature, such as Jet Lube SS-303 (P/N P-3580) or Jet Lube MP-503 (P/N P-9766) recommended by Autoclave Engineers.

4.2 Lubricate the o-ring prior to assembly onto the vessel body and place the o-ring into the provided groove.

4.3 Thread the body into the cover mounted to a stand. Resistance will be felt when the o-ring begins to contact the cover. Continue threading the body into the cover. Make sure there are no threads exposed on the body at the point.

5) The vessel may be pressurized at this time. Pressurize the autoclave to 400 psi with nitrogen and then close the nitrogen inlet valve on the autoclave and close the nitrogen bottle. Monitor the pressure gauge on the autoclave cover for 1 hour to ensure there are no leaks.

6) Install the band heater by sliding the band heater onto the vessel. Make certain the heater is lined up with the vessel bottom surface. The clamping knob may have to be turned counterclockwise to open up the heater inner diameter. Clamp the heater in place by turning the clamping knob clockwise until it is hand tight. Friction will hold the heater onto the vessel.

7) Warm up the autoclave to $100^{\circ} \mathrm{C}$. Higher temperature will facilitate the dissolution of catalyst into hydrogen donor solvent and crude oil. Set the 
output voltage in the DC power supplier for the built-in magnetic stirrer to $5 \mathrm{~V}$. Keep this temperature and blend the mixture constantly for 6 hours to dissolve solid catalyst into liquid to achieve a good mixture.

8) Let the autoclave cool down for 15 minutes, and then get a small amount of sample for pre-upgrading viscosity, specific gravity measurement. For the viscosity measurement, change the measurement temperature from $20^{\circ} \mathrm{C}$ to $70{ }^{\circ} \mathrm{C}$ at $10{ }^{\circ} \mathrm{C}$ interval by increasing the water bath's temperature. It takes about 10 minutes to increase the temperature by $10{ }^{\circ} \mathrm{C}$ and 30 minutes to cool it down by $10^{\circ} \mathrm{C}$.

9) Add specific amount of distilled water to the autoclave vessel and install the autoclave back following the method mentioned on step 4.3.

10) Pressurize the autoclave system to $400 \mathrm{psi}$ and monitor the pressure for 2 hours to check the sealing.

11) Purge oxygen out of the autoclave vessel by repeating filling it with nitrogen and releasing it to the atmosphere for 5 times.

12) Heat the system to the required reaction temperature and keep the temperature for a specific length of time, for example, 48 hours. Use temperature controller's autotune function to obtain optimal PID values. To study the effects of time, samples can be obtained through the sampling tub at certain time interval. Pressure will force the fluid up the dip tube and through the valve when the valve is opened. Use extreme caution to open the valve slowly and use a beaker to collect the samples. 
13) Turn of the temperature controller and cool the system down and then collect the gas sample using a gas sampling bag.

14) Separate water from the liquid by centrifuging. Heat the sample to $80^{\circ} \mathrm{C}$ by immerse it to a water bath and then put it into a centrifuge and centrifuge it at the spend of $3000 \mathrm{rpm}$. Since the sample would cool down during this process, it needs to be heated it up by a water bath again after 10 minutes. Repeat this procedure for 2 hours.

15) Analyze gas and upgraded mixture compositions by GC-MS analysis.

16) Measure the specific gravity and viscosity of the upgraded mixture.

17) Repeat the process for different mixtures and reaction temperatures as shown on tables in pages 71 and 73. 


\section{EXPERIMENTAL RESULTS}

\subsection{Overview}

A series of experiments was performed to study heavy oil upgrading effects using steam with hydrogen donor (tetralin and decalin) alone without catalyst, and with catalyst $\left(\mathrm{Fe}(\mathrm{acac})_{3}\right)$ alone without hydrogen donor. The synergetic effects of using hydrogen donor and catalyst together were also studied in the presence of steam. The effects of decalin and tetralin were compared. Also the extents of reaction were compared when the experiments were performed at different lengths of time.

\subsection{Upgrading of Crude Oil with Water}

At the beginning, API gravity and viscosity of crude oil alone were measured to be $11.42{ }^{\circ} \mathrm{API}$ and $1108 \mathrm{cp}$ (at $50{ }^{\circ} \mathrm{C}$ ). The viscosity of crude versus temperature is shown on Fig. 4.1. We can see that this crude oil was very viscous and heavy. The viscosity depended strongly on temperature. A $10{ }^{\circ} \mathrm{C}$ increase in temperature may lead to approximately $50 \%$ decrease in viscosity.

The crude oil and water were mixed at a mass ratio of $1: 1$ and heated to $300{ }^{\circ} \mathrm{C}$ for 48 hours to study the effects of aquathermolysis. This served as the base run. After the experiment, water was separated from oil by centrifuge and the viscosity and API gravity of upgraded oil were measured. The API gravity was measured to be $11.53{ }^{\circ} \mathrm{API}$ and the viscosity was $997 \mathrm{cp}$ when measured at $50{ }^{\circ} \mathrm{C}$. Viscosity of upgraded oil as a function of temperature is plotted in Fig. 4.1. Viscosity reduction expressed in 
percentages ((viscosity before upgrading - viscosity after upgrading) / viscosity before upgrading) is illustrated in Fig. 4.2. They show that the viscosity (at $50{ }^{\circ} \mathrm{C}$ ) was reduced by $10 \pm 2 \%$ due to the reaction with steam (we assume no contribution from traces of oxygen not removed by the nitrogen purge). And the viscosity was reduced by half when temperature was increased by $10^{\circ} \mathrm{C}$. The trend was the same as crude oil.

\subsection{Upgrading of Crude Oil with Water and Catalyst}

To study the effect of catalyst alone without hydrogen donors in heavy oil upgrading process, crude oil, water and catalyst mixture with a mass ratio of 100:10:1 was heated and stirred for 48 hours at $300{ }^{\circ} \mathrm{C}$. The viscosity and density of pre-upgrading crude oil and catalyst mixture were measured to be $1156 \mathrm{cp}\left(\right.$ at $50^{\circ} \mathrm{C}$ ) and 11.37 ${ }^{\circ}$ API. The upgraded mixture was dewatered and compared with crude oil and catalyst mixture before upgrading. The viscosity was reduced to $941 \mathrm{cp}\left(\right.$ at $\left.50^{\circ} \mathrm{C}\right)$ from $1156 \mathrm{cp}$ and the API gravity was increased to $11.72{ }^{\circ} \mathrm{API}$. The results showed some upgrading effects, which led to $19 \pm 3 \%$ reduction in viscosity and $0.35^{\circ} \mathrm{API}$ increase in API gravity. The function of upgraded mixture's viscosity versus temperature is shown on Fig. 4.1. Viscosity reduction expressed in percentages is illustrated in Fig. 4.2. They show that catalyst could reduce the viscosity further and improve the upgrading quality compared with steam alone. The viscosity and API gravity are also compared in the table on page 71 . 


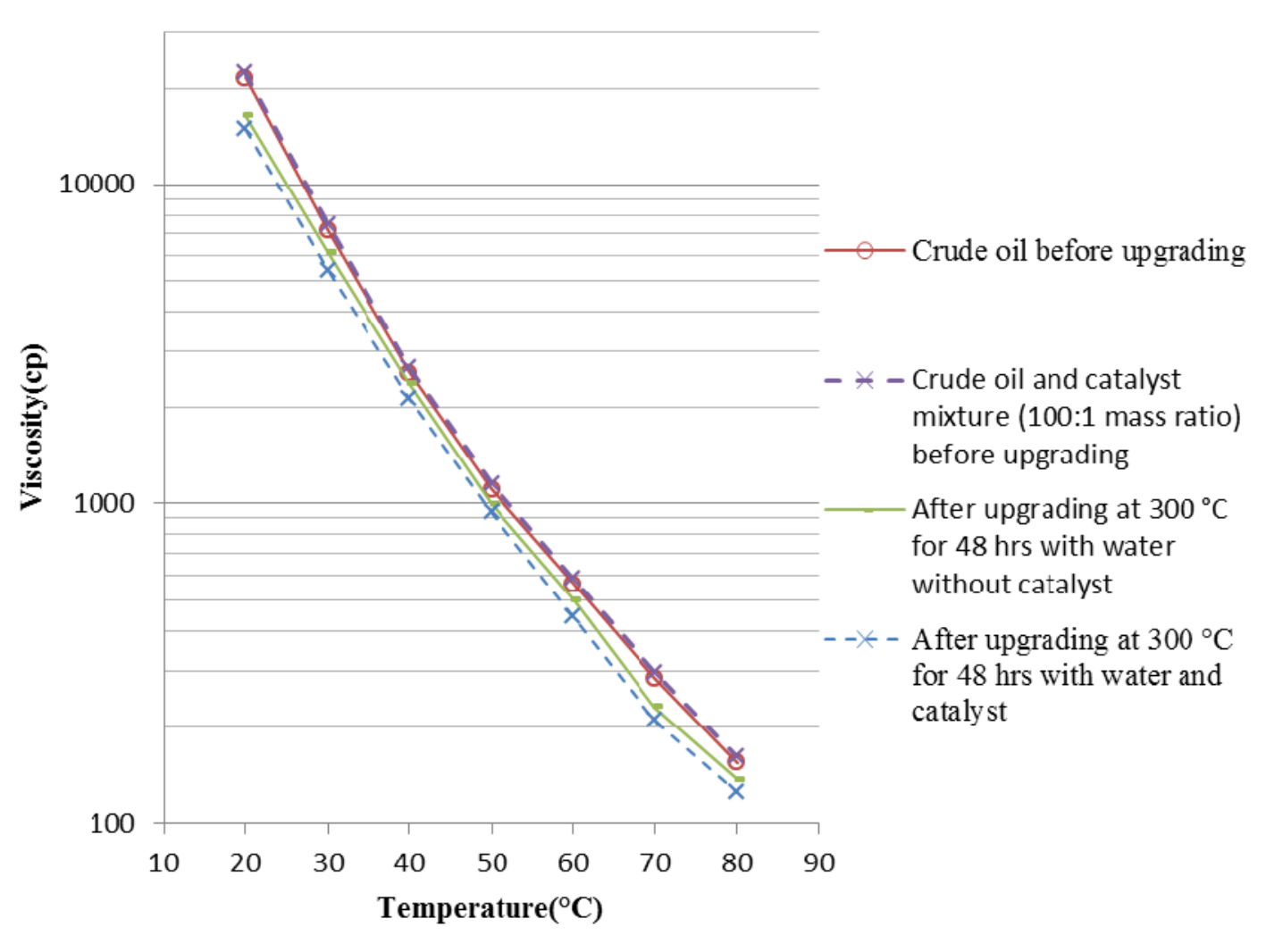

Fig. 4.1 Viscosity changes as function of temperature before and after crude oil react with water, and $w /$ or w/o catalyst. 


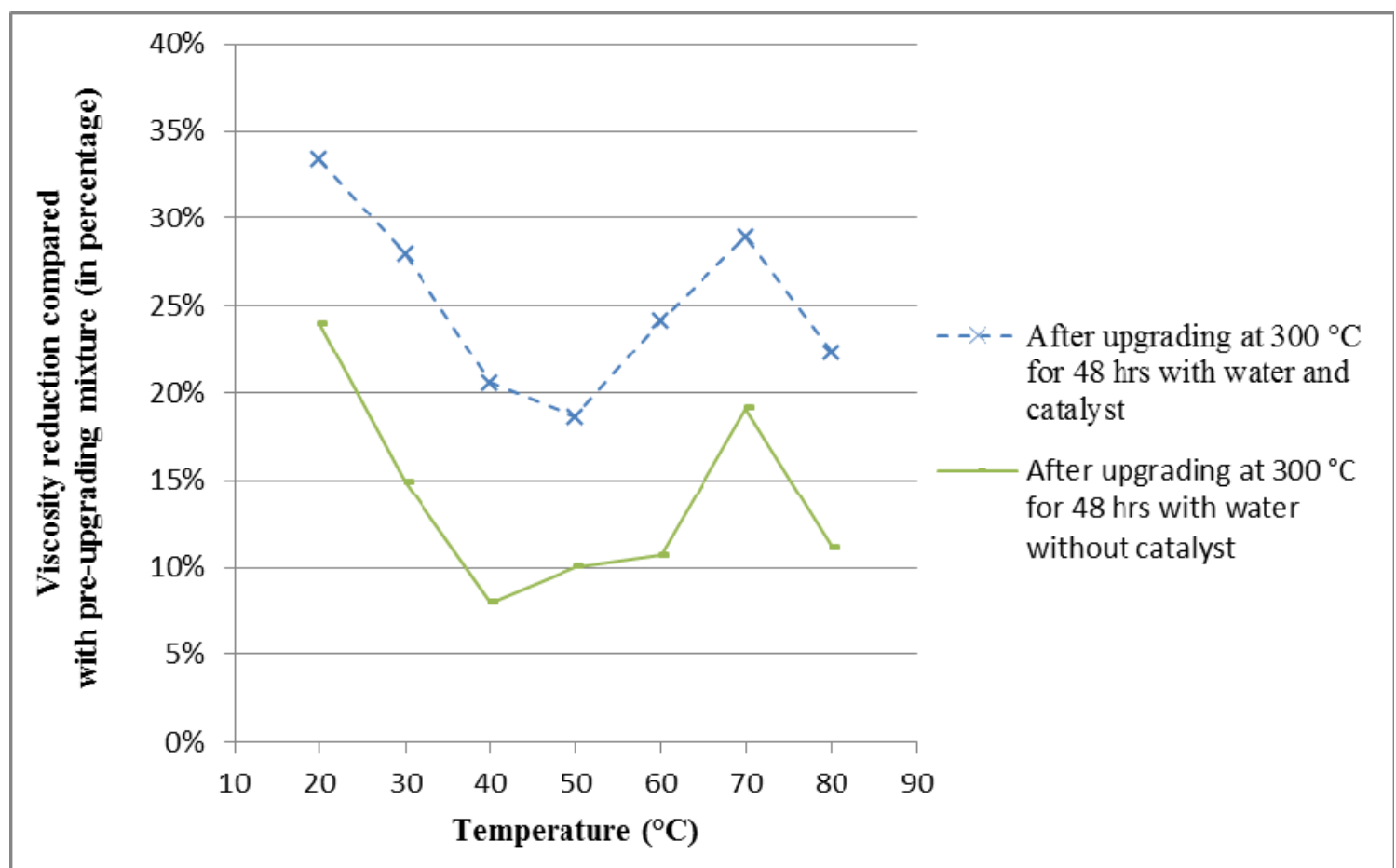

Fig. 4.2 Viscosity reductions ((viscosity before upgrading - viscosity after upgrading) / viscosity before upgrading) in percentages as function of temperature after crude oil react with water, and w/ or w/o catalyst.

\subsection{Crude Oil, Decalin or Tetralin Mixture before Upgrading}

Crude oil and tetralin or decalin were mixed at a weight ratio of 10:1 and the API gravity and viscosity were measured for later comparison. It was found that the API gravity and viscosity of crude oil and tetralin mixture were $11.86^{\circ} \mathrm{API}$ and $623 \mathrm{cp}$ (at $50{ }^{\circ} \mathrm{C}$ ), respectively. If decalin was used instead of tetralin, they were $12.74{ }^{\circ} \mathrm{API}$ and $679 \mathrm{cp}\left(\right.$ at $\left.50^{\circ} \mathrm{C}\right)$, respectively. The viscosity of crude oil and crude oil with tetralin or decalin mixture versus temperature was shown on Fig. 4.3. Viscosity reduction expressed in percentages is illustrated in Fig. 4.4. They show that $9 \%$ weight percent of tetralin alone could act as diluent to reduce the viscosity at $50{ }^{\circ} \mathrm{C}$ by $44 \pm 2 \%$ while the same fraction of decalin could reduce it by $39 \pm 3 \%$ compared with crude oil (1108cp). 
Both of them were good solvents for heavy oil recovery and transportation. The viscosity and API gravity are also tabbed and compared in the tables in page 72 and 73 .

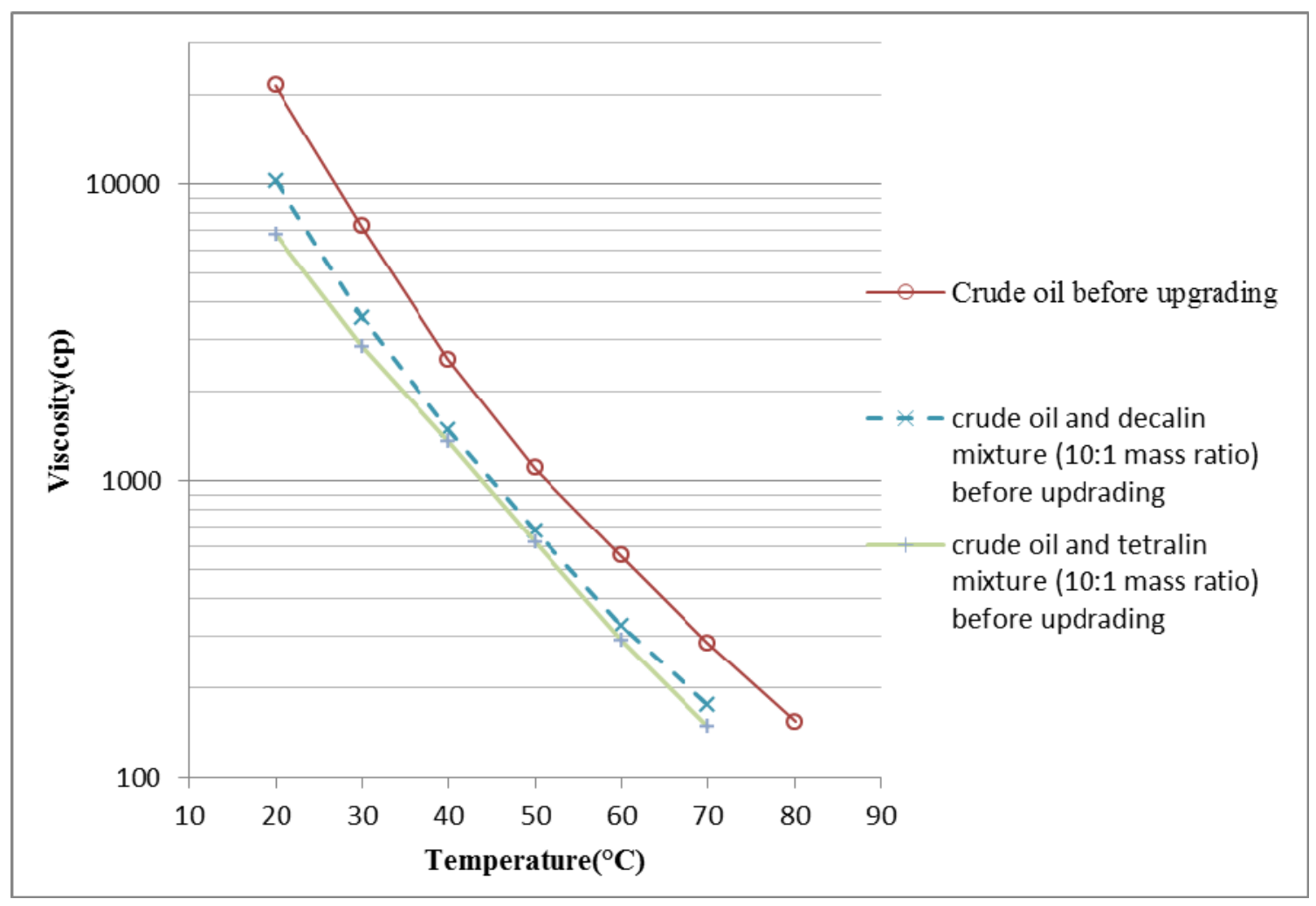

Fig. 4.3 Viscosity as a function of temperature for crude oil, decalin or tetralin mixture before upgrading. 


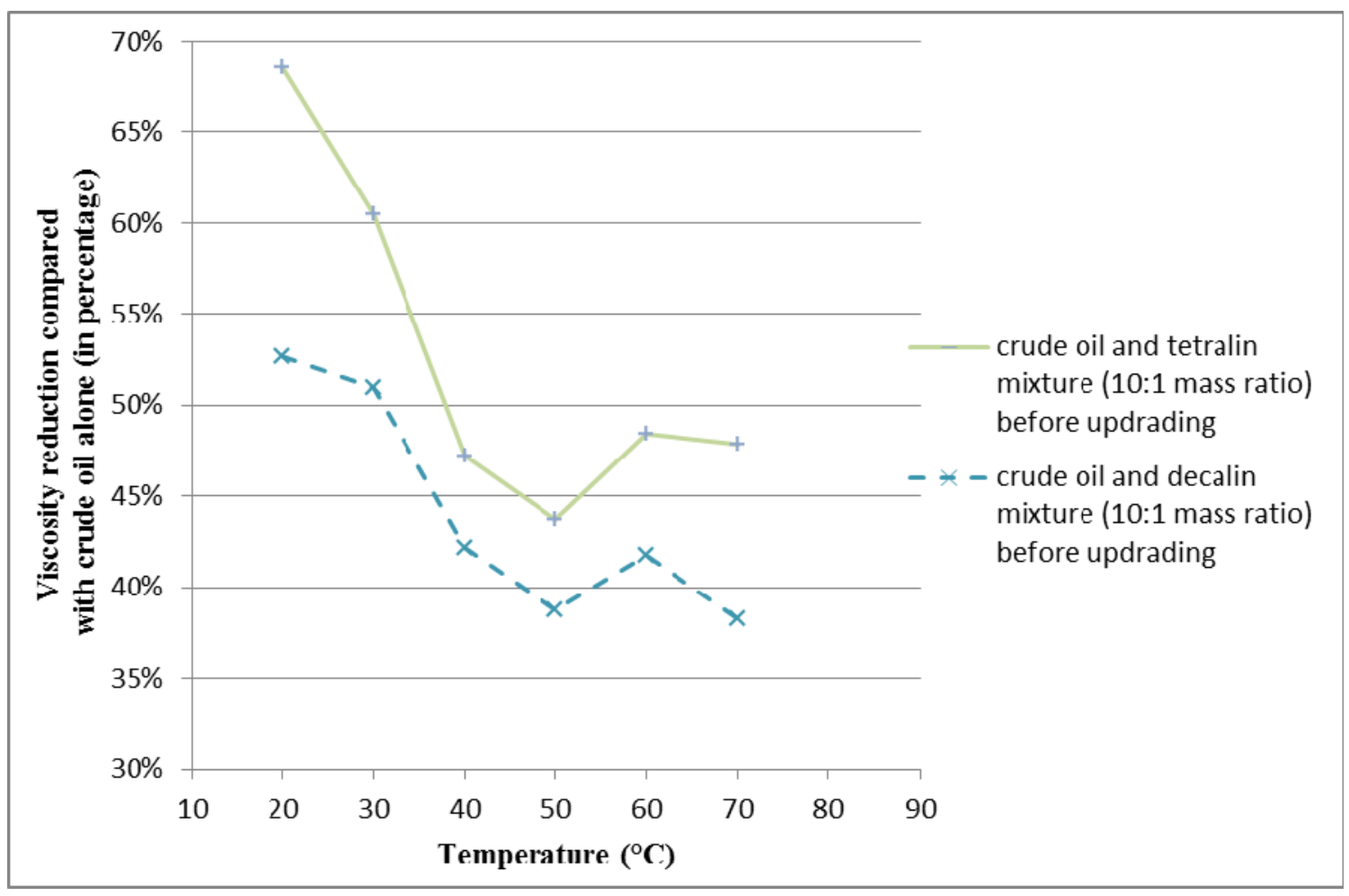

Fig. 4.4 Viscosity reduction ((viscosity before upgrading - viscosity after upgrading) / viscosity before upgrading) in percentages as a function of temperature for crude oil, decalin or tetralin mixture before upgrading.

\subsection{Upgrading of Crude Oil with Water and Tetralin}

To study the effect of tetralin without catalyst in heavy oil upgrading process, crude oil, water and tetralin mixture (10:10:1 mass ratio) was heated and stirred for 48 hours at $300{ }^{\circ} \mathrm{C}$. The results showed that there was some upgrading happened compared with the crude oil and tetralin mixture before upgrading. The viscosity was reduced to $590 \mathrm{cp}$ (measured at $50^{\circ} \mathrm{C}$ ) and the API gravity was increased to $12.11^{\circ} \mathrm{API}$. There was $5.4 \pm 4 \%$ viscosity reduction compared with pre-upgrading mixture $(623 \mathrm{cp})$. The changes were not significant. The viscosity and API gravity are also tabbed and compared in the table in page 72 . 


\subsection{Upgrading of Crude Oil with Water and Decalin}

When the same mass amount of decalin was used instead of tetralin that was being used in previous case, we could also see some upgrading effects compared with the crude oil and decalin mixture before upgrading. The viscosity was reduced to $650 \mathrm{cp}$ (measured at $50^{\circ} \mathrm{C}$ ) and the API gravity was increase to $12.86{ }^{\circ} \mathrm{API}$. There was $4 \pm 1 \%$ viscosity reduction compared with pre-upgrading mixture $(679 \mathrm{cp})$. The function of viscosity versus temperature is shown on Fig. 4.5. Viscosity reduction expressed in percentages is illustrated in Fig. 4.6. They show that decalin was an effective hydrogen donor for heavy oil upgrading purpose. The viscosity and API gravity are also tabbed and compared in the table in page 73.

\subsection{Upgrading of Crude Oil with Water, Tetralin and Catalyst}

To study the synergetic effects of tetralin and catalyst, crude oil, water, tetralin were mixed at a mass ratio of 100:100:10:1 first and then heated and stirred for 48 hours at $300{ }^{\circ} \mathrm{C}$. The curves for viscosity comparison are illustrated in Fig. 4.7. Viscosity change expressed in percentages is illustrated in Fig. 4.8. The analysis of upgraded mixture after dewatering shows that water, tetralin and catalyst together could reduce the viscosity by as much as $56 \pm 1 \%$ at $50^{\circ} \mathrm{C}$ compared with pre-upgrading crude oil, tetralin and catalyst mixture, from $650 \mathrm{cp}$ to $285 \mathrm{cp}$. The reduction was much larger than tetralin or catalyst alone. It shows that hydrogen donor and catalyst had synergetic effect on heavy oil upgrading. The viscosity and API gravity are also tabbed and compared in the table in page 72 . 


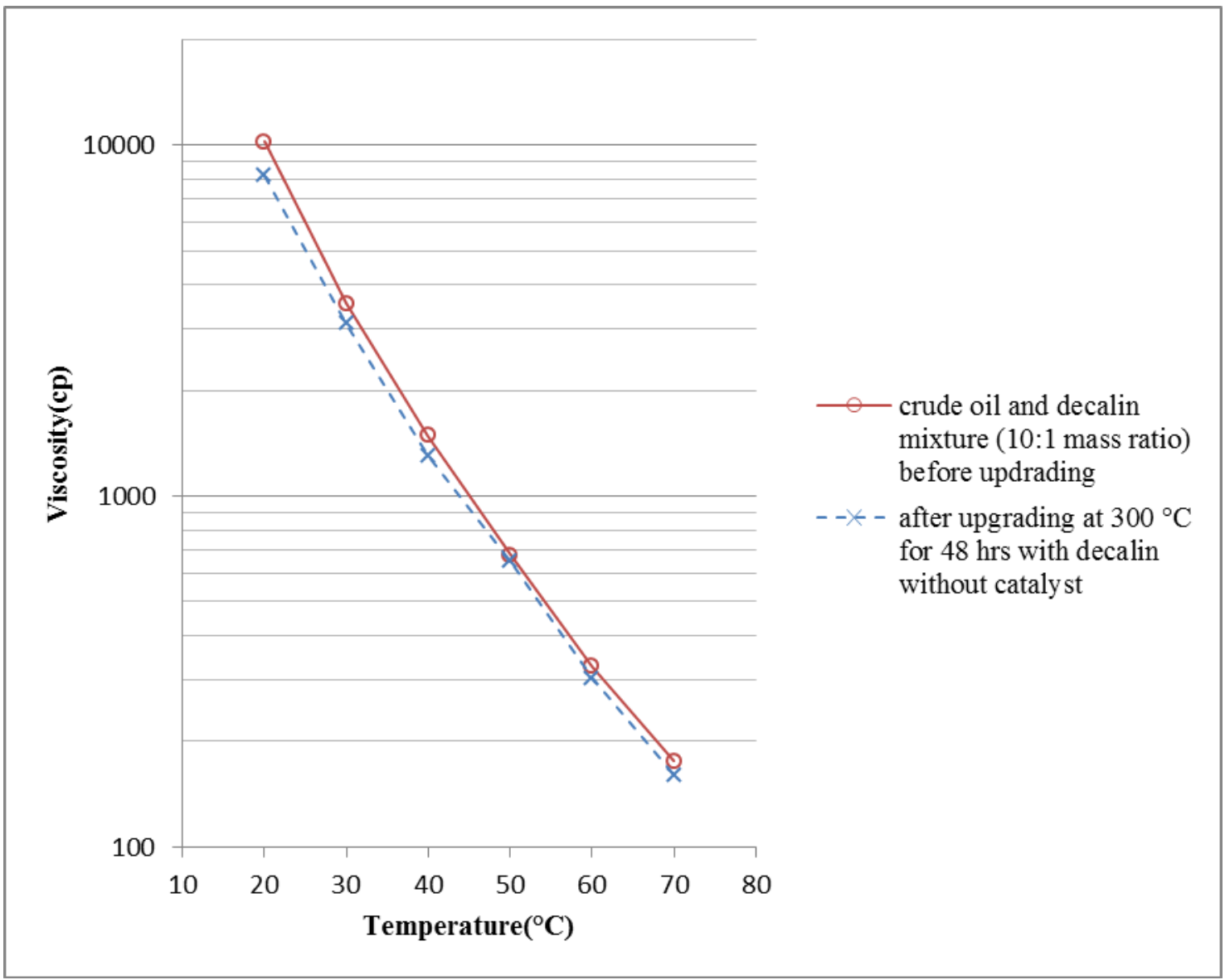

Fig. 4.5 The function of viscosity versus temperature for dewatered mixture before and after upgrading using crude oil, water and decalin. 


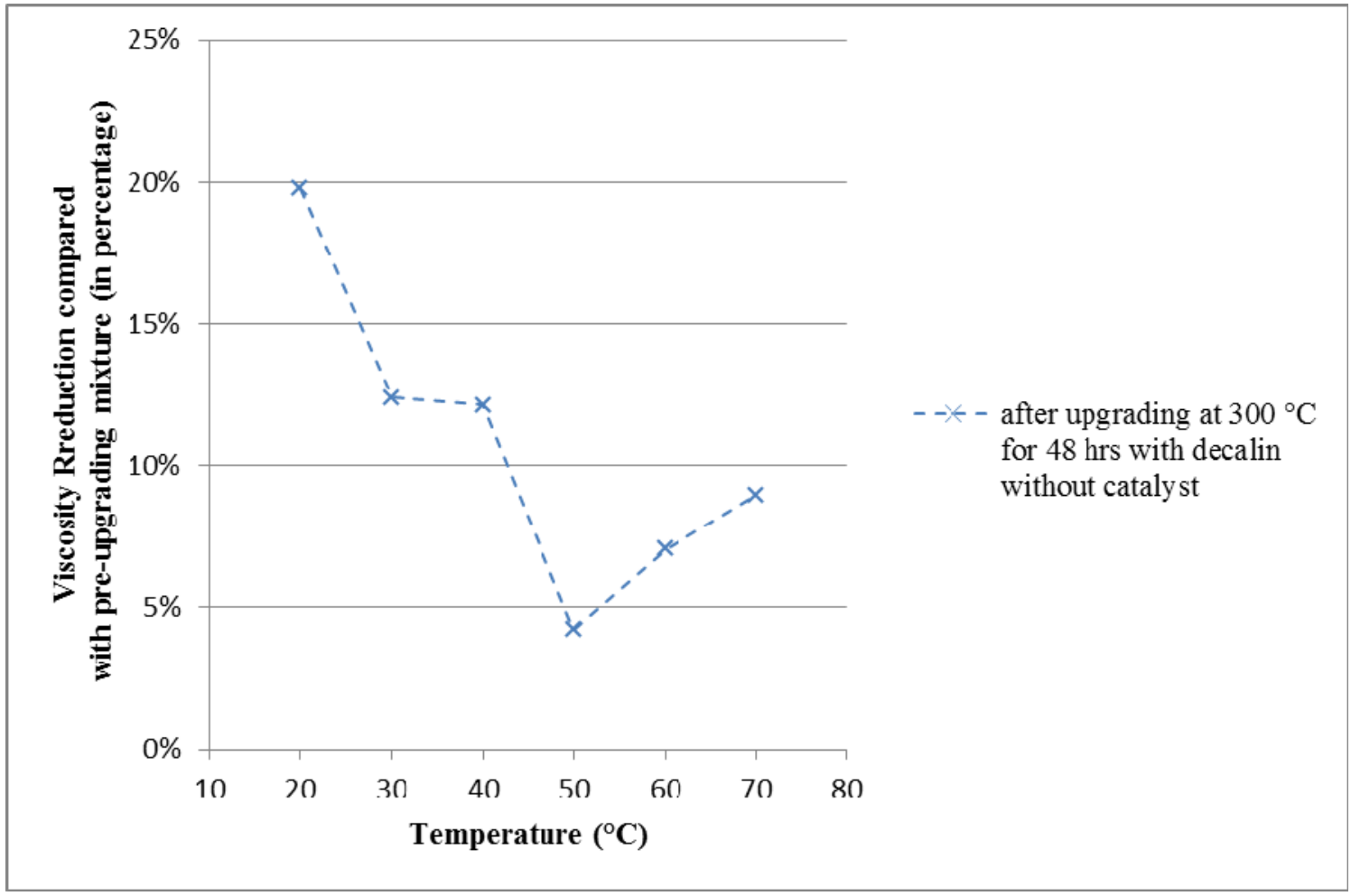

Fig. 4.6 The function of viscosity reductions ( (viscosity before upgrading - viscosity after upgrading) / viscosity before upgrading) in percentages versus temperature for dewatered mixture after upgrading using crude oil, water and decalin. 


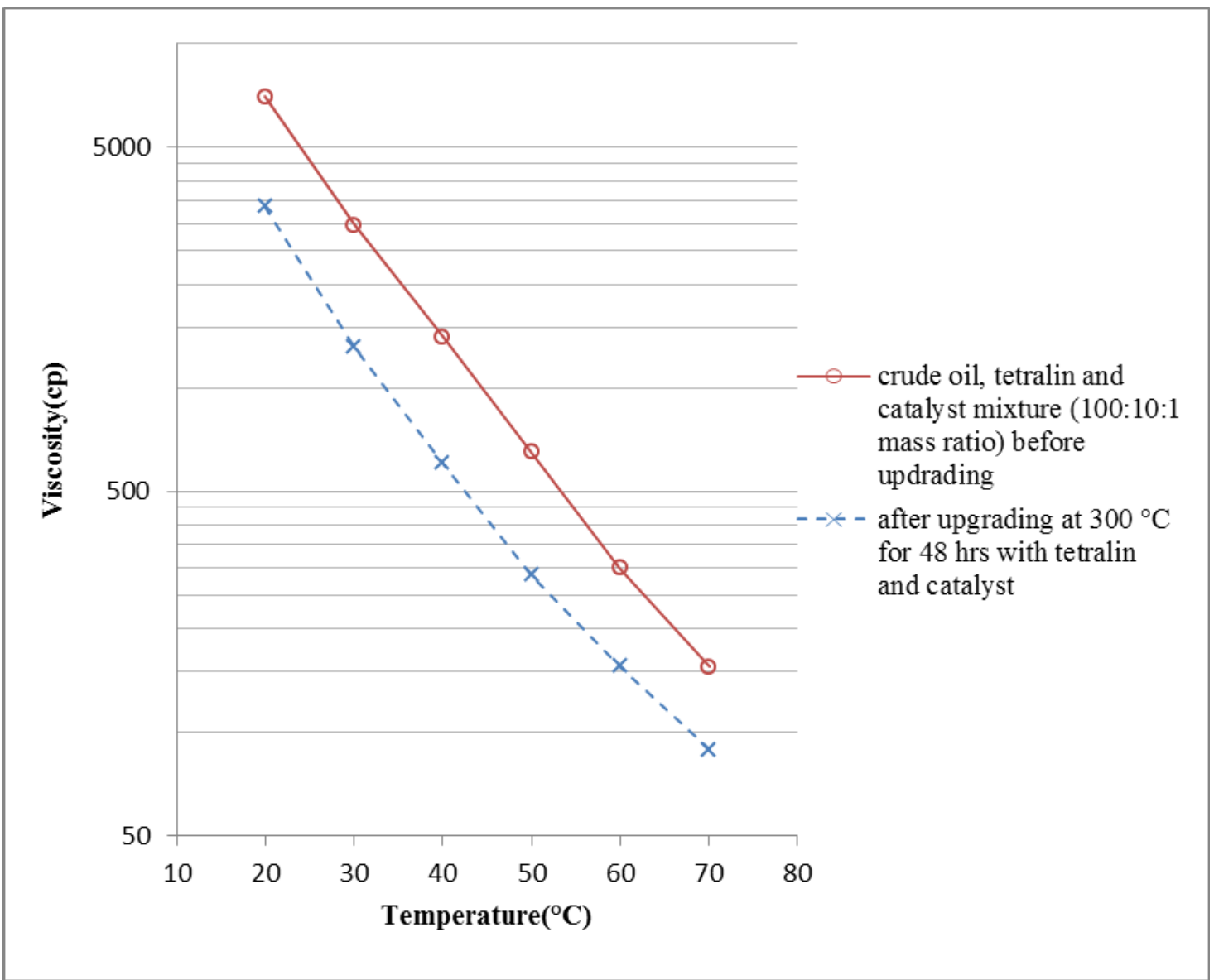

Fig. 4.7 Comparison of viscosity versus temperature for dewatered mixture before and after upgrading using crude oil, water, tetralin and catalyst. 


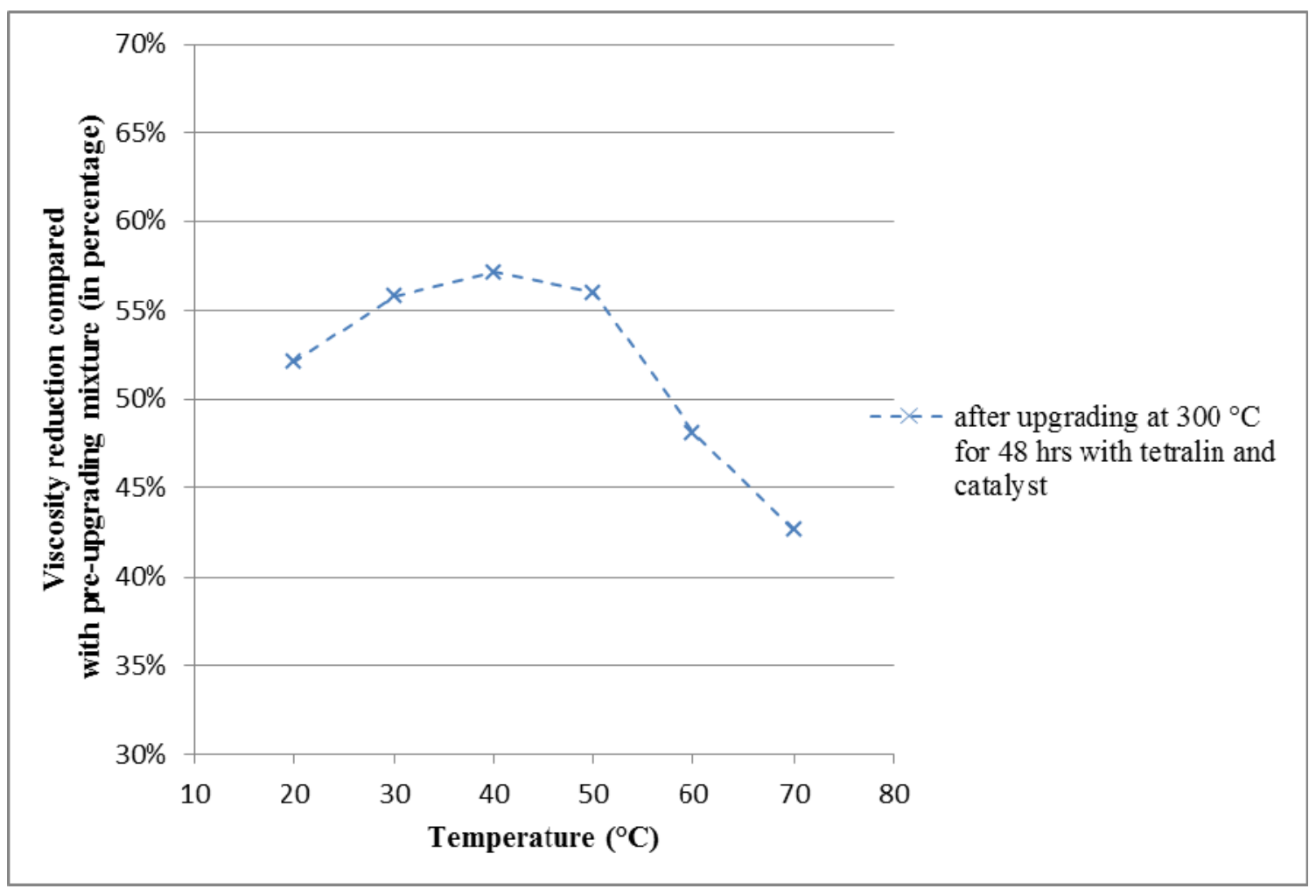

Fig. 4.8 Comparison of viscosity reductions ((viscosity before upgrading - viscosity after upgrading) / viscosity before upgrading) in percentages versus temperature for dewatered mixture after upgrading using crude oil, water, tetralin and catalyst.

\subsection{Upgrading of Crude Oil with Water, Decalin and Catalyst}

When the same amount of decalin was used instead of tetralin, the experiment results showed that the viscosity of upgraded mixture after dewatering was reduced by $72 \pm 1 \%$ compared with pre-upgrading mixture(from $711 \mathrm{cp}$ to $200 \mathrm{cp}$ at $50^{\circ} \mathrm{C}$ ). It shows that decalin and catalyst had strong synergetic effects on heavy oil upgrading. The viscosity reduction was even higher than using tetralin and catalyst. The viscosity versus temperature is plotted in Fig. 4.9. Viscosity reduction expressed in percentages is 
illustrated in Fig. 4.10. The viscosity and API gravity is also tabbed and compared in the table in page 73 .

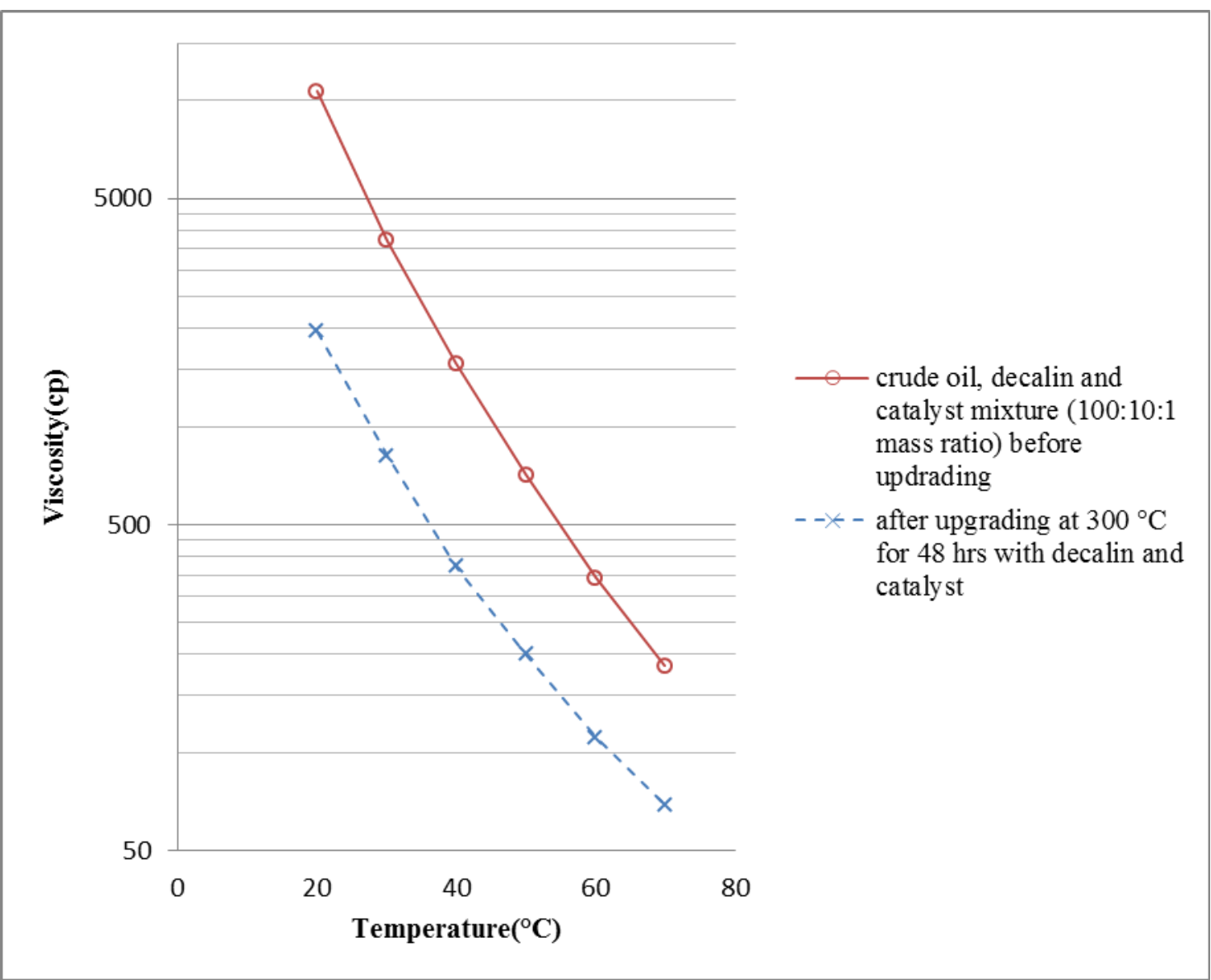

Fig. 4.9 Comparison of viscosity versus temperature for dewatered mixture before and after upgrading using crude oil, water, decalin and catalyst. 


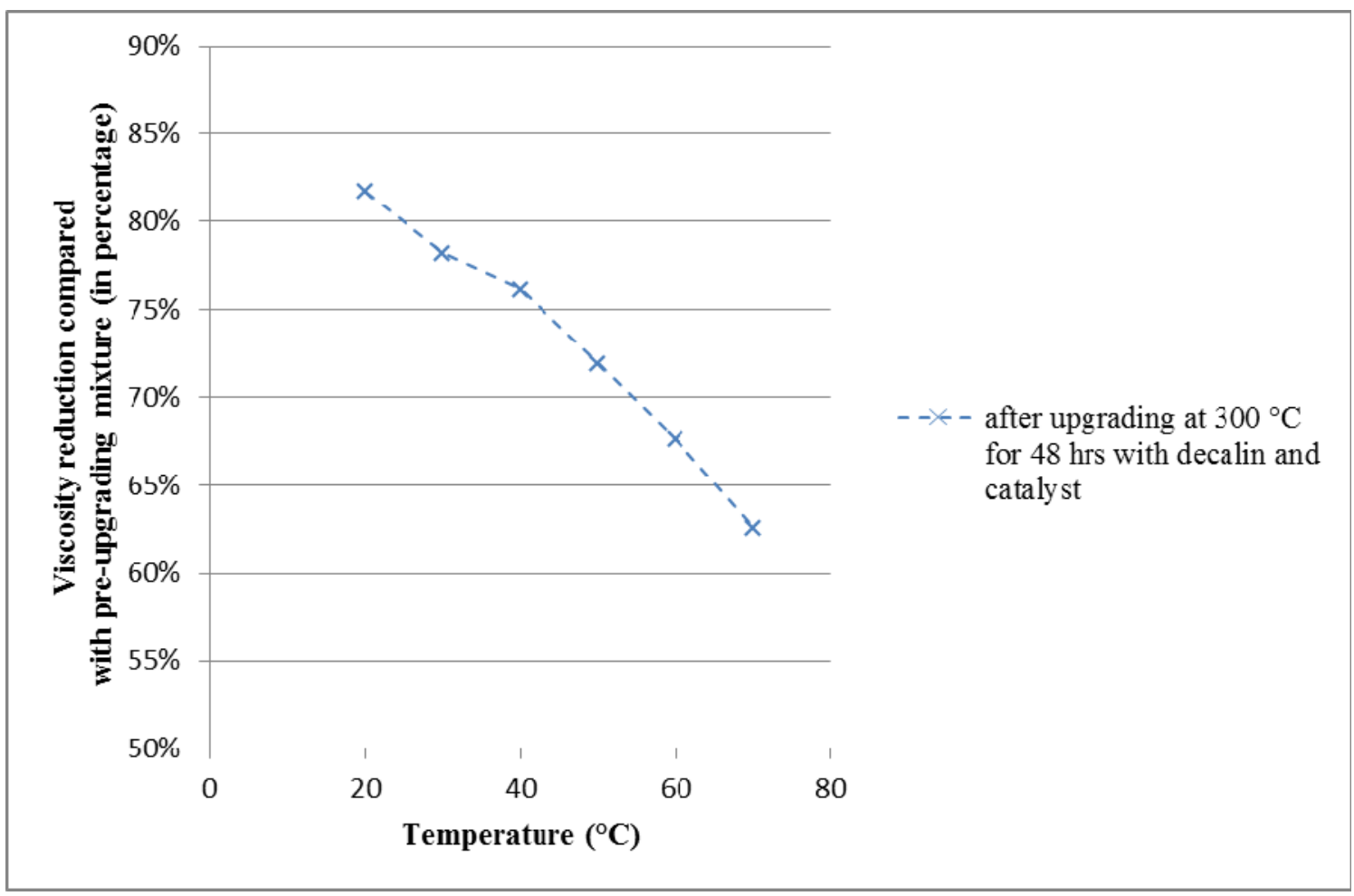

Fig. 4.10 Comparison of viscosity reductions ((viscosity before upgrading - viscosity after upgrading) / viscosity before upgrading) in percentages versus temperature for dewatered mixture after upgrading using crude oil, water, decalin and catalyst.

\subsection{Effects of Temperature on Heavy Oil Upgrading}

To study the effects of temperature on heavy oil upgrading, a series of experiments were performed with catalyst and tetralin or decalin mixture at $250{ }^{\circ} \mathrm{C}$, $275^{\circ} \mathrm{C}$ and $300^{\circ} \mathrm{C}$. The viscosity of upgrading mixture after dewatering is shown on Fig. 4.11 and Fig. 4.12 for comparison. Viscosity changes expressed in percentages are plotted in Fig. 4.13 and Fig. 4.14. The viscosity and API gravity are also tabbed and compared in the tables in page 72 and 73 . When tetralin was used, it can be observed that at the reaction temperature of $300{ }^{\circ} \mathrm{C}$, viscosity measured at $50{ }^{\circ} \mathrm{C}$ was reduced most significantly by $56 \pm 1 \%(650 \mathrm{cp}$ to $285 \mathrm{cp})$, for $275^{\circ} \mathrm{C}$ and $250{ }^{\circ} \mathrm{C}$, the changes were not 
very significant, only $9 \pm 2 \%(650 \mathrm{cp}$ to $590 \mathrm{cp})$ and $4 \pm 1 \%(650 \mathrm{cp}$ to $623 \mathrm{cp})$, respectively. Correspondingly, the API gravity was increased to $12.20^{\circ} \mathrm{API}, 12.11^{\circ} \mathrm{API}$ and $12.02^{\circ} \mathrm{API}$ after being reacted at $300{ }^{\circ} \mathrm{C}, 275^{\circ} \mathrm{C}$ and $250^{\circ} \mathrm{C}$.

When decalin was used, we could see that at reaction temperature of $300{ }^{\circ} \mathrm{C}$, viscosity measured at $50{ }^{\circ} \mathrm{C}$ was reduced even more significantly, by as much as $72 \pm 1 \%$ (711 cp to $200 \mathrm{cp}$ ). For $275{ }^{\circ} \mathrm{C}$ and $250{ }^{\circ} \mathrm{C}$, the changes were less significant, only $6 \%$ (711 cp to $670 \mathrm{cp}$ ) and $4 \pm 1 \%$ (711 cp to $690 \mathrm{cp})$. The API gravity was increased to 13.90 ${ }^{\circ} \mathrm{API}, 12.97{ }^{\circ} \mathrm{API}$ and $12.89^{\circ} \mathrm{API}$ after being reacted for 48 hours at $300^{\circ} \mathrm{C}, 275^{\circ} \mathrm{C}$ and $250^{\circ} \mathrm{C}$ accordingly.

They showed that there were threshold temperatures which were about $300{ }^{\circ} \mathrm{C}$, above which the upgrading effects were very noticeable. For our Jobo heavy crude, 300 ${ }^{\circ} \mathrm{C}$ was an effective upgrading temperature for both tetralin and decalin. And if the temperature was lower than $275^{\circ} \mathrm{C}$, we could observe some upgrading effects leading to some decrease in viscosity and increase in API gravity. However these changes were not as significant as those under the temperature of $300{ }^{\circ} \mathrm{C}$ due to lower reaction rates and less possible heavy chain cracking. 


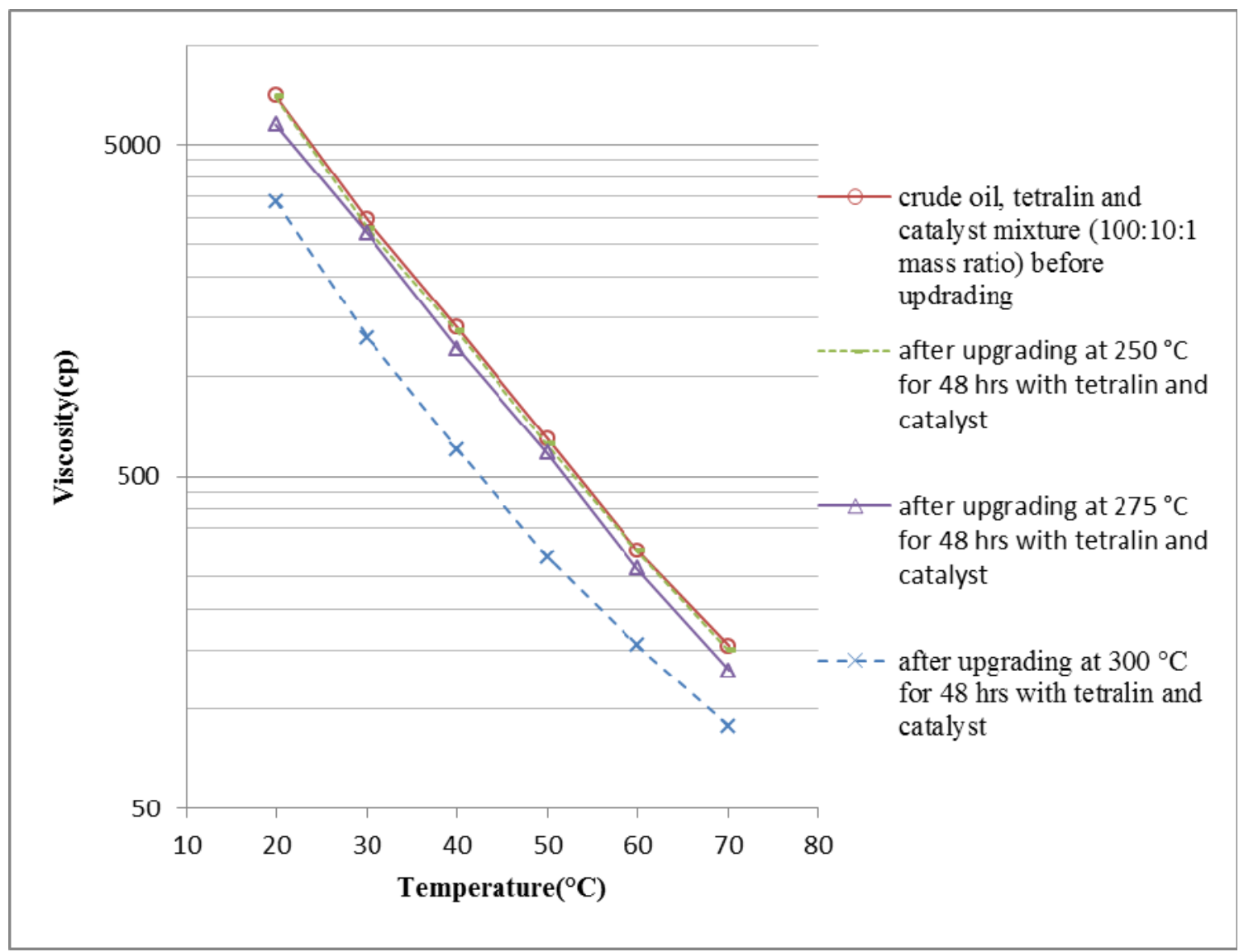

Fig. 4.11 Viscosity as a function of temperature before and after upgrading at different temperature using tetralin and catalyst. 


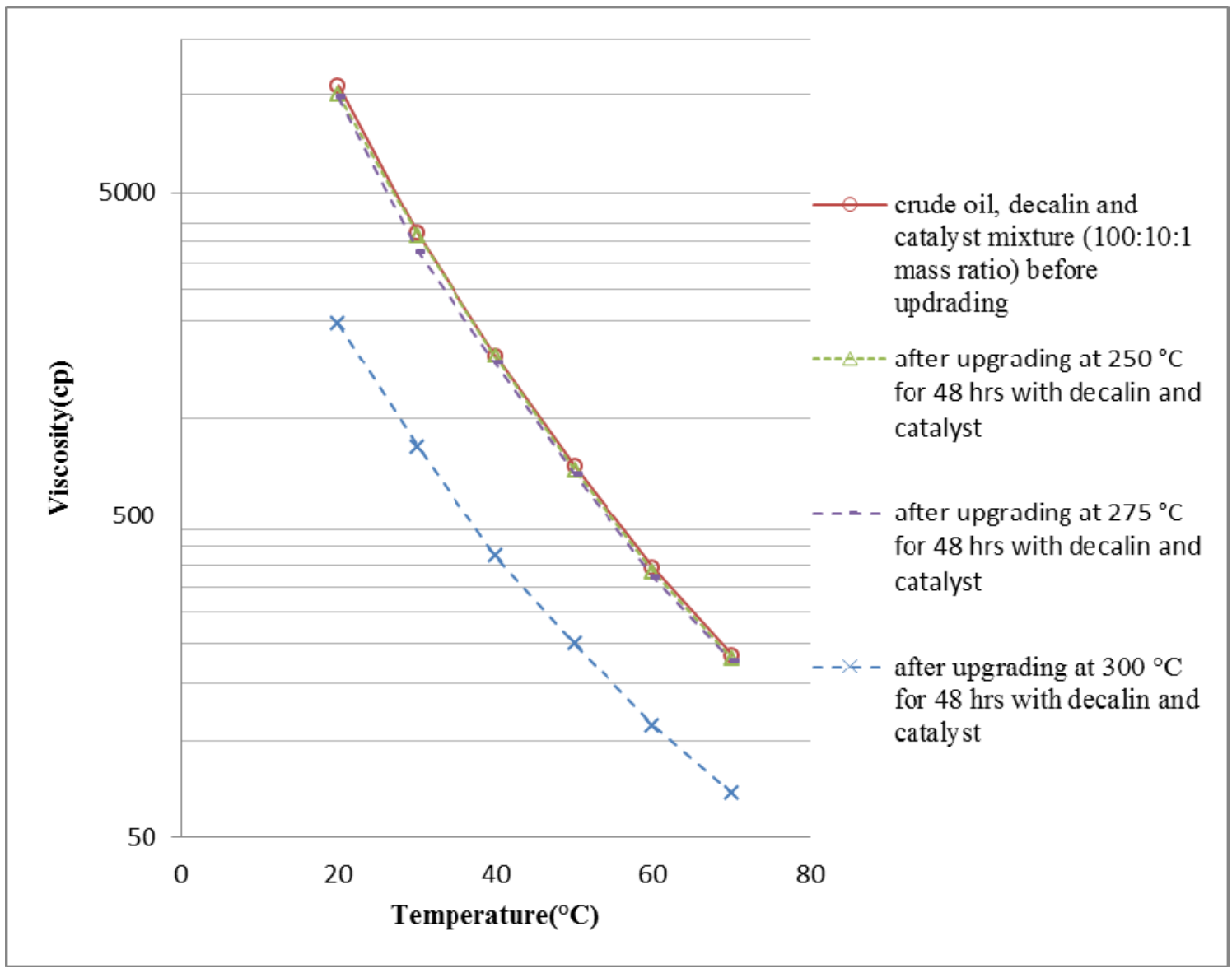

Fig. 4.12 Viscosity as a function of temperature before and after upgrading at different temperature using decalin and catalyst. 


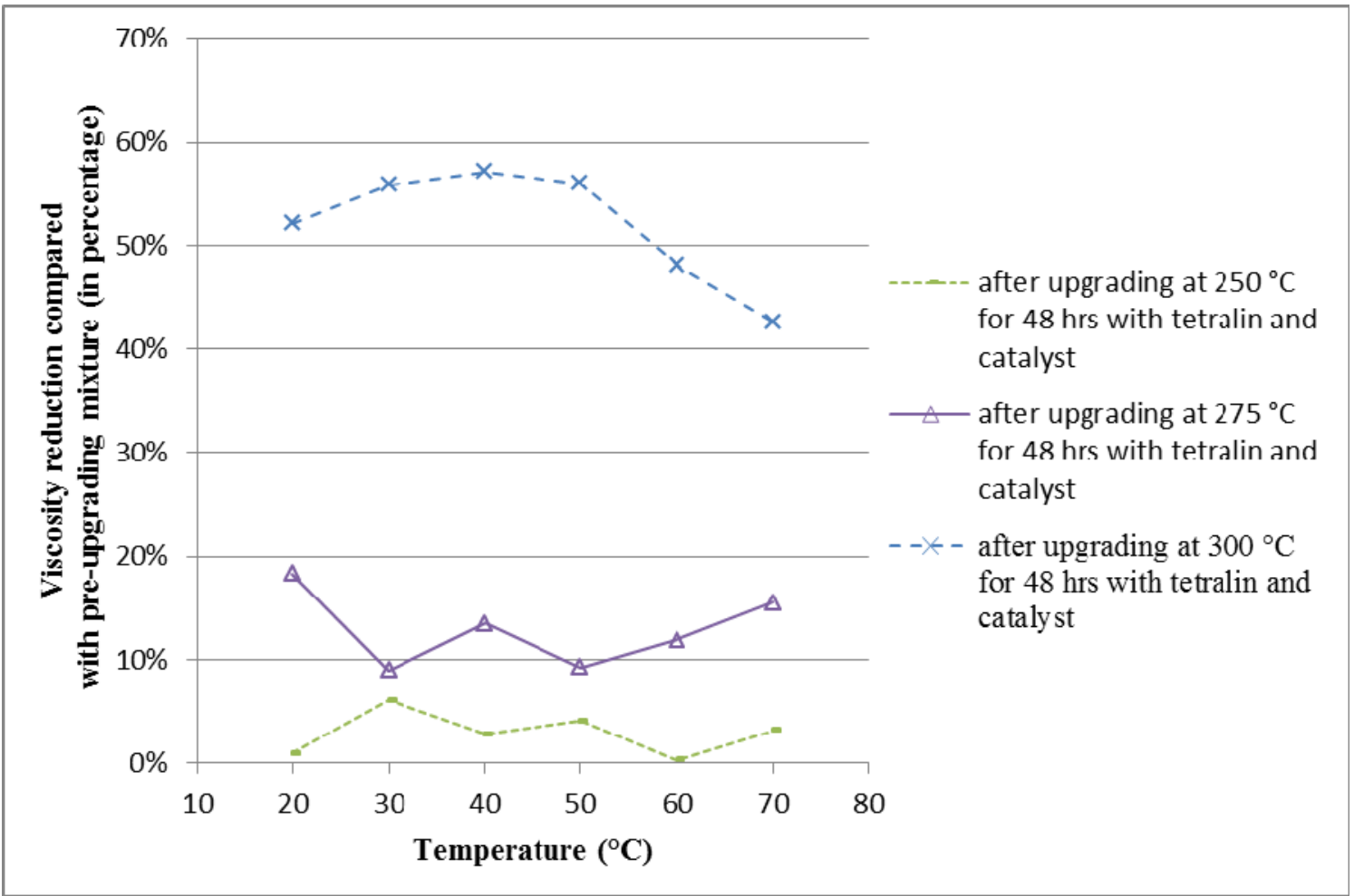

Fig. 4.13 Viscosity reductions ( (viscosity before upgrading - viscosity after upgrading) / viscosity before upgrading) in percentages as a function of temperature after upgrading at different temperature using tetralin and catalyst. 


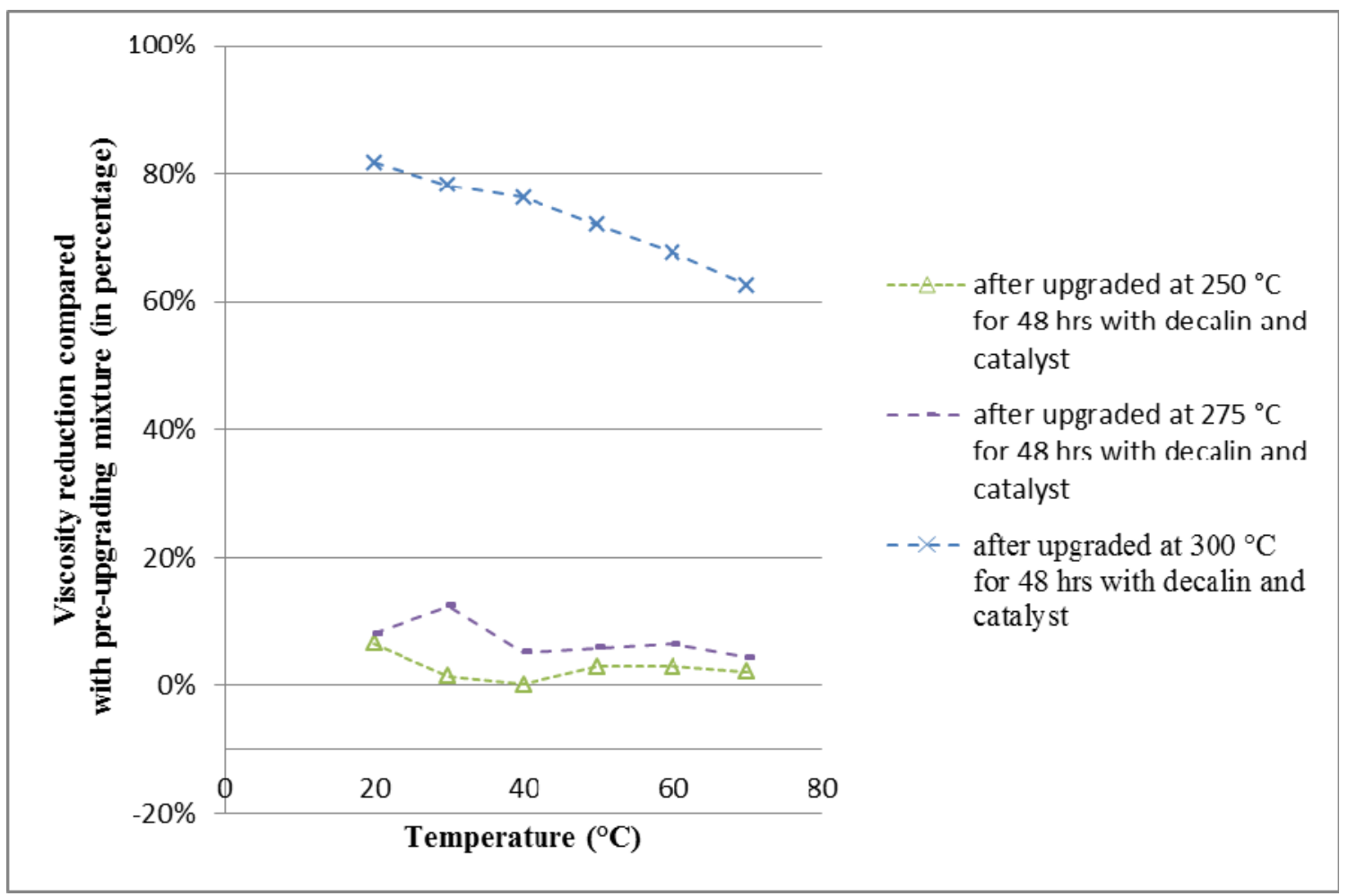

Fig. 4.14 Viscosity reductions ((viscosity before upgrading - viscosity after upgrading) / viscosity before upgrading) in percentages as a function of temperature after upgrading at different temperature using decalin and catalyst.

\subsection{Effects of Time on Heavy Oil Upgrading}

To study the effects of time for upgrading, a series of experiments were performed for different lengths of times, i.e. 24 hours, 48 hours and 72 hours.

For tetralin, after 24 hours, the viscosity measured at $50{ }^{\circ} \mathrm{C}$ was reduced by $45 \pm 1 \%$ (650 cp to $360 \mathrm{cp}$ ) and the API gravity of upgraded mixture after dewatering was increased to $12.14^{\circ} \mathrm{API}$. After 48 hours, the viscosity was reduced by $56 \pm 1 \%(650 \mathrm{cp}$ to $285 \mathrm{cp}$ ) and the API gravity of upgraded mixture after dewatering was increased to 12.20 ${ }^{\circ}$ API. After 72 hours, the viscosity was reduced by $58 \pm 2 \%(650 \mathrm{cp}$ to $271 \mathrm{cp})$ and the API gravity of upgraded mixture after dewatering was increased to $12.25^{\circ} \mathrm{API}$. The first 
24 hours led to $56 \pm 1 \%$ viscosity reduction and the additional two 24 hours led to extra $11 \%$ and $2 \%$ viscosity reduction. It can be inferred that the viscosity was reduced fastest for the first 24-hours and that the reaction slowed down during the second 24 hours. For the last 24 hours the reaction had almost reached the equilibrium state and only a little viscosity reduction (2\%) happened. Crude oil can be upgraded thoroughly using tetralin and catalyst in 48 hours. Viscosity measured at different temperature for these cases using different reaction time is plotted in Fig. 4.15. Viscosity reductions expressed in percentages are plotted in Fig. 4.16. Viscosity measured at $50{ }^{\circ} \mathrm{C}$ versus upgrading time after being upgraded using tetralin is plotted in Fig. 4.17 and its corresponding reductions expressed in percentages are shown in Fig. 4.18. We can see that viscosity reduced fast at the first 48 hours and kept almost constant after that.

When the same mass amount of decalin was used to replace tetralin, after 24 hours of reaction the viscosity of upgraded mixture after dewatering measured at $50{ }^{\circ} \mathrm{C}$ was reduced by $67 \pm 1 \%$ (711 cp to $232 \mathrm{cp}$ ) and the API gravity was increased to 13.71 ${ }^{\circ}$ API. After 48 hours, the viscosity of upgraded mixture after dewatering was reduced further by $72 \pm 1 \%$ (711 $\mathrm{cp}$ to $200 \mathrm{cp})$ while the API gravity was increased to $13.90^{\circ} \mathrm{API}$. After 72 hours, the viscosity of upgraded mixture after dewatering measured at $50{ }^{\circ} \mathrm{C}$ was reduced by $73 \pm 1 \%$ (711 $\mathrm{cp}$ to $192 \mathrm{cp}$ ) and at the mean while the API gravity was increased to $14.03{ }^{\circ} \mathrm{C}$. The first 24 hours led to $67 \pm 1 \%$ viscosity reduction and the additional two 24-hours led to extra $5 \%$ and $1 \%$ viscosity reduction. It meant the viscosity was reduced fastest at the first 24 hours. The reaction was slowed down during the second and third 24 -hours period, leading to an additional $6 \%$ reduction in total. The 
reaction had almost reached the equilibrium state in the second 24 hours and only a little viscosity reduction (5\%) happened. 24 hours was long enough for decalin and catalyst to upgrade the crude oil deeply. Viscosity measured at different temperature for these cases using different reaction time is plotted in Fig. 4.19. Viscosity reductions expressed in percentages are plotted in Fig. 4.20. Viscosity measured at $50{ }^{\circ} \mathrm{C}$ versus upgrading time after being upgraded using tetralin is plotted in Fig. 4.17 and its corresponding reductions expressed in percentages are shown in Fig. 4.18. We can see that viscosity reduced fast at the first 24 hours and kept almost constant after that.

The viscosity and API gravity are also tabbed and compared in the tables in page 72 and 73 . The time it took to reach thorough viscosity reduction was shorter using decalin than using tetralin. And decalin led to more viscosity reduction than tetralin.

Table 4.1 - 4.3 summarize and compare the viscosity and API gravity changes. 


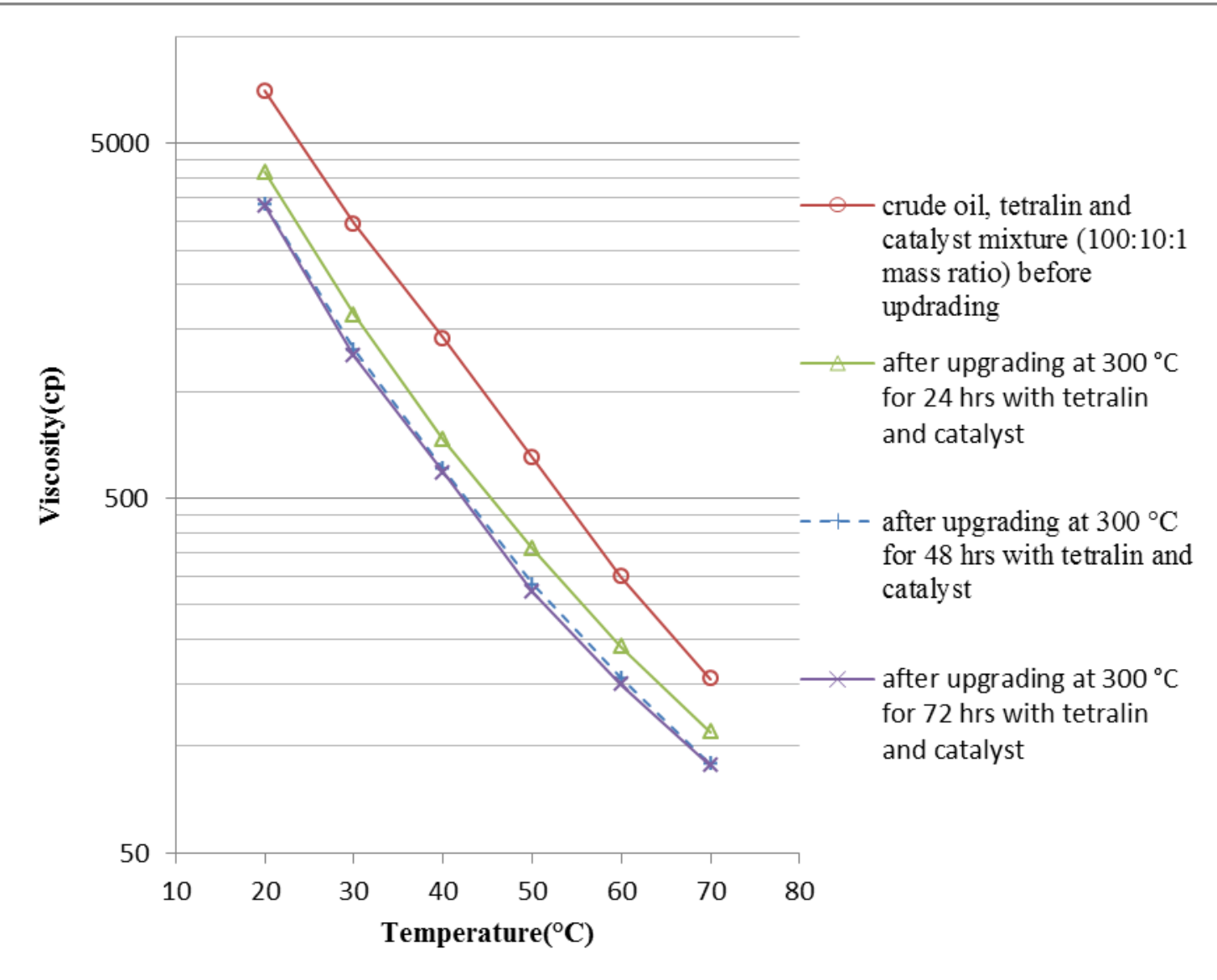

Fig. 4.15 Viscosity as a function of temperature before and after upgrading for different lengths of time using tetralin and catalyst. 


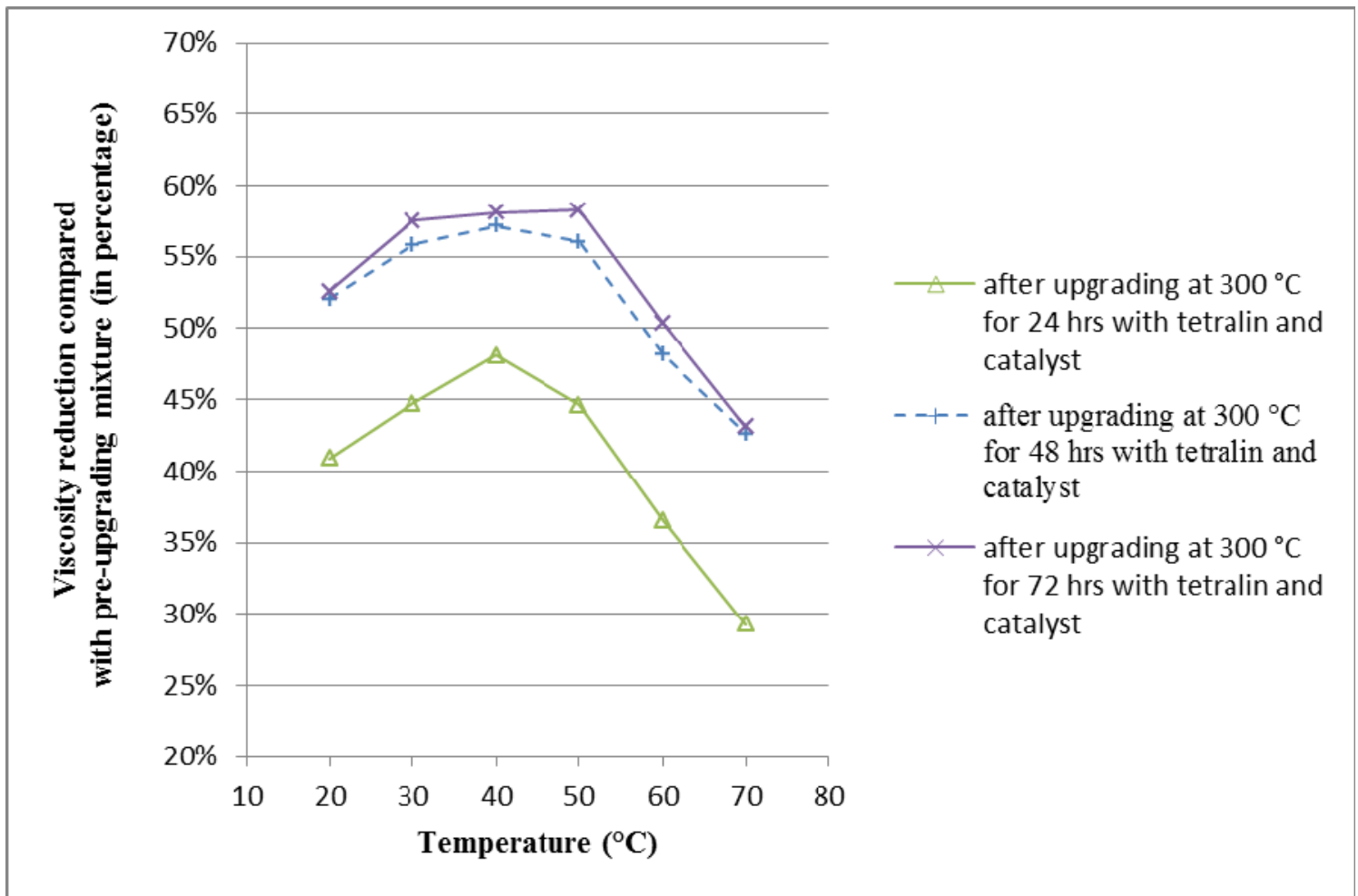

Fig. 4.16 Viscosity reductions ((viscosity before upgrading - viscosity after upgrading) / viscosity before upgrading) in percentages as a function of temperature after upgrading for different lengths of time using tetralin and catalyst. 


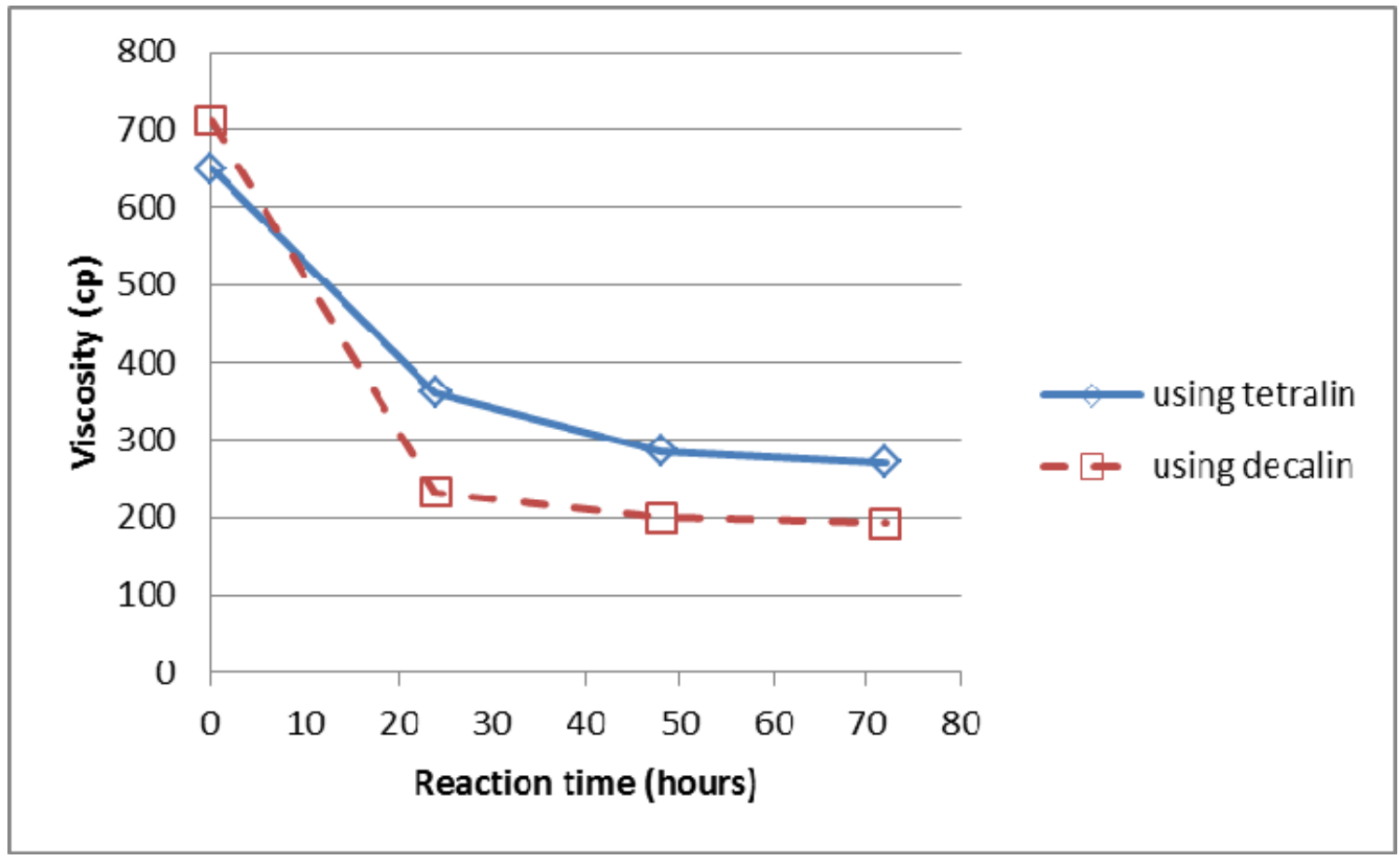

Fig. 4.17 Viscosity measured at $50{ }^{\circ} \mathrm{C}$ versus reaction time after upgrading using steam, tetralin or decalin and catalyst at $300{ }^{\circ} \mathrm{C}$. 


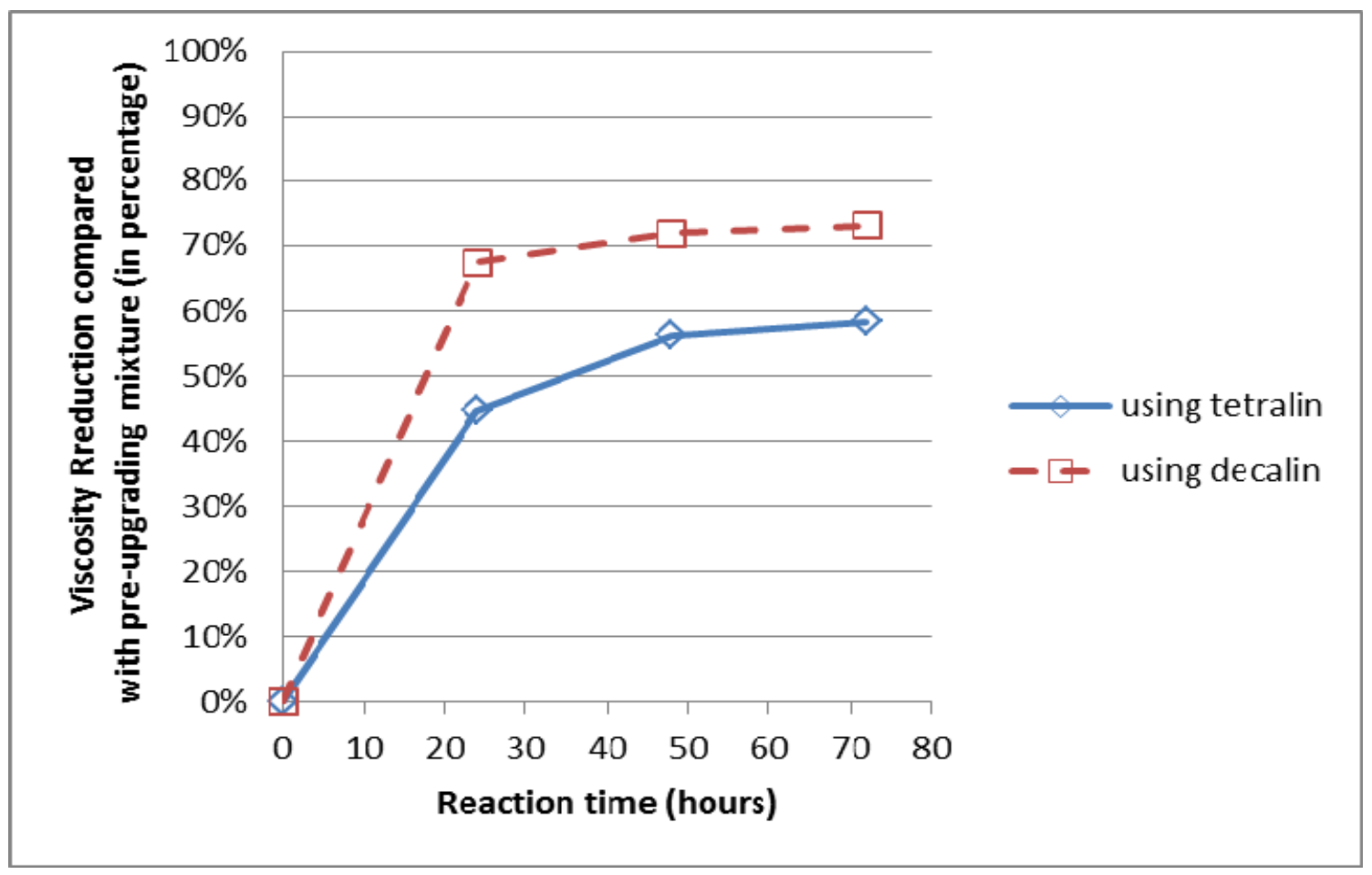

Fig. 4.18 Viscosity reductions ((viscosity before upgrading - viscosity after upgrading) / viscosity before upgrading) in percentages measured at $50^{\circ} \mathrm{C}$ versus reaction time after upgrading using steam, tetralin or decalin and catalyst at $300{ }^{\circ} \mathrm{C}$. 


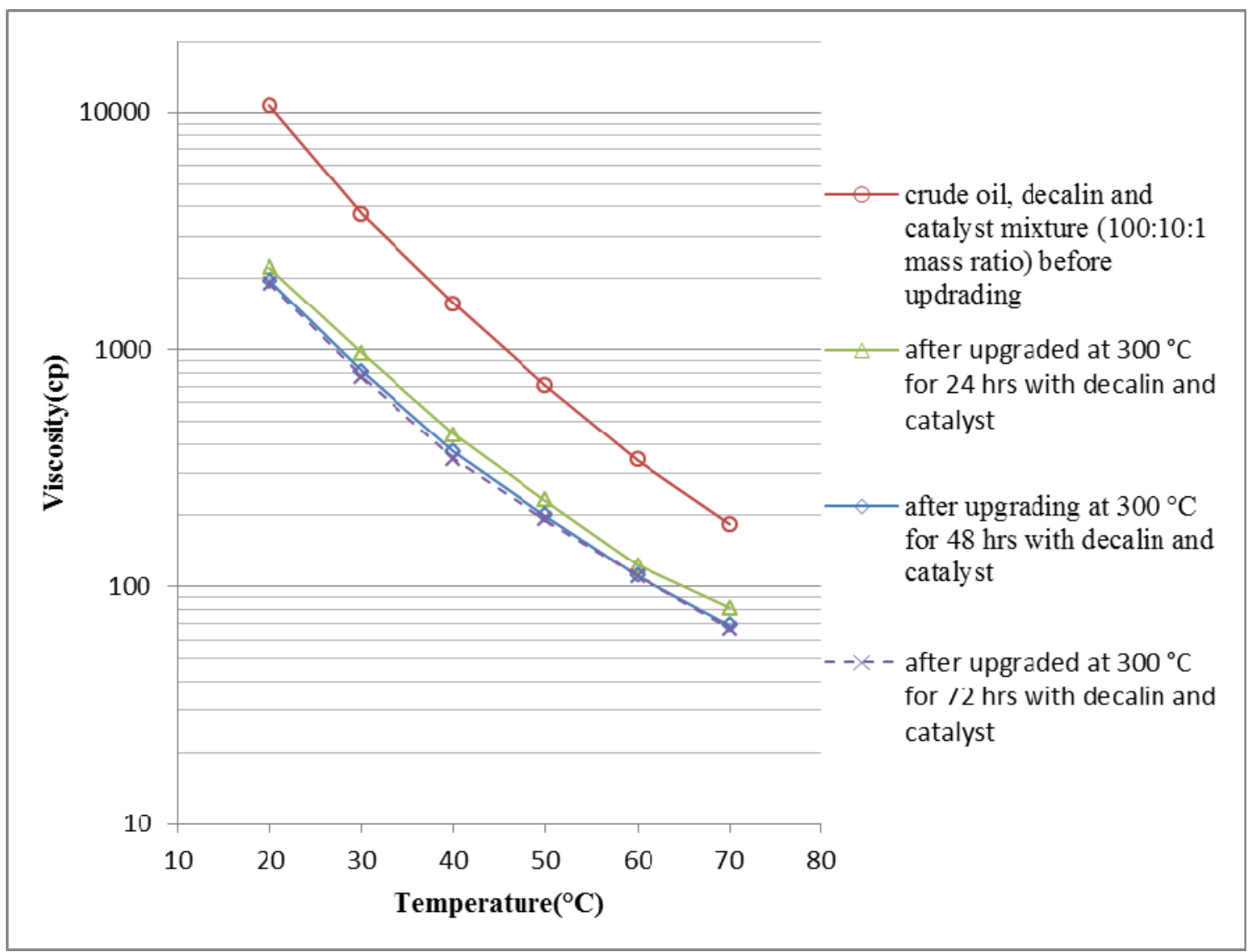

Fig. 4.19 Viscosity as a function of temperature before and after upgrading for different lengths of time using decalin and catalyst. 


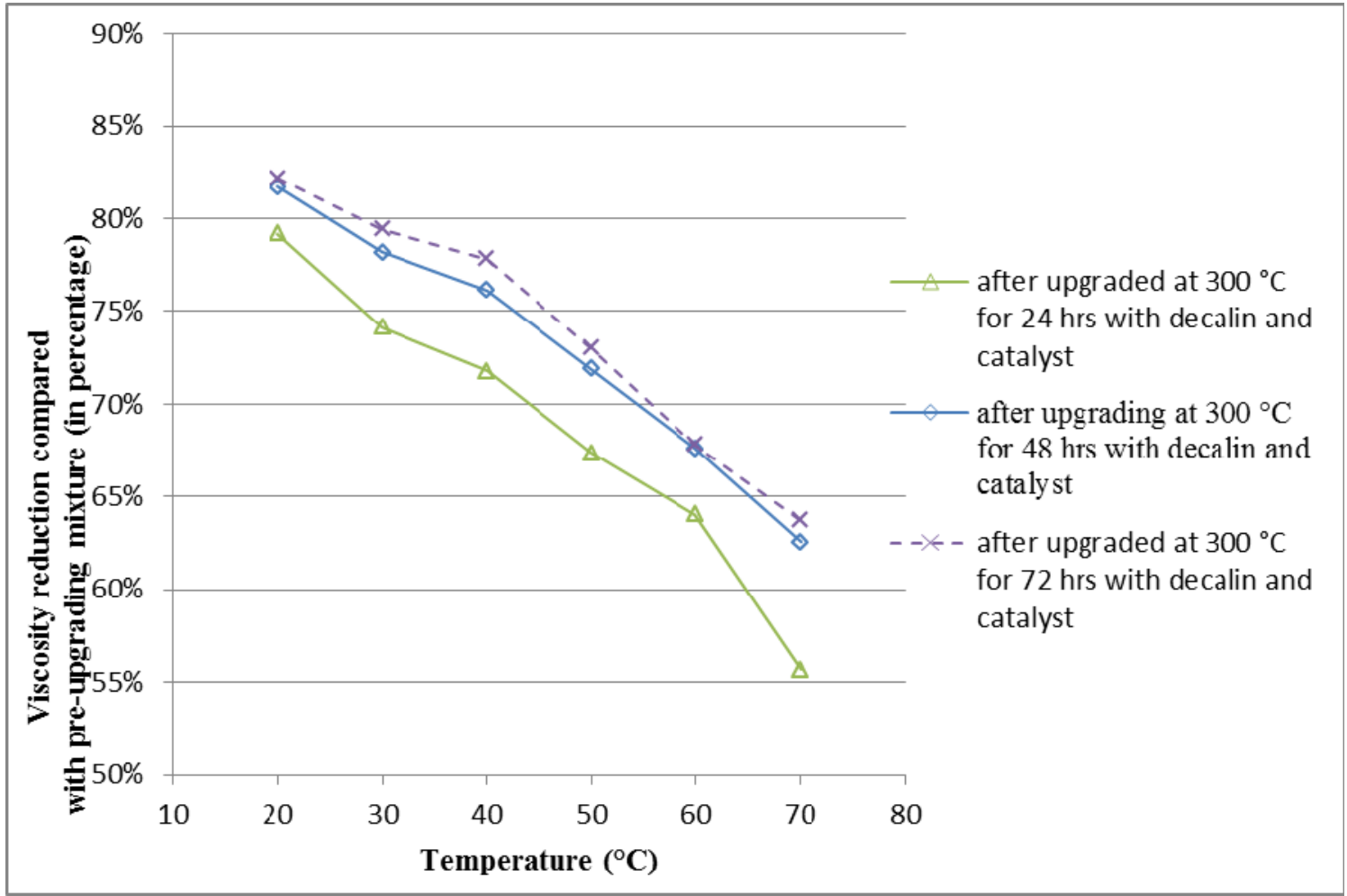

Fig. 4.20 Viscosity reductions ((viscosity before upgrading - viscosity after upgrading) / viscosity before upgrading) in percentages as a function of temperature after upgrading for different lengths of time using decalin and catalyst. 
Table 4.1 Viscosity and API gravity changes after upgrading using crude oil, steam and catalyst

\begin{tabular}{|c|c|c|c|c|c|c|c|c|c|}
\hline Temperature & $\begin{array}{c}\text { Crude } \\
\text { oil }\end{array}$ & Steam & Decalin & Tetralin & Catalyst & $\begin{array}{c}\text { Time } \\
\text { (hours) }\end{array}$ & $\begin{array}{c}\text { Viscosity } \\
\text { before } \\
\text { upgrading } \\
\left(\mathrm{cp} @ 50^{\circ} \mathrm{C}\right)\end{array}$ & $\begin{array}{c}\text { Viscosity } \\
\text { after } \\
\text { upgrading or } \\
\text { mixing (cp } \\
\left.\text { @ } 50^{\circ} \mathrm{C}\right)\end{array}$ & $\begin{array}{c}\text { Viscosity reductions in } \\
\text { percentages( (viscosity before } \\
\text { upgrading - viscosity after } \\
\text { upgrading) } / \text { viscosity before } \\
\text { upgrading) }\end{array}$ \\
\hline & $\mathrm{x}$ & & & & & & & 1108 & 1156 \\
\hline $300^{\circ} \mathrm{C}$ & $\mathrm{x}$ & & & & $\mathrm{x}$ & & & 11.42 \\
\hline $300^{\circ} \mathrm{C}$ & $\mathrm{x}$ & $\mathrm{x}$ & & & $\mathrm{x}$ & 48 & 1156 & 941 & 11.37 \\
\hline
\end{tabular}


Table 4.2 Viscosity and API gravity changes after upgrading using crude oil, steam, tetralin and catalyst

\begin{tabular}{|c|c|c|c|c|c|c|c|c|c|c|}
\hline Temperature & $\begin{array}{l}\text { Crude } \\
\text { oil }\end{array}$ & Steam & Decalin & Tetralin & Catalyst & $\begin{array}{l}\text { Time } \\
\text { (hours) }\end{array}$ & $\begin{array}{l}\text { Viscosity } \\
\text { before } \\
\text { upgrading } \\
\left(\mathrm{cp} @ 50^{\circ} \mathrm{C}\right)\end{array}$ & $\begin{array}{l}\text { Viscosity } \\
\text { after } \\
\text { upgrading or } \\
\text { mixing }(\mathrm{cp} \\
\left.\text { @ } 50^{\circ} \mathrm{C}\right)\end{array}$ & $\begin{array}{l}\text { Viscosity reductions in } \\
\text { percentages( (viscosity before } \\
\text { upgrading - viscosity after } \\
\text { upgrading) / viscosity before } \\
\text { upgrading) }\end{array}$ & $\begin{array}{c}\text { API } \\
\text { gravity }\end{array}$ \\
\hline & $\mathrm{x}$ & & & $\mathrm{x}$ & & & & 623 & & 11.86 \\
\hline & $\mathrm{x}$ & & & $\mathrm{x}$ & $\mathrm{x}$ & & & 650 & & 11.91 \\
\hline $300^{\circ} \mathrm{C}$ & $\mathrm{x}$ & $\mathrm{x}$ & & $\mathrm{x}$ & & 48 & 623 & 590 & $5.4 \pm 4 \%$ & 12.11 \\
\hline $250^{\circ} \mathrm{C}$ & $\mathrm{x}$ & $\mathrm{x}$ & & $\mathrm{x}$ & $\mathrm{x}$ & 48 & 650 & 623 & $4 \pm 3 \%$ & 12.02 \\
\hline $275^{\circ} \mathrm{C}$ & $\mathrm{x}$ & $\mathrm{x}$ & & $\mathrm{x}$ & $\mathrm{x}$ & 48 & 650 & 590 & $9 \pm 2 \%$ & 12.11 \\
\hline $300^{\circ} \mathrm{C}$ & $\mathrm{x}$ & $\mathrm{x}$ & & $\mathrm{x}$ & $\mathrm{x}$ & 24 & 650 & 360.1 & $45 \pm 1 \%$ & 12.14 \\
\hline $300^{\circ} \mathrm{C}$ & $\mathrm{x}$ & $\mathrm{x}$ & & $\mathrm{x}$ & $\mathrm{x}$ & 48 & 650 & 285.8 & $56 \pm 1 \%$ & 12.2 \\
\hline $300^{\circ} \mathrm{C}$ & $\mathrm{x}$ & $\mathrm{x}$ & & $\mathrm{x}$ & $\mathrm{x}$ & 72 & 650 & 271.5 & $58 \pm 2 \%$ & 12.25 \\
\hline
\end{tabular}


Table 4.3 Viscosity and API gravity changes after upgrading using crude oil, steam, decalin and catalyst

\begin{tabular}{|c|c|c|c|c|c|c|c|c|c|c|}
\hline Temperature & $\begin{array}{l}\text { Crude } \\
\text { oil }\end{array}$ & Steam & Decalin & Tetralin & Catalyst & $\begin{array}{l}\text { Time } \\
\text { (hours) }\end{array}$ & $\begin{array}{l}\text { Viscosity } \\
\text { before } \\
\text { upgrading } \\
\left(\mathrm{cp} @ 50^{\circ} \mathrm{C}\right)\end{array}$ & $\begin{array}{l}\text { Viscosity } \\
\text { after } \\
\text { upgrading or } \\
\text { mixing }(\mathrm{cp} \\
\left.\text { @ } 50^{\circ} \mathrm{C}\right)\end{array}$ & $\begin{array}{l}\text { Viscosity reductions in } \\
\text { percentages( (viscosity before } \\
\text { upgrading - viscosity after } \\
\text { upgrading) / viscosity before } \\
\text { upgrading) }\end{array}$ & $\begin{array}{c}\text { API } \\
\text { gravity }\end{array}$ \\
\hline & $\mathrm{x}$ & & $\mathrm{x}$ & & & & & 679 & & 12.74 \\
\hline & $\mathrm{x}$ & & $\mathrm{x}$ & & $\mathrm{x}$ & & & 711 & & 12.8 \\
\hline $300^{\circ} \mathrm{C}$ & $\mathrm{x}$ & $\mathrm{x}$ & $\mathrm{x}$ & & & 48 & 679 & 650 & $4.2 \pm 1 \%$ & 12.86 \\
\hline $250^{\circ} \mathrm{C}$ & $\mathrm{x}$ & $\mathrm{x}$ & $\mathrm{x}$ & & $\mathrm{x}$ & 48 & 711 & 690 & $3.0 \pm 2 \%$ & 12.89 \\
\hline $275^{\circ} \mathrm{C}$ & $\mathrm{x}$ & $\mathrm{x}$ & $\mathrm{x}$ & & $\mathrm{x}$ & 48 & 711 & 670 & $5.8 \pm 4 \%$ & 12.97 \\
\hline $300^{\circ} \mathrm{C}$ & $\mathrm{x}$ & $\mathrm{x}$ & $\mathrm{x}$ & & $\mathrm{x}$ & 24 & 711 & 232 & $67 \pm 1 \%$ & 13.71 \\
\hline $300^{\circ} \mathrm{C}$ & $\mathrm{x}$ & $\mathrm{x}$ & $\mathrm{x}$ & & $\mathrm{x}$ & 48 & 711 & 200 & $71.9 \pm 1 \%$ & 13.9 \\
\hline $300^{\circ} \mathrm{C}$ & $\mathrm{x}$ & $\mathrm{x}$ & $\mathrm{x}$ & & $\mathrm{x}$ & 72 & 711 & 192 & $73 \pm 1 \%$ & 14.03 \\
\hline
\end{tabular}




\subsection{Gas and Liquid Component Analysis after Upgrading Using Tetralin and Catalyst}

In this study, crude oil, water, tetralin and catalyst were mixed at a mass ratio of 100:100:10:1 and then heated and stirred at $300{ }^{\circ} \mathrm{C}$ for 48 hours. After the reaction, the components of the gases produced in the reaction system were collected and measured using GC-MS machine according to the gases analysis procedure. The results are given in Table 4.4. We can see that heavy oil upgrading occurred under $300{ }^{\circ} \mathrm{C}$ and a large amount of light hydrocarbons were produced. The light hydrocarbons should come from the cracking of heavy oil. The light hydrocarbon could undoubtedly reduce viscosity, thus improving their flowing ability in oil reservoir, therefor increasing oil production and improving oil recovery.

The upgraded liquid mixture was also analyzed using GC-MS. The dominate components are given in Table 4.5. We can see that there was still large amount of tetralin $\left(\mathrm{C}_{10} \mathrm{H}_{12}\right)$ left. The amount of tetralin we used was more than enough for heavy oil upgrading. We also observed large amount of naphthalene, which agreed with other researcher's finding (Ovalles et al., 2003). The presence of Cyclohexene $\left(\mathrm{C}_{6} \mathrm{H}_{10}\right)$ and 1(2H)-Naphthalenone, 3,4-dihydro $\left(\mathrm{C}_{10} \mathrm{H}_{8} \mathrm{O}\right)$ after upgrading also supported that tetralin acted as hydrogen donor by giving hydrogen to heavy oil and cracking oil. Other single hydrocarbon component's weight percentage was much less than decalin and most of them were heavy hydrocarbon components that could not be separated by GC. They were not reported by GC-MS analysis. 
Table 4.4 Gas components after reaction at $300{ }^{\circ} \mathrm{C}$ for 48 hours with water, tetralin and catalyst

\begin{tabular}{|c|c|c|c|}
\hline & Compounds & Weigh & Percent \\
\hline \multirow{3}{*}{$\mathrm{C} 4$} & 2-Butene & $14.75 \%$ & \multirow{3}{*}{$22.79 \%$} \\
\hline & 1-Propene, 2-methyl- & $3.76 \%$ & \\
\hline & 1-Butene & $4.28 \%$ & \\
\hline \multirow{6}{*}{$\mathrm{C} 5$} & 1-Butene, 3-methyl- & $7.67 \%$ & \multirow{6}{*}{$53.38 \%$} \\
\hline & Butane, 2-methyl- & $7.86 \%$ & \\
\hline & 2-Methyl-1-butene & $6.89 \%$ & \\
\hline & Pentane & $13.30 \%$ & \\
\hline & Cyclopropane, 1,2-dimethyl & $6.70 \%$ & \\
\hline & 2-Butene, 2-methyl- & $10.95 \%$ & \\
\hline \multirow{4}{*}{ C6 } & Pentane, 2-methyl- & $7.15 \%$ & \multirow{4}{*}{$23.83 \%$} \\
\hline & Pentane, 3-methyl- & $3.71 \%$ & \\
\hline & 1-Pentene, 2-methyl- & $6.94 \%$ & \\
\hline & Hexane & $6.04 \%$ & \\
\hline
\end{tabular}

Table 4.5 Major liquid components after upgraded at $300{ }^{\circ} \mathrm{C}$ for 48 hours with water, tetralin and catalyst

\begin{tabular}{|l|l|}
\hline Compounds & Weight Percent \\
\hline Cyclohexene $\left(\mathrm{C}_{6} \mathrm{H}_{10}\right)$ & $3.60 \%$ \\
\hline Tetralin $\left(\mathrm{C}_{10} \mathrm{H}_{12}\right)$ & $78.50 \%$ \\
\hline Naphthalene $\left(\mathrm{C}_{10} \mathrm{H}_{8}\right)$ & $13.95 \%$ \\
\hline $1(2 \mathrm{H})$-Naphthalenone, 3,4-dihydro $\left(\mathrm{C}_{10} \mathrm{H}_{8} \mathrm{O}\right)$ & $3.96 \%$ \\
\hline
\end{tabular}

\subsection{Gas and Liquid Component Analysis after Upgrading Using Decalin and Catalyst}

In this study, crude oil, water, decalin and catalyst were mixed at a mass ratio of 100:100:10:1 and then heated and stirred at $300{ }^{\circ} \mathrm{C}$ for 48 hours. After the reaction, the components of the gases produced in the reaction system were collected and analyzed using GC-MS machine following the gases analysis procedure. The results were given in

Table 4.6 where we can see that heavy oil upgrading occurred under $300{ }^{\circ} \mathrm{C}$ and 
produced a large amount of $\mathrm{CO}_{2}$, butane, and light hydrocarbon gases. The generation of carbon dioxide may be partly attributed to the aquathermolysis. Carbon dioxide can also be produced via water-gas shift reaction in the presence of steam and $\mathrm{CO}$ that came from the aquathermolysis of heavy oils according to the reaction mechanism. Besides, the decarbonxylation of carboxylic derivatives known to be present in heavy oils may also contribute to carbon dioxide generation. The carbon dioxide can undoubtedly reduce viscosity and improve recovery of heavy oils. The C3-C6 light hydrocarbon, acting as a solvent, can reduce viscosity of heavy oils and improve their flowing ability in oil reservoir. Thus the oil production can be increased and oil recovery factor can be increased too.

Table 4.6 Gas components after reaction at $300^{\circ}$ for 48 hours with water, decalin and catalyst

\begin{tabular}{|l|l|c|c|}
\hline & Compounds & \multicolumn{2}{|c|}{ Weight Percent } \\
\hline & Carbon dioxide & $22.27 \%$ & $22.27 \%$ \\
\hline C3 & Propene & $7.63 \%$ & $7.63 \%$ \\
\hline \multirow{3}{*}{ C4 } & Isobutane & $1.67 \%$ & \multirow{4}{*}{$52.69 \%$} \\
\cline { 2 - 3 } & 1-Propene, 2-methyl- & $3.72 \%$ & \\
\cline { 2 - 3 } & Butane & $47.30 \%$ & \\
\hline \multirow{3}{*}{ C5 } & Butane, 2-methyl- & $4.28 \%$ & \multirow{4}{*}{$10.10 \%$} \\
\cline { 2 - 3 } & Pentane & $4.50 \%$ & \\
\cline { 2 - 3 } & Cyclopropane, 1,2-dimethyl & $1.32 \%$ & \\
\hline \multirow{3}{*}{ C6 6} & Pentane, 2-methyl- & $3.83 \%$ & \multirow{3}{*}{$7.32 \%$} \\
\cline { 2 - 3 } & Pentane, 3-methyl- & $1.65 \%$ \\
\cline { 2 - 3 } & Hexane & $1.84 \%$ & \\
\hline
\end{tabular}


Table 4.7 Major liquid components after being upgraded at $300^{\circ}$ for 48 hours with water, decalin and catalyst

\begin{tabular}{|l|c|}
\hline Compounds & Weight Percent \\
\hline Cyclohexene $\left(\mathrm{C}_{6} \mathrm{H}_{10}\right)$ & $2.08 \%$ \\
\hline cis-Decahydronaphthalene (c-Decalin, $\left.\mathrm{C}_{10} \mathrm{H}_{18}\right)$ & $59.27 \%$ \\
\hline trans-Decahydronaphthalene (t-Decalin, $\left.\mathrm{C}_{10} \mathrm{H}_{18}\right)$ & $38.66 \%$ \\
\hline
\end{tabular}

The upgraded liquid mixture was analyzed using GC-MS. The dominant components are given in Table 4.7. The decalin we used was a mixture of cis-Decahydronaphthalene (c-Decalin) and trans-Decahydronaphthalene (t-Decalin). We can see that there was still a large amount of decalin $\left(\mathrm{C}_{10} \mathrm{H}_{18}\right)$ left after reaction and it was still a mixture of c-Decalin and t-Decalin. The amount of decalin we used was more than enough for the upgrading reaction. Other single hydrocarbon component's weight percentage was much less than that of decalin. And most of them were heavy hydrocarbon components that could not be separated by GC. Therefore, they were not reported by the GC-MS analyses. However, we did observe $2.08 \%$ of cyclohexene $\left(\mathrm{C}_{6} \mathrm{H}_{10}\right)$ presented. Probably it was the product of upgrading process from decalin after it donated hydrogen to heavy crude.

In previous case using tetralin, no $\mathrm{CO}_{2}$ was observed in the gas phase. However, we found oxygen atoms in liquid product in the form of 1(2H)-Naphthalenone,3,4-dihydro $\left(\mathrm{C}_{10} \mathrm{H}_{8} \mathrm{O}\right)$. The reaction mechanism is quite different for these two hydrogen donors. 


\subsection{Comparison and Discussion of Results}

Tetralin and decalin alone could be used as solvents for heavy oil recovery. $9 \%$ weight percent of tetralin could reduce the Jobo crude oil's viscosity by $44 \pm 2 \%$, and the same amount of decalin could reduce the Jobo crude oil viscosity by $39 \pm 3 \%$.

Steam alone did not have noticeable upgrading effects in the sense of viscosity reduction and API gravity increase. The steam cracking of oil (hydrous pyrolysis) did not show significant decomposition of organic material.

Tetralin, decalin or catalyst showed some upgrading effects when used with steam. The viscosity reduction caused by upgrading was $5 \%, 4 \%$ and $19 \%$, respectively. API gravity was increased a little bit for all the cases.

When hydrogen donor tetralin or decalin was used in the presence of catalyst the viscosity of the mixture was reduced most, by $56 \pm 1 \%$ and $72 \pm 1 \%$ compared with pre-upgrading mixture. It can be concluded that hydrogen donor and catalyst had synergetic effects on heavy oil upgrading.

After comparing upgrading results for $250{ }^{\circ} \mathrm{C}, 275^{\circ} \mathrm{C}$ and $300{ }^{\circ} \mathrm{C}$, we found that for $250{ }^{\circ} \mathrm{C}$ and $275{ }^{\circ} \mathrm{C}$, the viscosity reductions were not very significant. However when the temperature was $300{ }^{\circ} \mathrm{C}$, it showed great upgrading effects. That was because high temperature could supply energy higher than the activation energy and the chemical reaction rate was much faster. Most successful steam-injection projects operate at pressures on the order of 1,500 psi or lower (Green and Willhite, 1998). The saturation temperature for steam at $1,500 \mathrm{psi}$ is $313{ }^{\circ} \mathrm{C}$. Thus the practical reservoir temperature is 
lower than $310{ }^{\circ} \mathrm{C}$. Therefore, $300{ }^{\circ} \mathrm{C}$ is close to the optimal temperature for in-situ upgrading under steam injection condition.

At the study of effects of reaction time for upgrading using steam, tetralin and catalyst, we found that 24 hours could lead to reduction of viscosity by $45 \pm 1 \%$, and 48 hours could result a $56 \pm 1 \%$ viscosity reduction. However, additional 24 hours after the first 48 hours could only reduce the viscosity by $2 \%$ further. It meant that 48 hours was enough for viscosity reduction purpose. When Decalin was used, it showed similar results, after 24 hours, 48 hours and 72 hours, the viscosity was reduced by $67 \pm 1 \%$, $72 \pm 1 \%$ and $73 \pm 1 \%$, respectively.

For all the upgrading processes, we observed that the API gravity was increased correspondingly with the viscosity reduction.

The coupled Gas chromatography and mass spectrometry analysis of the gas component showed there were a lot of hydrocarbon gas components and $\mathrm{CO}_{2}$ produced during the reaction of crude oil with decalin and catalyst. However, there was no $\mathrm{CO}_{2}$ observed when tetralin was used instead of decalin. But we noticed there was $1(2 \mathrm{H})$-Naphthalenone,3,4-dihydro $\left(\mathrm{C}_{10} \mathrm{H}_{8} \mathrm{O}\right)$ in the liquid phase. The oxygen atoms from heavy oil went to this liquid product. The upgrading process must be quite different for these two reactions using different kinds of hydrogen donors.

There was still a large amount of tetralin or decalin left in the upgraded fluid. The amount of hydrogen donors we used is more than enough for the upgrading reaction. 
Decalin, when used together with steam and catalyst, led to the largest viscosity reduction. The viscosity reduction effect was larger than tetralin, probably because it has more hydrogen atom per molecule than tetralin. 


\section{SUMMARY, CONCLUSIONS AND RECOMMENDATIONS}

\subsection{Summary}

Mohammad and Mamora (2008) verified the feasibility of heavy crude oil in-situ upgrading by using a hydrogen donor (tetralin) and an organometallic catalyst (Fe(acac $\left.)_{3}\right)$. They observed limited heavy oil upgrading during steam flooding but suspected that the reaction time was too short and the contact between heavy crude, tetralin and catalyst was poor. In our experiment we used an autoclave and a magnetic stirrer to achieve good mixing and faster reaction rate. This setting also allows longer residence times than what could be achieved from steam flooding in a sand pack such that conversion rates are maximized.

Mateshov (2010) used decalin $\left(\mathrm{C}_{10} \mathrm{H}_{18}\right)$ as a hydrogen donor for in-situ combustion of Gulf of Mexico heavy oil. Decalin as a hydrogen donor had not been used for in-situ upgrading under steam injection condition. Our research is the first time to investigate the upgrading abilities of decalin with a catalyst during steam flooding for Jobo heavy oil from Venezuela.

Our research consisted of an experimental evaluation of the feasibility of in-situ upgrading for Jobo heavy oil in the presence of steam, hydrogen donor (tetralin and decalin) and catalyst. Many experiments were performed in an autoclave to study the roles of steam, tetralin, decalin and $\mathrm{Fe}(\mathrm{acac})_{3}$ catalyst, alone or combined, during subsurface in-situ heavy oil upgrading. It was found that each of them played an important role in the aquathermolysis reaction. When they were used together, the 
synergetic effects were observed, leading to significant viscosity reductions and increases in API gravity. The experiments showed that decalin and organometallic catalyst performed better than tetralin and catalyst. Decalin is a better candidate for in-situ upgrading of heavy oil during cyclic steam stimulation and steam flooding.

\subsection{Conclusions}

1. Aquathermolysis in-situ heavy oil upgrading has great application potential in the heavy and extra heavy oil recovery. It has been proved technically feasible by this work that catalyst may lead to cleavage of some components in heavy oil during aquathermolysis, then the active $\mathrm{H}$ (hydrogen atom) from $\mathrm{H}_{2} \mathrm{O}$ and hydrogen donors connects with fragments or radicals cleaved. In the end, some bonds of heavy oil are broken. Therefore, the synergetic effects of catalyst and hydrogen donor lead to chemical changes in structures and compositions, leading to reduction in viscosity of heavy oil.

2. Tetralin and decalin alone were good solvents for heavy oil recovery. $9 \%$ weight percent of tetralin or decalin could reduce the Jobo crude oil viscosity measured at $50{ }^{\circ} \mathrm{C}$ by $44 \pm 2 \%$ and $39 \pm 3 \%$.

3. Steam alone had some upgrading effects in the sense of viscosity reduction and API gravity increase. After reaction at $300^{\circ} \mathrm{C}$ for 48 hours, it could reduce the oil viscosity by $10 \pm 2 \%$, which was not very significant.

4. Tetralin or decalin alone does not have significant upgrading effects (only $5.4 \pm 4 \%, 4 \pm 1 \%$ viscosity reductions) when used with steam after reaction at 
$300^{\circ} \mathrm{C}$ for 48 hours; however, catalyst alone with steam showed noticeable upgrading effects by causing $19 \pm 3 \%$ viscosity reduction after reaction at same temperature and length of time. Increases in API gravity for these cases are negligible.

5. The combination of hydrogen donor tetralin or decalin and catalyst reduced the viscosity of the mixture the most, by $56 \pm 1 \%$ and $72 \pm 1 \%$ compared with pre-upgrading mixture after 48 hours of upgrading at $300{ }^{\circ} \mathrm{C}$. It can be concluded that hydrogen donor and catalyst had strong synergetic effects on heavy oil upgrading.

6. $300{ }^{\circ} \mathrm{C}$ was an effective temperature for heavy oil upgrading in the presence of steam, hydrogen donor and catalyst. It showed great upgrading effects because high temperature could supply energy that was higher than the activation energy and the chemical reaction rate was much faster. When the experiments were performed for $250{ }^{\circ} \mathrm{C}, 275^{\circ} \mathrm{C}$, the viscosity reductions were not as significant. And the practical saturated steam temperature in a reservoir is less than $315^{\circ} \mathrm{C}$. So $300{ }^{\circ} \mathrm{C}$ was close to the optimal temperature for in-situ upgrading.

7. We found that for heavy oil upgrading in the presence of steam, tetralin and catalyst, the first 24 hours reaction period could lead to reduction of viscosity significantly (by $45 \pm 1 \%$ ), and the second 24 hours reaction period could result a noticeable viscosity reduction (by additional $11 \pm 1 \%$ ). However, the third 24 hours reaction period could barely reduce viscosity (by extra $2 \%$ only); thus 48 hours was long enough for viscosity reduction purpose. When decalin was used, 
it showed similar results, the viscosity was reduced by $67 \pm 1 \%, 72 \pm 1 \%$ and $73 \pm 1 \%$ at the end of 24 hours, 48 hours and 72 hours, respectively. Therefore, 24 hours was long enough for viscosity reduction using decalin.

8. The upgrading processes were different for using tetralin and decalin. The GC-MS analysis of the gas components showed there were a lot of hydrocarbon gas components and $\mathrm{CO}_{2}$ generated after reaction with decalin and catalyst; however, there is no $\mathrm{CO}_{2}$ observed when tetralin is used instead of decalin. But we noticed there was $1(2 \mathrm{H})$-Naphthalenone, 3,4-dihydro $\left(\mathrm{C}_{10} \mathrm{H}_{8} \mathrm{O}\right)$ in the liquid phase. The oxygen from heavy oil was transferred to this liquid component.

9. Decalin, when used together with steam and catalyst, reduced the mixture to the lowest viscosity. The viscosity reduction effect is more significant than tetralin, probably due to the fact that it has more hydrogen atoms than tetralin per molecule.

10. The amount of tetralin and decalin we used is more than enough for upgrading reaction. There are still a large amount of tetralin and decalin left after reaction if they are used at a mass amount of $10 \mathrm{wt} \%$ of heavy oil.

\subsection{Recommendations}

There are many more researches that can be done in the further investigations, such as:

1. Investigate a way to disperse tetralin or decalin and catalyst into the reservoir and mix them with crude oil efficiently. 
2. Perform elemental analysis to study changes in $\mathrm{H} / \mathrm{C}$ ratios. If $\mathrm{H}$ is donated from $\mathrm{H}_{2} \mathrm{O}$ and hydrogen donor to hydrocarbon, it is expected to see an increase in $\mathrm{H} / \mathrm{C}$ ratio after reaction.

3. Consider SARA analysis to study the changes in saturate, aromatic, resin and asphaltene mass ratio.

4. Investigate the economics of applying in-situ upgrading with tetralin or decalin with catalyst in heavy oil recovery.

5. Investigate the mechanism further for more details. There are different aquathermolytic reactions for heavy oil components with different molecular structures and function groups.

6. Quantify the amounts of light hydrocarbons produced as percent of total heavy crude present in the experiment and quantify decalin/tetralin decomposition products as percentage of total decalin/tetralin present in the experiment. However, there may be some overlap between light hydrocarbons and decalin/tetralin reaction products and these two recommendations may be difficult to do. 


\section{REFERENCES}

Belgrave, J.D.M., Moore, R.G., and Ursenbach, M.G. 1997. Comprehensive Kinetic Models for the Aquathermolysis of Heavy Oils. Journal of Canadian Petroleum Technology 36 (4): 38-44.

Besson, C. 2005. Resources to Reserves - Oil and Gas Technologies for the Energy Markets of the Future. Paris: International Energy Agency.

Chen, Y., Wang, Y., Wu, C. et al. 2008. Laboratory Experiments and Field Tests of an Amphiphilic Metallic Chelate for Catalytic Aquathermolysis of Heavy Oil. Energy \& Fuels 22 (3): 1502-1508.

Clark, B. 2007. Working Document of the Npc Global Oil \& Gas Study. http://www.npc.org/Study_Topic_Papers/22-TTG-Heavy-Oil.pdf.

Clark, P., Clarke, R., Hyne, J. et al. 1990. Studies on the Effect of Metal Species on Oil Sands Undergoing Steam Treatments. AOSTRA Journal of Research 6 (1): 53-64.

Fan, H., Liu, Y., and Zhong, L. 2001. Studies on the Synergetic Effects of Mineral and Steam on the Composition Changes of Heavy Oils. Energy \& Fuels 15 (6): $1475-1479$.

Fan, H., Liu, Y., Zhang, L. et al. 2002. The Study on Composition Changes of Heavy Oils During Steam Stimulation Processes. Fuel 81 (13): 1733-1738.

Fan, H., Zhang, Y., and Lin, Y. 2004. The Catalytic Effects of Minerals on Aquathermolysis of Heavy Oils. Fuel 83 (14-15): 2035-2039. 
Green, D.W. and Willhite, G.P. 1998. Enhanced Oil Recovery. SPE Textbook Series. Richardson, Texas: SPE.

Hyne, J.B., Greidanus, J.W., Tyrer, J.D. et al. 1982. Aquathermolysis of Heavy Oil. Paper presented at the 2nd International Conference on Heavy Crude and Tar Sands, Caracas, Venezuela.

Jiang, S., Liu, X., Liu, Y. et al. 2005. In Situ Upgrading Heavy Oil by Aquathermolytic Treatment under Steam Injection Conditions. Paper SPE 91973 presented at the SPE International Symposium on Oilfield Chemistry, The Woodlands, Texas..

Liu, Y. and Fan, H. 2002. The Effect of Hydrogen Donor Additive on the Viscosity of Heavy Oil During Steam Stimulation. Energy \& Fuels 16 (4): 842-846.

Mateshov, D. 2010. Experimental Study of in Situ Combustion with Decalin and Metallic Catalyst. Master of Science, Texas A\&M University, College Station.

Mohammad, A.A.A. 2008. Experimental Investigation of in Situ Upgrading of Heavy Oil by Using a Hydrogen Donor and Catalyst During Steam Injection. Doctor of Philosophy, Texas A\&M University, College Station.

Mohammad, A.A.A. and Mamora, D.D. 2008. In Situ Upgrading of Heavy Oil under Steam Injection with Tetralin and Catalyst. Paper SPE 117604 presented at the International Thermal Operations and Heavy Oil Symposium, Calgary, Alberta, Canada.

Nares, H.R., Schacht-Hernandez, P., Cabrera-Reyes, M.C. et al. 2006. Upgrading of Heavy Crude Oil with Supported and Unsupported Transition Metals. Paper presented at the Canadian International Petroleum Conference, Calgary, Alberta. 
Ovalles, C., Filgueiras, E., Morales, A. et al. 1998. Use of a Dispersed Molybdenum Catalyst and Mechanistic Studies for Upgrading Extra-Heavy Crude Oil Using Methane as Source of Hydrogen. Energy \& Fuels 12 (2): 379-385.

Ovalles, C., Hamana, A., Rojas, I. et al. 1995. Upgrading of Extra-Heavy Crude Oil by Direct Use of Methane in the Presence of Water: Deuterium-Labelled Experiments and Mechanistic Considerations. Fuel 74 (8): 1162-1168.

Ovalles, C., Martinis, J., Perez-Perez, A. et al. 2001. Physical and Numerical Simulation of an Extra-Heavy Crude Oil Downhole Upgrading Process Using Hydrogen Donors under Cyclic Steam Injection Conditions. Paper SPE 69561 presented at the SPE Latin American and Caribbean Petroleum Engineering Conference, Buenos Aires, Argentina.

Ovalles, C. and Rodriguez, H. 2008. Extra Heavy Crude Oil Downhole Upgrading Using Hydrogen Donors under Cyclic Steam Injection Conditions: Physical and Numerical Simulation Studies. Journal of Canadian Petroleum Technology 47 (1): $43-51$.

Ovalles, C., Vallejos, C., Vasquez, T. et al. 2003. Downhole Upgrading of Extra-Heavy Crude Oil Using Hydrogen Donors and Methane under Steam Injection Conditions. Petroleum Science and Technology 21 (1): 255-274.

Prats, M. 1986. Thermal Recovery. Monograph Series. New York: SPE.

Wang, Y., Chen, Y., He, J. et al. 2010. Mechanism of Catalytic Aquathermolysis: Influences on Heavy Oil by Two Types of Efficient Catalytic Ions: Fe3+ and Mo6+. Energy \& Fuels 24 (3): 1502-1510. 
Wen, S., Zhao, Y., Liu, Y. et al. 2007. A Study on Catalytic Aquathermolysis of Heavy Crude Oil During Steam Stimulation. Paper SPE 106180 presented at the International Symposium on Oilfield Chemistry, Houston, Texas, U.S.A.

Wu, C., Lei, G., Yao, C. et al. 2010. In Situ Upgraging Extra-Heavy Oil by Catalytic Aquathermolysis Treatment Using a New Catalyst Based Anamphiphilic Molybdenum Chelate. Paper SPE 130333 presented at the International Oil and Gas Conference and Exhibition in China, Beijing, China.

Yi, Y., Li, S., Ding, F. et al. 2009. Change of Asphaltene and Resin Properties after Catalytic Aquathermolysis. Petroleum Science 6 (2): 194-200.

Zhao, F., Liu, Y., Wen, S. et al. 2006. Advances in Researches on Aquathermolysis Catalysts for Heavy Crude Oils. Oilfield Chemistry 23 (3): 277-283.

Zhong, L.G., Liu, Y.J., Fan, H.F. et al. 2003. Liaohe Extra-Heavy Crude Oil Underground Aquathermolytic Treatments Using Catalyst and Hydrogen Donors under Steam Injection Conditions. Paper SPE 84863 presented at the SPE International Improved Oil Recovery Conference in Asia Pacific, Kuala Lumpur, Malaysia. 


\section{APPENDIX A}

\section{DATA TABLES}

Table A.1 Viscosity of Jobo crude oil

\begin{tabular}{|c|c|c|c|}
\hline \multirow{2}{*}{ Temperature $\left({ }^{\circ} \mathrm{C}\right)$} & \multicolumn{3}{|c|}{ Viscosity $(\mathrm{cp})$} \\
\cline { 2 - 4 } & $1^{\text {st }}$ measurement & $2^{\text {ed }}$ measurement & average \\
\hline 20 & 21047 & 21975 & 21511 \\
\hline 30 & 7048 & 7352 & 7200 \\
\hline 40 & 2480 & 2660 & 2570 \\
\hline 50 & 1082 & 1134 & 1108 \\
\hline 60 & 545 & 575 & 560 \\
\hline 70 & 279 & 291 & 285 \\
\hline 80 & 150 & 158 & 154 \\
\hline
\end{tabular}

Table A.2 Viscosity of Jobo crude oil and catalyst mixture (100:1)

\begin{tabular}{|c|c|c|c|}
\hline \multirow{2}{*}{ Temperature $\left({ }^{\circ} \mathrm{C}\right)$} & \multicolumn{3}{|c|}{ Viscosity $(\mathrm{cp})$} \\
\cline { 2 - 4 } & $1^{\text {st }}$ measurement & $2^{\text {ed }}$ measurement & average \\
\hline 20 & 21724 & 22917 & 22320 \\
\hline 30 & 7202 & 7763 & 7483 \\
\hline 40 & 2618 & 2743 & 2681 \\
\hline 50 & 1121 & 1192 & 1156 \\
\hline 60 & 560 & 606 & 583 \\
\hline 70 & 290 & 303 & 296 \\
\hline 80 & 155 & 167 & 161 \\
\hline
\end{tabular}


Table A.3 Viscosity dewatered crude oil after upgrading with steam for 48 hours at $300{ }^{\circ} \mathrm{C}$

\begin{tabular}{|c|c|c|c|c|c|}
\hline \multirow{2}{*}{ Temperature $\left({ }^{\circ} \mathrm{C}\right)$} & \multirow{2}{*}{$\begin{array}{c}\text { Viscosity } \\
\text { before }\end{array}$} & \multicolumn{3}{|c|}{ Viscosity after upgrading (cp) } & \multirow{2}{*}{$\begin{array}{c}\text { Viscosity } \\
\text { reductions in } \\
\text { percentages }\end{array}$} \\
\cline { 3 - 5 } & 21511 & 15768 & 16953 & 16360 & $24 \pm 2 \%$ \\
\hline 20 & 7200 & 5895 & 6359 & 6127 & $15 \pm 3 \%$ \\
\hline 30 & 2570 & 2316 & 2414 & 2365 & $8 \pm 3 \%$ \\
\hline 40 & 1108 & 971 & 1023 & 997 & $10 \pm 2 \%$ \\
\hline 50 & 560 & 487 & 514 & 500 & $11 \pm 2 \%$ \\
\hline 60 & 285 & 224 & 237 & 231 & $19 \pm 2 \%$ \\
\hline 70 & 154 & 132 & 142 & 137 & $11 \pm 2 \%$ \\
\hline 80 & & & & & \\
\hline
\end{tabular}

Table A.4 Viscosity of dewatered mixture after upgrading of crude with steam and catalyst (100:100:1) for 48 hours at $300{ }^{\circ} \mathrm{C}$

\begin{tabular}{|c|c|c|c|c|c|}
\hline \multirow{2}{*}{ Temperature $\left({ }^{\circ} \mathrm{C}\right)$} & \multirow{2}{*}{$\begin{array}{c}\text { Viscosity } \\
\text { before } \\
\text { upgrading (cp) }\end{array}$} & \multicolumn{2}{|c|}{ Viscosity after upgrading (cp) } & \multirow{2}{*}{$\begin{array}{c}\text { Viscosity } \\
\text { reductions in } \\
\text { percentages }\end{array}$} \\
\cline { 3 - 5 } & 22320 & 14546 & 15212 & 14879 & $33 \pm 1 \%$ \\
\hline 20 & 7483 & 5181 & 5600 & 5391 & $28 \pm 2 \%$ \\
\hline 30 & 2681 & 2062 & 2198 & 2130 & $21 \pm 3 \%$ \\
\hline 40 & 1156 & 906 & 976 & 941 & $19 \pm 3 \%$ \\
\hline 50 & 583 & 433 & 452 & 442 & $24 \pm 3 \%$ \\
\hline 60 & 296 & 205 & 216 & 211 & $29 \pm 3 \%$ \\
\hline 70 & 161 & 122 & 128 & 125 & $22 \pm 3 \%$ \\
\hline 80 & & & & & \\
\hline
\end{tabular}


Table A.5 Viscosity of crude oil and tetralin mixture (100:10)

\begin{tabular}{|c|c|c|c|c|c|}
\hline \multirow{2}{*}{ Temperature $\left({ }^{\circ} \mathrm{C}\right)$} & \multirow{2}{*}{$\begin{array}{c}\text { Viscosity } \\
\text { before mixing } \\
\end{array}$} & \multicolumn{3}{|c|}{ Viscosity $(\mathrm{cp})$} & \multirow{2}{*}{$\begin{array}{c}\text { Viscosity } \\
\text { reductions in } \\
\text { percentages }\end{array}$} \\
\cline { 3 - 5 } & 21511 & 6609 & 6944 & 6776 & $68 \pm 1 \%$ \\
\hline 20 & 7200 & 2751 & 2940 & 2846 & $60 \pm 1 \%$ \\
\hline 30 & 2570 & 1324 & 1391 & 1358 & $47 \pm 1 \%$ \\
\hline 40 & 1108 & 605 & 642 & 624 & $44 \pm 2 \%$ \\
\hline 50 & 560 & 281 & 296 & 289 & $48 \pm 2 \%$ \\
\hline 60 & 285 & 145 & 152 & 149 & $48 \pm 2 \%$ \\
\hline 70 & & & & & \\
\hline
\end{tabular}

Table A.6 Viscosity of crude oil tetralin and catalyst mixture (100:10:1)

\begin{tabular}{|c|c|c|c|c|c|}
\hline \multirow{2}{*}{ Temperature $\left({ }^{\circ} \mathrm{C}\right)$} & \multirow{2}{*}{$\begin{array}{c}\text { Viscosity } \\
\text { before mixing } \\
\text { (cp) }\end{array}$} & \multicolumn{3}{|c|}{ Viscosity (cp) } & \multirow{2}{*}{$\begin{array}{l}\text { Viscosity } \\
\text { reductions in } \\
\text { percentages }\end{array}$} \\
\hline & & $1^{\text {st }}$ measurement & $2^{\text {ed }}$ measurement & average & \\
\hline 20 & 22320 & 6743 & 7304 & 7023 & $69 \pm 1 \%$ \\
\hline 30 & 7483 & 2867 & 3069 & 2968 & $60 \pm 1 \%$ \\
\hline 40 & 2681 & 1368 & 1447 & 1408 & $47 \pm 1 \%$ \\
\hline 50 & 1156 & 629 & 671 & 650 & $44 \pm 1 \%$ \\
\hline 60 & 583 & 291 & 309 & 300 & $49 \pm 1 \%$ \\
\hline 70 & 296 & 152 & 158 & 155 & $48 \pm 1 \%$ \\
\hline
\end{tabular}

Table A.7 Viscosity of dewatered mixture after upgrading of crude oil with steam, tetralin and catalyst (100:100:10:1) at $250{ }^{\circ} \mathrm{C}$ for 48 hours

\begin{tabular}{|c|c|c|c|c|c|}
\hline \multirow{2}{*}{ Temperature $\left({ }^{\circ} \mathrm{C}\right)$} & \multirow{2}{*}{$\begin{array}{c}\text { Viscosity } \\
\text { before } \\
\text { upgrading }(\mathrm{cp})\end{array}$} & \multicolumn{3}{|c|}{ Viscosity after upgrading (cp) } & \multirow{2}{*}{$\begin{array}{c}\text { Viscosity } \\
\text { reductions in } \\
\text { percentages }\end{array}$} \\
\hline & & $1^{\text {st }}$ measurement & $2^{\text {ed }}$ measurement & average & \\
\hline 20 & 7023 & 6839 & 7071 & 6955 & $1 \pm 2 \%$ \\
\hline 30 & 2968 & 2747 & 2822 & 2784 & $6 \pm 1 \%$ \\
\hline 40 & 1408 & 1344 & 1392 & 1368 & $3 \pm 3 \%$ \\
\hline 50 & 650 & 614 & 632 & 623 & $4 \pm 3 \%$ \\
\hline 60 & 300 & 291 & 307 & 299 & $0 \pm 2 \%$ \\
\hline 70 & 155 & 147 & 153 & 150 & $3 \pm 2 \%$ \\
\hline
\end{tabular}


Table A.8 Viscosity of dewatered mixture after upgrading of crude oil with steam, tetralin and catalyst (100:100:10:1) at $275^{\circ} \mathrm{C}$ for 48 hours

\begin{tabular}{|c|c|c|c|c|c|}
\hline \multirow{2}{*}{ Temperature $\left({ }^{\circ} \mathrm{C}\right)$} & \multirow{2}{*}{$\begin{array}{c}\text { Viscosity } \\
\text { before } \\
\text { upgrading }(\mathrm{cp})\end{array}$} & \multicolumn{3}{|c|}{ Viscosity after upgrading (cp) } & \multirow{2}{*}{$\begin{array}{c}\text { Viscosity } \\
\text { reductions in } \\
\text { percentages }\end{array}$} \\
\hline & & $1^{\text {st }}$ measurement & $2^{\text {ed }}$ measurement & average & \\
\hline 20 & 7023 & 5640 & 5832 & 5736 & $18 \pm 1 \%$ \\
\hline 30 & 2968 & 2662 & 2740 & 2701 & $9 \pm 2 \%$ \\
\hline 40 & 1408 & 1198 & 1237 & 1217 & $14 \pm 1 \%$ \\
\hline 50 & 650 & 574 & 606 & 590 & $9 \pm 2 \%$ \\
\hline 60 & 300 & 258 & 271 & 264 & $12 \pm 2 \%$ \\
\hline 70 & 155 & 129 & 132 & 131 & $16 \pm 1 \%$ \\
\hline
\end{tabular}

Table A.9 Viscosity of dewatered mixture after upgrading of crude oil with steam, tetralin and catalyst (100:100:10:1) at $300{ }^{\circ} \mathrm{C}$ for 48 hours

\begin{tabular}{|c|c|c|c|c|c|}
\hline \multirow{2}{*}{ Temperature $\left({ }^{\circ} \mathrm{C}\right)$} & \multirow{2}{*}{$\begin{array}{c}\text { Viscosity } \\
\text { before } \\
\text { upgrading }(\mathrm{cp})\end{array}$} & \multicolumn{3}{|c|}{ Viscosity after upgrading (cp) } & \multirow{2}{*}{$\begin{array}{c}\text { Viscosity } \\
\text { reductions in } \\
\text { percentages }\end{array}$} \\
\hline & & $1^{\text {st }}$ measurement & $2^{\text {ed }}$ measurement & average & \\
\hline 20 & 7023 & 3283 & 3449 & 3366 & $52 \pm 1 \%$ \\
\hline 30 & 2968 & 1297 & 1325 & 1311 & $56 \pm 1 \%$ \\
\hline 40 & 1408 & 590 & 617 & 603 & $57 \pm 1 \%$ \\
\hline 50 & 650 & 282 & 290 & 286 & $56 \pm 1 \%$ \\
\hline 60 & 300 & 153 & 158 & 156 & $48 \pm 1 \%$ \\
\hline 70 & 155 & 88 & 90 & 89 & $43 \pm 1 \%$ \\
\hline
\end{tabular}

Table A.10 Viscosity of dewatered mixture after upgrading of crude oil with steam, tetralin (100:100:10) at $300{ }^{\circ} \mathrm{C}$ for 48 hours

\begin{tabular}{|c|c|c|c|c|c|}
\hline \multirow[b]{2}{*}{ Temperature $\left({ }^{\circ} \mathrm{C}\right)$} & \multirow{2}{*}{$\begin{array}{l}\text { Viscosity } \\
\text { before } \\
\text { upgrading (cp) }\end{array}$} & \multicolumn{3}{|c|}{ Viscosity after upgrading (cp) } & \multirow{2}{*}{$\begin{array}{l}\text { Viscosity } \\
\text { reductions in } \\
\text { percentages }\end{array}$} \\
\hline & & $1^{\text {st }}$ measurement & $2^{\text {ed }}$ measurement & average & \\
\hline 20 & 6776 & 6717 & 6164 & 6441 & $5.0 \pm 3 \%$ \\
\hline 30 & 2846 & 2787 & 2567 & 2677 & $5.9 \pm 4 \%$ \\
\hline 40 & 1358 & 1309 & 1210 & 1259 & $7.2 \pm 3 \%$ \\
\hline 50 & 624 & 609 & 571 & 590 & $5.4 \pm 4 \%$ \\
\hline 60 & 289 & 284 & 261 & 273 & $5.7 \pm 4 \%$ \\
\hline 70 & 149 & 140 & 130 & 135 & $9.1 \pm 4 \%$ \\
\hline
\end{tabular}


Table A.11 Viscosity of dewatered mixture after upgrading of crude oil with steam, tetralin and catalyst (100:100:10:1) at $300^{\circ} \mathrm{C}$ for 24 hours

\begin{tabular}{|c|c|c|c|c|c|}
\hline \multirow{2}{*}{ Temperature $\left({ }^{\circ} \mathrm{C}\right)$} & \multirow{2}{*}{$\begin{array}{c}\text { Viscosity } \\
\text { before } \\
\text { upgrading (cp) }\end{array}$} & \multicolumn{3}{|c|}{ Viscosity after upgrading (cp) } & \multirow{2}{*}{$\begin{array}{l}\text { Viscosity } \\
\text { reductions in } \\
\text { percentages }\end{array}$} \\
\hline & & $1^{\text {st }}$ measurement & $2^{\text {ed }}$ measurement & average & \\
\hline 20 & 7023 & 4092 & 4207 & 4150 & $41 \pm 1 \%$ \\
\hline 30 & 2968 & 1597 & 1683 & 1640 & $45 \pm 1 \%$ \\
\hline 40 & 1408 & 711 & 750 & 731 & $48 \pm 2 \%$ \\
\hline 50 & 650 & 352 & 368 & 360 & $45 \pm 1 \%$ \\
\hline 60 & 300 & 186 & 195 & 191 & $36 \pm 1 \%$ \\
\hline 70 & 155 & 107 & 113 & 110 & $29 \pm 1 \%$ \\
\hline
\end{tabular}

Table A.12 Viscosity of dewatered mixture after upgrading of crude oil with steam, tetralin and catalyst (100:100:10:1) at $300{ }^{\circ} \mathrm{C}$ for 72 hours

\begin{tabular}{|c|c|c|c|c|c|}
\hline \multirow{2}{*}{ Temperature $\left({ }^{\circ} \mathrm{C}\right)$} & \multirow{2}{*}{$\begin{array}{c}\text { Viscosity } \\
\text { before } \\
\text { upgrading (cp) }\end{array}$} & \multicolumn{3}{|c|}{ Viscosity after upgrading (cp) } & \multirow{2}{*}{$\begin{array}{l}\text { Viscosity } \\
\text { reductions in } \\
\text { percentages }\end{array}$} \\
\hline & & $1^{\text {st }}$ measurement & $2^{\text {ed }}$ measurement & average & \\
\hline 20 & 7023 & 3458 & 3204 & 3331 & $53 \pm 1 \%$ \\
\hline 30 & 2968 & 1299 & 1222 & 1260 & $58 \pm 2 \%$ \\
\hline 40 & 1408 & 612 & 567 & 590 & $58 \pm 2 \%$ \\
\hline 50 & 650 & 284 & 259 & 272 & $58 \pm 2 \%$ \\
\hline 60 & 300 & 156 & 142 & 149 & $50 \pm 2 \%$ \\
\hline 70 & 155 & 92 & 84 & 88 & $43 \pm 2 \%$ \\
\hline
\end{tabular}


Table A.13 Viscosity of crude oil and decalin mixture (100:10)

\begin{tabular}{|c|c|c|c|c|c|}
\hline \multirow{2}{*}{ Temperature $\left({ }^{\circ} \mathrm{C}\right)$} & \multirow{2}{*}{$\begin{array}{c}\text { Viscosity } \\
\text { before mixing } \\
\end{array}$} & \multicolumn{3}{|c|}{ Viscosity $(\mathrm{cp})$} & \multirow{2}{*}{$\begin{array}{c}\text { Viscosity } \\
\text { reductions in } \\
\text { percentages }\end{array}$} \\
\cline { 3 - 5 } & $1^{\text {st }}$ measurement & $2^{\text {ed }}$ measurement & average & $53 \pm 2 \%$ \\
\hline 20 & 21511 & 10609 & 9771 & 10190 & $51 \pm 2 \%$ \\
\hline 30 & 7200 & 3672 & 3395 & 3534 & $42 \pm 2 \%$ \\
\hline 40 & 2570 & 1550 & 1422 & 1486 & $39 \pm 3 \%$ \\
\hline 50 & 1108 & 708 & 649 & 679 & $42 \pm 2 \%$ \\
\hline 60 & 560 & 339 & 314 & 326 & $38 \pm 3 \%$ \\
\hline 70 & 285 & 184 & 168 & 176 & \\
\hline
\end{tabular}

Table A.14 Viscosity of crude oil decalin and catalyst mixture (100:10:1)

\begin{tabular}{|c|c|c|c|c|c|}
\hline \multirow{2}{*}{ Temperature $\left({ }^{\circ} \mathrm{C}\right)$} & \multirow{2}{*}{$\begin{array}{c}\text { Viscosity } \\
\text { before mixing } \\
\text { (cp) }\end{array}$} & \multicolumn{3}{|c|}{ Viscosity (cp) } & \multirow{2}{*}{$\begin{array}{l}\text { Viscosity } \\
\text { reductions in } \\
\text { percentages }\end{array}$} \\
\hline & & $1^{\text {st }}$ measurement & $2^{\text {ed }}$ measurement & average & \\
\hline 20 & 22320 & 10474 & 10904 & 10689 & $52 \pm 1 \%$ \\
\hline 30 & 7483 & 3642 & 3808 & 3725 & $50 \pm 1 \%$ \\
\hline 40 & 2681 & 1518 & 1594 & 1556 & $42 \pm 1 \%$ \\
\hline 50 & 1156 & 696 & 727 & 711 & $38 \pm 2 \%$ \\
\hline 60 & 583 & 337 & 349 & 343 & $41 \pm 2 \%$ \\
\hline 70 & 296 & 180 & 188 & 184 & $38 \pm 1 \%$ \\
\hline
\end{tabular}

Table A.15 Viscosity of dewatered mixture after upgrading of crude oil with steam, decalin and catalyst (100:100:10:1) at $250{ }^{\circ} \mathrm{C}$ for 48 hours

\begin{tabular}{|c|c|c|c|c|c|}
\hline \multirow{2}{*}{ Temperature $\left({ }^{\circ} \mathrm{C}\right)$} & \multirow{2}{*}{$\begin{array}{c}\text { Viscosity } \\
\text { before } \\
\text { upgrading (cp) }\end{array}$} & \multicolumn{3}{|c|}{ Viscosity after upgrading (cp) } & \multirow{2}{*}{$\begin{array}{l}\text { Viscosity } \\
\text { reductions in } \\
\text { percentages }\end{array}$} \\
\hline & & $1^{\text {st }}$ measurement & $2^{\text {ed }}$ measurement & average & \\
\hline 20 & 10689 & 9824 & 10157 & 9991 & $6.5 \pm 2 \%$ \\
\hline 30 & 3725 & 3625 & 3718 & 3671 & $1.4 \pm 1 \%$ \\
\hline 40 & 1556 & 1516 & 1591 & 1553 & $0.2 \pm 2 \%$ \\
\hline 50 & 711 & 677 & 703 & 690 & $3.0 \pm 2 \%$ \\
\hline 60 & 343 & 329 & 337 & 333 & $2.9 \pm 2 \%$ \\
\hline 70 & 184 & 176 & 184 & 180 & $2.2 \pm 3 \%$ \\
\hline
\end{tabular}


Table A.16 Viscosity of dewatered mixture after upgrading of crude oil with steam, decalin and catalyst (100:100:10:1) at $275^{\circ} \mathrm{C}$ for 48 hours

\begin{tabular}{|c|c|c|c|c|c|}
\hline \multirow{2}{*}{ Temperature $\left({ }^{\circ} \mathrm{C}\right)$} & \multirow{2}{*}{$\begin{array}{c}\text { Viscosity } \\
\text { before } \\
\text { upgrading }(\mathrm{cp})\end{array}$} & \multicolumn{2}{|c|}{ Viscosity after upgrading $(\mathrm{cp})$} & \multirow{2}{*}{$\begin{array}{c}\text { Viscosity } \\
\text { reductions in } \\
\text { percentages }\end{array}$} \\
\cline { 3 - 5 } & 10689 & 10306 & 9369 & 9838 & $8.0 \pm 3 \%$ \\
\hline 20 & 3725 & 3403 & 3134 & 3268 & $12.3 \pm 4 \%$ \\
\hline 30 & 1556 & 1537 & 1417 & 1477 & $5.1 \pm 4 \%$ \\
\hline 40 & 711 & 702 & 638 & 670 & $5.8 \pm 4 \%$ \\
\hline 50 & 343 & 336 & 306 & 321 & $6.4 \pm 3 \%$ \\
\hline 60 & 184 & 182 & 170 & 176 & $4.3 \pm 3 \%$ \\
\hline 70 & & & & & \\
\hline
\end{tabular}

Table A.17 Viscosity of dewatered mixture after upgrading of crude oil with steam, decalin and catalyst (100:100:10:1) at $300{ }^{\circ} \mathrm{C}$ for 48 hours

\begin{tabular}{|c|c|c|c|c|c|}
\hline \multirow{2}{*}{ Temperature $\left({ }^{\circ} \mathrm{C}\right)$} & \multirow{2}{*}{$\begin{array}{c}\text { Viscosity } \\
\text { before } \\
\text { upgrading }(\mathrm{cp})\end{array}$} & \multicolumn{3}{|c|}{ Viscosity after upgrading (cp) } & \multirow{2}{*}{$\begin{array}{c}\text { Viscosity } \\
\text { reductions in } \\
\text { percentages }\end{array}$} \\
\hline & & $1^{\text {st }}$ measurement & $2^{\text {ed }}$ measurement & average & \\
\hline 20 & 10689 & 1919 & 1993 & 1956 & $81.7 \pm 0.5 \%$ \\
\hline 30 & 3725 & 795 & 830 & 813 & $78.2 \pm 0.4 \%$ \\
\hline 40 & 1556 & 361 & 382 & 372 & $76.1 \pm 0.2 \%$ \\
\hline 50 & 711 & 195 & 205 & 200 & $71.9 \pm 0.8 \%$ \\
\hline 60 & 343 & 108 & 114 & 111 & $67.6 \pm 0.5 \%$ \\
\hline 70 & 184 & 68 & 70 & 69 & $62.6 \pm 0.8 \%$ \\
\hline
\end{tabular}

Table A.18 Viscosity of dewatered mixture after upgrading of crude oil with steam, decalin (100:100:10) at $300{ }^{\circ} \mathrm{C}$ for 48 hours

\begin{tabular}{|c|c|c|c|c|c|}
\hline \multirow{2}{*}{ Temperature $\left({ }^{\circ} \mathrm{C}\right)$} & \multirow{2}{*}{$\begin{array}{c}\text { Viscosity } \\
\text { before } \\
\text { upgrading (cp) }\end{array}$} & \multicolumn{3}{|c|}{ Viscosity after upgrading (cp) } & \multirow{2}{*}{$\begin{array}{l}\text { Viscosity } \\
\text { reductions in } \\
\text { percentages }\end{array}$} \\
\hline & & $1^{\text {st }}$ measurement & $2^{\text {ed }}$ measurement & average & \\
\hline 20 & 10190 & 7932 & 8419 & 8176 & $20 \pm 1 \%$ \\
\hline 30 & 3534 & 3039 & 3152 & 3096 & $12 \pm 2 \%$ \\
\hline 40 & 1486 & 1290 & 1322 & 1306 & $12 \pm 2 \%$ \\
\hline 50 & 679 & 641 & 659 & 650 & $4.2 \pm 1 \%$ \\
\hline 60 & 326 & 300 & 307 & 303 & $7.1 \pm 2 \%$ \\
\hline 70 & 176 & 157 & 163 & 160 & $9.0 \pm 2 \%$ \\
\hline
\end{tabular}


Table A.19 Viscosity of dewatered mixture after upgrading of crude oil with steam, decalin and catalyst (100:100:10:1) at $300{ }^{\circ} \mathrm{C}$ for 24 hours

\begin{tabular}{|c|c|c|c|c|c|}
\hline \multirow{2}{*}{ Temperature $\left({ }^{\circ} \mathrm{C}\right)$} & \multirow{2}{*}{$\begin{array}{c}\text { Viscosity } \\
\text { before } \\
\text { upgrading }(\mathrm{cp})\end{array}$} & \multicolumn{2}{|c|}{ Viscosity after upgrading $(\mathrm{cp})$} & \multirow{2}{*}{$\begin{array}{c}\text { Viscosity } \\
\text { reductions in } \\
\text { percentages }\end{array}$} \\
\cline { 3 - 6 } & 10689 & 2304 & 2145 & 2224 & $79 \pm 1 \%$ \\
\hline 20 & 3725 & 1010 & 918 & 964 & $74 \pm 1 \%$ \\
\hline 30 & 1556 & 457 & 421 & 439 & $72 \pm 1 \%$ \\
\hline 40 & 711 & 241 & 223 & 232 & $67 \pm 1 \%$ \\
\hline 50 & 343 & 129 & 118 & 123 & $64 \pm 1 \%$ \\
\hline 60 & 184 & 84 & 79 & 82 & $56 \pm 2 \%$ \\
\hline 70 & & & & & measurement \\
\hline
\end{tabular}

Table A.20 Viscosity of dewatered mixture after upgrading of crude oil with steam, decalin and catalyst (100:100:10:1) at $300{ }^{\circ} \mathrm{C}$ for 72 hours

\begin{tabular}{|c|c|c|c|c|c|}
\hline \multirow{2}{*}{ Temperature $\left({ }^{\circ} \mathrm{C}\right)$} & \multirow{2}{*}{$\begin{array}{c}\text { Viscosity } \\
\text { before } \\
\text { upgrading }(\mathrm{cp})\end{array}$} & $1^{\text {st }}$ measurement & $2^{\text {ed }}$ measurement & average & \multirow{2}{*}{$\begin{array}{c}\text { Viscosity } \\
\text { reductions in } \\
\text { percentages }\end{array}$} \\
\cline { 3 - 6 } & 10689 & 1989 & 1821 & 1905 & $82 \pm 1 \%$ \\
\hline 20 & 3725 & 797 & 737 & 767 & $79 \pm 1 \%$ \\
\hline 30 & 1556 & 356 & 334 & 345 & $78 \pm 1 \%$ \\
\hline 50 & 711 & 199 & 185 & 192 & $73 \pm 1 \%$ \\
\hline 60 & 343 & 115 & 106 & 110 & $68 \pm 1 \%$ \\
\hline 70 & 184 & 70 & 63 & 67 & $64 \pm 1 \%$ \\
\hline
\end{tabular}


Table A.21 API gravity before and after upgrading using crude oil, steam and catalyst

\begin{tabular}{|c|c|c|c|c|c|c|c|c|c|c|c|}
\hline \multirow{2}{*}{$\begin{array}{c}\text { Reaction } \\
\text { temperature } \\
\left({ }^{\circ} \mathrm{C}\right)\end{array}$} & \multirow{2}{*}{$\begin{array}{l}\text { Crude } \\
\text { oil }\end{array}$} & \multirow[b]{2}{*}{ Steam } & \multirow[b]{2}{*}{ Decalin } & \multirow[b]{2}{*}{ Tetralin } & \multirow{2}{*}{ Catalyst } & \multirow{2}{*}{$\begin{array}{c}\text { Reaction } \\
\text { time } \\
\text { (hours) }\end{array}$} & \multirow{2}{*}{$\begin{array}{l}\text { API gravity } \\
\text { before } \\
\text { upgrading } \\
\left({ }^{\circ} \mathrm{API}\right)\end{array}$} & \multicolumn{3}{|c|}{$\begin{array}{l}\text { API gravity after upgrading or mixing } \\
\left({ }^{\circ} \mathrm{API}\right)\end{array}$} & \multirow{2}{*}{$\begin{array}{c}\text { Increase in } \\
\text { API } \\
\text { gravity } \\
\left({ }^{\circ} \mathrm{API}\right)\end{array}$} \\
\hline & & & & & & & & $\begin{array}{c}1^{\text {st }} \\
\text { measurement }\end{array}$ & $\begin{array}{c}2^{\text {ed }} \\
\text { measurement }\end{array}$ & average & \\
\hline & $\mathrm{x}$ & & & & & & & 11.41 & 11.42 & 11.42 & \\
\hline & $\mathrm{x}$ & & & & $\mathrm{x}$ & & & 11.37 & 11.37 & 11.37 & \\
\hline 300 & $\mathrm{x}$ & $\mathrm{x}$ & & & & 48 & 11.42 & 11.54 & 11.52 & 11.53 & 0.11 \\
\hline 300 & $\mathrm{x}$ & $\mathrm{x}$ & & & $\mathrm{x}$ & 48 & 11.37 & 11.71 & 11.72 & 11.72 & 0.35 \\
\hline
\end{tabular}

Table A.22 API gravity before and after upgrading using crude oil, steam, tetralin and catalyst

\begin{tabular}{|c|c|c|c|c|c|c|c|c|c|c|c|}
\hline \multirow{2}{*}{$\begin{array}{c}\text { Reaction } \\
\text { temperature } \\
\left({ }^{\circ} \mathrm{C}\right)\end{array}$} & \multirow{2}{*}{$\begin{array}{c}\text { Crude } \\
\text { oil }\end{array}$} & \multirow[b]{2}{*}{ Steam } & \multirow[b]{2}{*}{ Decalin } & \multirow[b]{2}{*}{ Tetralin } & \multirow[b]{2}{*}{ Catalyst } & \multirow{2}{*}{$\begin{array}{c}\text { Reaction } \\
\text { time } \\
\text { (hours) }\end{array}$} & \multirow{2}{*}{$\begin{array}{l}\text { API gravity } \\
\text { before } \\
\text { upgrading } \\
\left({ }^{\circ} \mathrm{API}\right)\end{array}$} & \multicolumn{3}{|c|}{$\begin{array}{c}\text { API gravity after upgrading or mixing } \\
\left({ }^{\circ} \mathrm{API}\right)\end{array}$} & \multirow{2}{*}{$\begin{array}{c}\text { Increase in } \\
\text { API } \\
\text { gravity } \\
\left({ }^{\circ} \mathrm{API}\right)\end{array}$} \\
\hline & & & & & & & & $\begin{array}{c}1^{\text {st }} \\
\text { measurement }\end{array}$ & $\begin{array}{c}2^{\text {ed }} \\
\text { measurement }\end{array}$ & average & \\
\hline & $\mathrm{x}$ & & & $\mathrm{x}$ & & & & 11.86 & 11.86 & 11.86 & \\
\hline & $\mathrm{x}$ & & & $\mathrm{x}$ & $\mathrm{x}$ & & & 11.89 & 11.93 & 11.91 & \\
\hline 300 & $\mathrm{x}$ & $\mathrm{x}$ & & $\mathrm{x}$ & & 48 & 11.86 & 12.11 & 12.11 & 12.11 & 0.15 \\
\hline 250 & $\mathrm{x}$ & $\mathrm{x}$ & & $\mathrm{x}$ & $\mathrm{x}$ & 48 & 11.91 & 12 & 12.03 & 12.02 & 0.11 \\
\hline 275 & $\mathrm{x}$ & $\mathrm{x}$ & & $\mathrm{x}$ & $\mathrm{x}$ & 48 & 11.91 & 12.11 & 12.11 & 12.11 & 0.2 \\
\hline 300 & $\mathrm{x}$ & $\mathrm{x}$ & & $\mathrm{x}$ & $\mathrm{x}$ & 24 & 11.91 & 12.14 & 12.14 & 12.14 & 0.23 \\
\hline 300 & $\mathrm{x}$ & $\mathrm{x}$ & & $\mathrm{x}$ & $\mathrm{x}$ & 48 & 11.91 & 12.19 & 12.21 & 12.2 & 0.29 \\
\hline 300 & $\mathrm{x}$ & $\mathrm{x}$ & & $\mathrm{x}$ & $\mathrm{x}$ & 72 & 11.91 & 12.25 & 12.25 & 12.25 & 0.34 \\
\hline
\end{tabular}


Table A.23 API gravity before and after upgrading using crude oil, steam, decalin and catalyst

\begin{tabular}{|c|c|c|c|c|c|c|c|c|c|c|c|}
\hline \multirow{2}{*}{$\begin{array}{c}\text { Reaction } \\
\text { temperature } \\
\left({ }^{\circ} \mathrm{C}\right)\end{array}$} & \multirow{2}{*}{$\begin{array}{l}\text { Crude } \\
\text { oil }\end{array}$} & \multirow[b]{2}{*}{ Steam } & \multirow[b]{2}{*}{ Decalin } & \multirow[b]{2}{*}{ Tetralin } & \multirow[b]{2}{*}{ Catalyst } & \multirow{2}{*}{$\begin{array}{l}\text { Reaction } \\
\text { time } \\
\text { (hours) }\end{array}$} & \multirow{2}{*}{$\begin{array}{l}\text { API gravity } \\
\text { before } \\
\text { upgrading } \\
\left.\text { ( }{ }^{\circ} \mathrm{API}\right)\end{array}$} & \multicolumn{3}{|c|}{$\begin{array}{l}\text { API gravity after upgrading or mixing } \\
\left({ }^{\circ} \mathrm{API}\right)\end{array}$} & \multirow{2}{*}{$\begin{array}{c}\text { Increase in } \\
\text { API } \\
\text { gravity } \\
\left({ }^{\circ} \mathrm{API}\right)\end{array}$} \\
\hline & & & & & & & & $1^{\text {st }}$ measurement & $\begin{array}{l}2^{\text {ed }} \\
\text { measurement }\end{array}$ & average & \\
\hline & $\mathrm{x}$ & & $\mathrm{x}$ & & & & & 12.74 & 12.74 & 12.74 & \\
\hline & $\mathrm{x}$ & & $\mathrm{x}$ & & $\mathrm{x}$ & & & 12.81 & 12.79 & 12.8 & \\
\hline 300 & $\mathrm{x}$ & $\mathrm{x}$ & $\mathrm{x}$ & & & 48 & 12.74 & 12.86 & 12.86 & 12.86 & 0.12 \\
\hline 250 & $\mathrm{x}$ & $\mathrm{x}$ & $\mathrm{x}$ & & $\mathrm{x}$ & 48 & 12.8 & 12.88 & 12.9 & 12.89 & 0.09 \\
\hline 275 & $\mathrm{x}$ & $\mathrm{x}$ & $\mathrm{x}$ & & $\mathrm{x}$ & 48 & 12.8 & 12.97 & 12.96 & 12.97 & 0.17 \\
\hline 300 & $\mathrm{x}$ & $\mathrm{x}$ & $\mathrm{x}$ & & $\mathrm{x}$ & 24 & 12.8 & 13.71 & 13.71 & 13.71 & 0.91 \\
\hline 300 & $\mathrm{x}$ & $\mathrm{x}$ & $\mathrm{x}$ & & $\mathrm{x}$ & 48 & 12.8 & 13.91 & 13.89 & 13.9 & 1.1 \\
\hline 300 & $\mathrm{x}$ & $x$ & $x$ & & $x$ & 72 & 12.8 & 14.02 & 14.03 & 14.03 & 1.23 \\
\hline
\end{tabular}




\section{VITA}

\begin{tabular}{|c|c|}
\hline Name: & Zhiyong Zhang \\
\hline Address: & $\begin{array}{l}3116 \text { TAMU, Richardson Building } \\
\text { Texas A\&M University } \\
\text { College Station, TX, } 77843\end{array}$ \\
\hline Email Address: & zhangzhiyong@mail.com \\
\hline \multirow[t]{3}{*}{ Education: } & $\begin{array}{l}\text { M.S., Petroleum Engineering } \\
\text { Texas A\&M University, } \\
\text { College Station, TX } 77843 \\
\text { May } 2011\end{array}$ \\
\hline & $\begin{array}{l}\text { M.S., Mechanical Engineering } \\
\text { Peking University } \\
\text { Beijing, } 100871 \text {, P.R. China } \\
\text { July } 2007\end{array}$ \\
\hline & $\begin{array}{l}\text { B.S., Mechanical Engineering, } \\
\text { Tsinghua University, } \\
\text { Beijing, 100084, P.R. China } \\
\text { July } 2004\end{array}$ \\
\hline
\end{tabular}

